\title{
LA-UR-98- 1398
}

\section{TASK COMPLETION REPORT FOR UPDATE FXCFM}

by

Robert G. Steinke

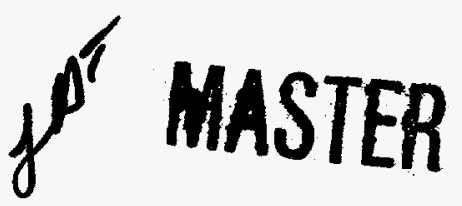

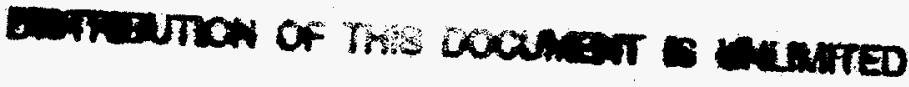

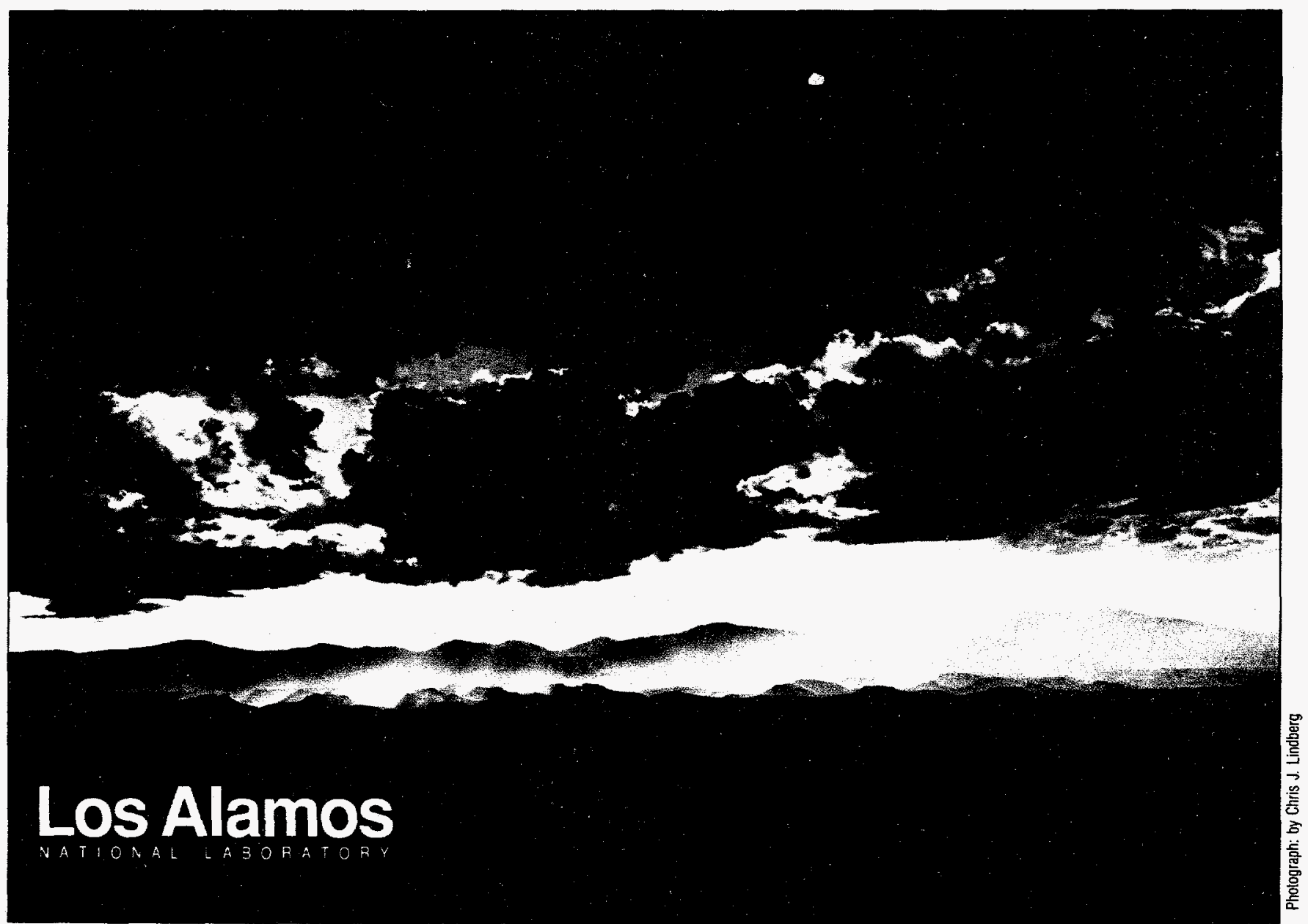

Los Alamos National Laboratory, an affirmative action/equal opportunity employer, is operated by the University of California for the U.S. Department of Energy under contract W-7405-ENG-36. By acceptance of this article, the publisher recognizes that the U.S. Govermment retains a nonexclusive, royalty-free license to publish or reproduce the
published form of this contribution, or to allow others to do so, for U.S. Government purposes. The Los Alamos National Laboratory reguests that the publisher identify this article published form of this contribution, or to allow others to do so, for U.S. Govemment purposes. The Los Alamos National Laboratory requests that the publisher identify this article
as work performed under the auspices of the U.S. Department of Energy. Los Alamos National Laboratory strongly supports academic freedom and a researcher's right to publish; therefore, the Laboratory as an institution does not endorse the viewpoint of a publication or guarantee its technical correctness. 


\section{DISCLAIMER}

This report was prepared as an account of work sponsored by an agency of the United States Goverament. Neither the United States Government nor any agency thereof, nor any of their employees, makes any warranty, express or implied, or assumes any legal liability or responsibility for the accuracy, completeness, or usefulness of any information, apparatus, product, or process disclosed, or represents that its use would not infringe privately owned rights. Reference herein to any specific commercial product, process, or service by trade name, trademark, manufac. turer; or otherwise does not necessarily constitute or imply its endorsement, recommendation, or favoring by the United States Government or any agency thereof. The views and opinions of authors expressed herein do not necessarily state or reflect those of the United States Government or any agency thereof. 


\section{DISCLAIMER}

Portions of this document may be illegible in electronic image products. Images are produced from the best available original document. 


\section{TASK COMPLETION REPORT}

FOR UPDATE FXCFM

by

Robert G. Steinke, James F. Lime, Richard J. Smith, and James L. Steiner

January 21,1998 


\title{
TASK COMPLETION REPORT FOR UPDATE FXCFM
}

\author{
Robert G. Steinke, James F. Lime, Richard J. Smith, and James L. Steiner
}

\begin{abstract}
Update FXCFM corrects five areas of the TRAC-P choked-flow model that address TRAC-P Trouble Report items 235, 259, and 260. Knolls Atomic Power Laboratory, Marviken, Edwards, and Scientech criticalflow test problems were used to investigate the reported errors and further errors that were found and to verify their correction.
\end{abstract}

\subsection{INTRODUCTION}

Nonphysical behavior was observed in the critical-flow (choked-flow) model of TRAC-P by Knolls Atomic Power Laboratory (KAPL) and Scientech in problems they created and used for testing. TRAC-P Trouble Report items 259 and 235 report the deficiencies they observed. KAPL noted that the choked-flow interface adjacent downstream-cell pressure became lower than its adjacent BREAK-cell pressure. Scientech noted that the saturated choked mass flow predicted by TRAC-P was half that predicted by RELAP-5, and they did not get proportional adjustment of the twophase saturated choked mass flow when adjusting the two-phase choked-flow multiplier. KAPL requested that how the subcooled and two-phase choked-flow multipliers are applied in TRAC-P be investigated and more clearly documented. During the TRAC-modernization effort at Los Alamos, use of a single variable for three argument variables in the subroutine CHOKE call to subroutine SOUND was noted in TRAC-P Trouble Report item 260. This is a bad programming practice that needs to be corrected.

All these items were investigated, and appropriate corrections were made to the choked-flow model in TRAC-P. This report describes the corrections made by update FXCFM (FiX Choked-Flow Model) and the testing done to verify that the programming changes were done correctly and their corrections were made.

\subsection{CHOKED-FLOW MODEL CORRECTIONS}

Investigating the downstream-pressure error in the KAPL test problem resulted in the following three programming deficiencies being found in the TRAC-P chokedflow model.

1. The choked-flow velocity was timestep averaged by $10 \%$ of its new-time value and $90 \%$ of its old-time value for both steady-state and transient calculations. While this is appropriate for a steady-state calculation, a transient calculation should have $\mathrm{C} 1 \pm \mathrm{C}^{*} \Delta \mathrm{t}$ time-constant constraints factors 
applied to the choked-flow velocity as is done for thermal-hydraulic coefficients during transient calculations. Time-constant constraints preserve the time delay of physical phenomena during transient calculations while eliminating timestep-size dependence. In addition to constraining the choked-flow velocity $\mathrm{V}$ by $\mathrm{V}_{\mathrm{o}}^{*} \mathrm{C} 1^{-\mathrm{C} 2^{*} \Delta \mathrm{t}} \leq \mathrm{V} \leq \mathrm{V}_{\mathrm{o}}^{*} \mathrm{C} 1+\mathrm{C} 2^{*} \Delta \mathrm{t}$ during timestep $\Delta t$ (based on the old \{previous\} timestep velocity $V_{o}$ ) to define the new timestep velocity $V_{n}=V$, the $d V / d P_{d}$ choked-flow velocity derivative with respect to its donor-cell pressure also needs to be constrained. The new timestep derivative $\mathrm{dV}_{\mathrm{n}} / \mathrm{dP}_{\mathrm{d}}$ is defined to vary linearly from the value $d V / d P_{d}$ when $V=V_{o}$ to the value $0.1^{*} d V / d P_{d}$ when $\mathrm{V}=\mathrm{V}_{\mathrm{o}}{ }^{*} \mathrm{C} 1^{ \pm \mathrm{C} 2^{*} \Delta t}$. Both $\mathrm{V}$ and $\mathrm{dV} / \mathrm{dP}_{\mathrm{d}}$ are evaluated by subroutine CHOKF and need to be constrained by this procedure for transient calculations.

2. The choked-flow model was applied to the basic motion equations in subroutine TF1DS1 during the outer-iteration stage but not to the stabilizer motion equations in subroutine FEMOM during the prep stage. An existing programmed attempt to do the later in subroutine FEMOM failed because BITN (rather than BIT) had its 33rd bit tested for being set to 1 to indicate choked flow to define the present-timestep stabilizer velocity by the previous timestep choked basic velocity. During the prep stage, BIT has the bit information from the previous timestep while BITN has all its bits reset to 0 before they are set for the present timestep. Correcting this error by changing BITN to BIT would have left another error of inconsistently defining the present timestep stabilizer velocity by the previous timestep choked basic velocity. This needs to be corrected by calling subroutine CHOKE from subroutine FEMOM rather than from subroutine TF1DS1 to determine the choked-flow velocity for its consistent application in both the prep and outer-iteration stages of the same timestep.

3. Both upstream and downstream adjacent-cell pressure dependence of the choked-flow velocity was being modeled by the basic motion equations during the outer iteration. When an interface velocity is choked, there is no downstream pressure dependence. The subroutine TF1DS logic that defines the component and network-junction pressure-matrix equations needs to be programmed to remove adjacent downstream-cell pressure dependence on the choked-flow interface velocity.

Update FXCFM was programmed to correct these three errors. A listing of update FXCFM and the LABPRG input-data file LABCFM for defining SI/English units information for update FXCFM is shown in Appendix A. The second error was found to cause the choked-flow interface adjacent downstream-cell pressure to become lower than its adjacent BREAK-cell pressure in the KAPL test problem. The first and third errors had little effect on this adjacent downstream-cell pressure being too low. Further details are presented in Appendix B on how these errors were corrected and the testing done to investigate and verify the corrections that were made. 
TRAC-P Trouble Report item 260 was corrected by update FXCFM as its fourth correction. This involved replacing the single variable TC or TSAT with three variables for the TL, TV, and TSAT arguments in five calls to subroutine THERMO from subroutine SOUND (which is called by subroutine CHOKE). Doing this results in TL and TV being undefined when IEOS $=1$ or when IEOS $=0$ and EL and EV are not defined by 1.0 or 2.0 for internal initialization of the phasic temperatures by subroutine THERMO. Initialization of the argument variables for TL and TV before calling subroutine THERMO also was needed to deal with these cases of undefined TL and TV.

Subroutine SOUND calls subroutine THERMO ten times. Two calls are at donorcell vapor and liquid conditions, 3 calls are at donor-cell vapor and saturated-liquid conditions, and 5 calls are at donor-cell saturated-vapor and saturated-liquid conditions. The first 5 calls have different variables for the TL, TV, and TSAT arguments, but in the later 3 of these 5 calls, the saturated-liquid temperature is initialized now with SATTMP(PC) by update FXCFM before calling subroutine THERMO. The last five calls that defined TL, TV, and TSAT by TC or TSAT are changed to TLSATC, TVSATC, TC or TLSAT, TVSAT, TSAT, respectively, with TLSATC, TVSATC, TLSAT, and TVSAT initialized now with SATTMP(PC) by update FXCFM before calling subroutine THERMO.

With these four corrections programmed in update FXCFM (except for constraining the $\mathrm{dV} / \mathrm{dP}_{\mathrm{d}}$ derivative in the first correction), the KAPL, the Marviken and Edwards blowdown experiment, and the Scientech test problems were evaluated. A technical design review of update FXCFi 1 and its test results was held in Los Alamos on October 21, 1997. The four corrections were described with emphasis on their underlying assumptions and the errors they corrected. The KAPL test problem results that were presented are shown in App. B (except for the results on page B-6 concerning Fig. B.25). With these corrections, the KAPL test-problem downstreampressure error was eliminated and the calculation ran more robustly with $49 \%$ fewer timesteps. The Marviken and Edwards blowdown test-problem results showed little difference without and with update FXCFM. With update FXCDM, however, some of the Marviken test-problem results showed oscillatory behavior not present in the data or calculated by TRAC-P Version 5.4.28 without update FXCFM. Marviken Test 24 with the shortest nozzle aborted after a few timesteps. Test 24 could be made to run by halving the DTMIN minimum timestep sizes. The Scientech test-problem mass-flow results from TRAC-P Version 5.4.28 without update FXCFM did not agree with the results quoted in the TRAC-P Trouble Report 235 documentation. It was felt that this was because the Scientech input-data files were not being provided and that they needed to be recreated from limited information in the documentation. It was decided that the actual input-data files needed to be requested from Scientech so that their results could be recreated and then fixed by the existing or further corrections made to update FXCFM.

Seven concerns were expressed by the technical-design-review committee that needed to be addressed before the development and testing of update FXCFM could be considered finished and ready for final review. Those concerns and the followup responses to them are discussed in App. C. From those responses, the following four correction changes were made to update FXCFM. 
1. The subroutine CHOKE evaluation of the choked-velocity derivative with respect to its donor-cell pressure, $\mathrm{dV} / \mathrm{dP} \mathrm{P}_{\mathrm{d}} \cong 100.0^{*}\left(\mathrm{~V}_{\text {new }}-\mathrm{V} 1_{\text {new }}\right) / \mathrm{P}_{\mathrm{d}}$ needs to be moved ahead of the $V_{0}^{*} C 1 \pm C 2 * \Delta t$ constraint on the choked velocity $\mathrm{V}_{\text {new }}$ at a donor-cell pressure of $\mathrm{P}_{\mathrm{d}}$ and the choked velocity $\mathrm{V} 1_{\text {new }}$ at a donor-cell pressure of $0.99^{*} \mathrm{P}_{\mathrm{d}}$. This is discussed in response 2 of App. C.

2. The subroutine CHOKE evaluation of two-phase critical flow applies the two-phase choked-flow multiplier CHMLT2 to the liquid velocity VELL and the gas velocity VELV, but not to the mixture velocity VELM. It is the mixture velocity that is compared with the predictor-stabilizer mixture velocity VM in the statement: IF(ABS(VM).LT.ABS(VELM)) RETURN to determine if a choked-flow condition doesn't exist wherein a RETURN occurs. The mixture velocity VELM needs to be multiplied by CHMLT2 before this choked-flow test is performed. This fifth major area of correction by update FXCFM is discussed in response 3 of App. C.

3. In moving the call to subroutine CHOKE for evaluating the choked-flow model from subroutine TF1DS1 in the outer-iteration stage to subroutine FEMOM in the prep stage, bit 33 in BITN(J) should no longer be reset to 0 when doing a backup to the beginning of subroutine OUTER. Bit 33 in BITN $(J)$ was being reset to 0 by entry ON1123 of subroutine BITS because subroutine CHOKE would be called again by subroutine TF1DS1 when reevaluating the start of the outer iteration. Now with subroutine CHOKE called by subroutine FEMOM during the prep stage, its determination that choked flow exists at interface J needs to be saved by not resetting bit 33 in BITN $(\mathrm{J})$ to 0 during a backup to the beginning of subroutine OUTER. This is discussed in response 5 of App. C.

4. Before, when a water-packing backup to the beginning of subroutine OUTER occurred, subroutine CHOKE was not called if the interface basic velocity flows into the packed cell and the inflow basic velocity was reset to $0.01 \mathrm{~m} \mathrm{~s}^{-1}$. Now, with subroutine CHOKE called by subroutine FEMOM during the prep stage, bit 33 of $B I T N(J)$ is reset to 0 if the choked velocity flows in to the packed cell and the inflow choked velocity is reset to $0.01 \mathrm{~m} \mathrm{~s}^{-1}$. During the initial evaluation of the Marviken blowdown test problem, applying the choked velocity in subroutine TF1DS1, even though its inflow cell was water packed, caused numerical-solution difficulties as discussed in response 7 of App. C.

With the above additional correction changes in update FXCFM, the KAPL test problem results were the same. Increasing the number of mesh cells between the upstream BREAK-component pressure boundary condition and the choked-flow interface was found to decrease the magnitude of the mass-flow oscillation each timestep in the KAPL test problem. This was a later investigative response to Concern 1 in App. C. 
The Marviken-blowdown test-problem solution still oscillated for some test cases, and Test 24 still aborted after a few iterations. The cause of the Marviken testproblem oscillation was traced to two further changes needed in update FXCFM:

1. Constrain the $d V / d P_{d}$ derivative value as described in the description of the first correction on page 2.

2. Reduce the time-constant value of $\mathrm{C} 2$ from $10.0 \mathrm{~s}^{-1}$ to $1.0 \mathrm{~s}^{-1}$ to further time delay the change in the choked-flow velocity.

This eliminated the oscillation in the Marviken test-case solutions except for the mass flow in Test 4 . Using a C2 value of $0.1 \mathrm{~s}^{-1}$ or smaller eliminated all solution oscillation but appeared to apply too much time-delay damping to the solutions.

With a constrained $\mathrm{dV} / \mathrm{dP}_{\mathrm{d}}$ derivative and $\mathrm{C} 2=1.0 \mathrm{~s}^{-1}$, Marviken Test 24 still aborted, but now after 67 timesteps. The cause of the abort was traced to an inappropriately large step-change increase in the timestep size from $\sim 0.003$ to $0.01 \mathrm{~s}$ when applying the second timestep-data set with DTMIN $=0.01 \mathrm{~s}$ at $0.1 \mathrm{~s}$ after 51 timesteps. The excessive time-delay dampening of a $10 \%$-new and $90 \%$-old weighting of the choked velocity in TRAC-P Version 5.4.28 without update FXCFM was sufficient to prevent the Test 24 abort. It also could be avoided with update FXCFM by using physically inappropriate small values of C2 less than $0.1 \mathrm{~s}^{-1}$. The Test 24 abort was resolved by redefining the timestep data of all Marviken test cases so they did not have this large step-change increase in the timestep size.

Appendix D provides mass flow and pressure vs time plots calculated by TRAC-P Version 5.4.28 without and with update FXCFM along with experimental data from the Marviken-blowdown Tests 4, 13, 20, 22, and 24 and the Edwards-blowdown test. The effect of the update-FXCFM corrections on the calculated mass-flow and upstream-pressure results of these experiments was found to be small. This is because the choked-flow interface is the junction of the BREAK component that models the downstream-pressure boundary condition in the TRAC-P models of all these tests. This modeling situation reduces the effect of the errors corrected by update FXCFM.

TRAC-P input-data files were received from Scientech to evaluate and investigate the errors reported in TRAC-P Trouble Report item 235. For a subcooled chokedflow test problem, they reported a mass flow of $96.7 \mathrm{~kg} \mathrm{~s}^{-1}$ from RELAP-5 and $103.0 \mathrm{~kg} \mathrm{~s}^{-1}$ from TRAC-P, which are in reasonable agreement. For a saturated choked-flow test problem, they reported a mass flow of $107.9 \mathrm{~kg} \mathrm{~s}^{-1}$ from RELAP-5 and $47.3 \mathrm{~kg} \mathrm{~s}^{-1}$ from TRAC-P. They believed the saturated mass flow from RELAP-5 to be correct and that TRAC-P is predicting half the saturated mass flow that it should. They attempted to increase the saturated mass flow predicted by TRAC-P by applying a two-phase choked-flow multiplier, CHM2, $>1.0$ to the choked velocity. While they expected the TRAC-P saturated mass flow to increase in proportion to the value of CHM2 applied, they found the saturated mass flow increased very little when CHM2 was increased above 1.0. At CHM2 $=3.45 \pm 0.05$, the saturated mass flow underwent a doubling step change followed by a proportional to CHM2 increase in the saturated mass flow for larger values of CHM2. This behavior is shown in Fig. 1 
by the open-circle data-point curve. This highly nonlinear behavior in the saturated two-phase mass flow with respect to the two-phase choked-flow multiplier applied was the reported error of TRAC-P Trouble Report item 235.

The two input data files received from Scientech model a TEE-component sidechannel small break with BREAK-component pressure boundary conditions at each of the three junctions. The two input-data-file models extract the TEE-component solution state from a full-system model small-break loss-of-coolant transient at 500 and $1000 \mathrm{~s}$. The input-data-file model at $1000 \mathrm{~s}$ is the saturated mass-flow test problem. TRAC-P Version 5.4.28 evaluated the same $47.3 \mathrm{~kg} \mathrm{~s}^{-1}$ mass flow as the one Scientech evaluated with TRAC-P Version 5.4.28c. TRAC-P Version 5.4.28 with update FXCFM evaluated a mass flow of $47.2 \mathrm{~kg} \mathrm{~s}^{-1}$. The model at $500 \mathrm{~s}$ is not the subcooled mass-flow test problem. because with TRAC-P Version 5.4.28 it evaluates a saturated mass flow of $60.4 \mathrm{~kg} \mathrm{~s}^{-1}$. With TRAC-P Version 5.4 .28 with update FXCFM, the model evaluates a saturated mass flow of $60.3 \mathrm{~kg} \mathrm{~s}^{-1}$. As earlier, a subcooled mass-flow test problem input-data file needs to be created. This was done by assuming the input data of the model at $1000 \mathrm{~s}$ applies except for changing the pressure from 5.0642 to $1.95 \mathrm{MPa}$ and the liquid temperature from 537.2 to $419.6 \mathrm{~K}$, as reported in the TRAC-P Trouble Report item-235 documentation. With this inputdata model, TRAC-P Version 5.4.28 and TRAC-P Version 5.4.28 with update FXCFM both calculate a subcooled mass flow of $105.9 \mathrm{~kg} \mathrm{~s}^{-1}$. This compares with $103.0 \mathrm{~kg} \mathrm{~s}^{-1}$ calculated by Scientech with TRAC-P Version $5.4 .28 \mathrm{c}$ and a different input-data file.

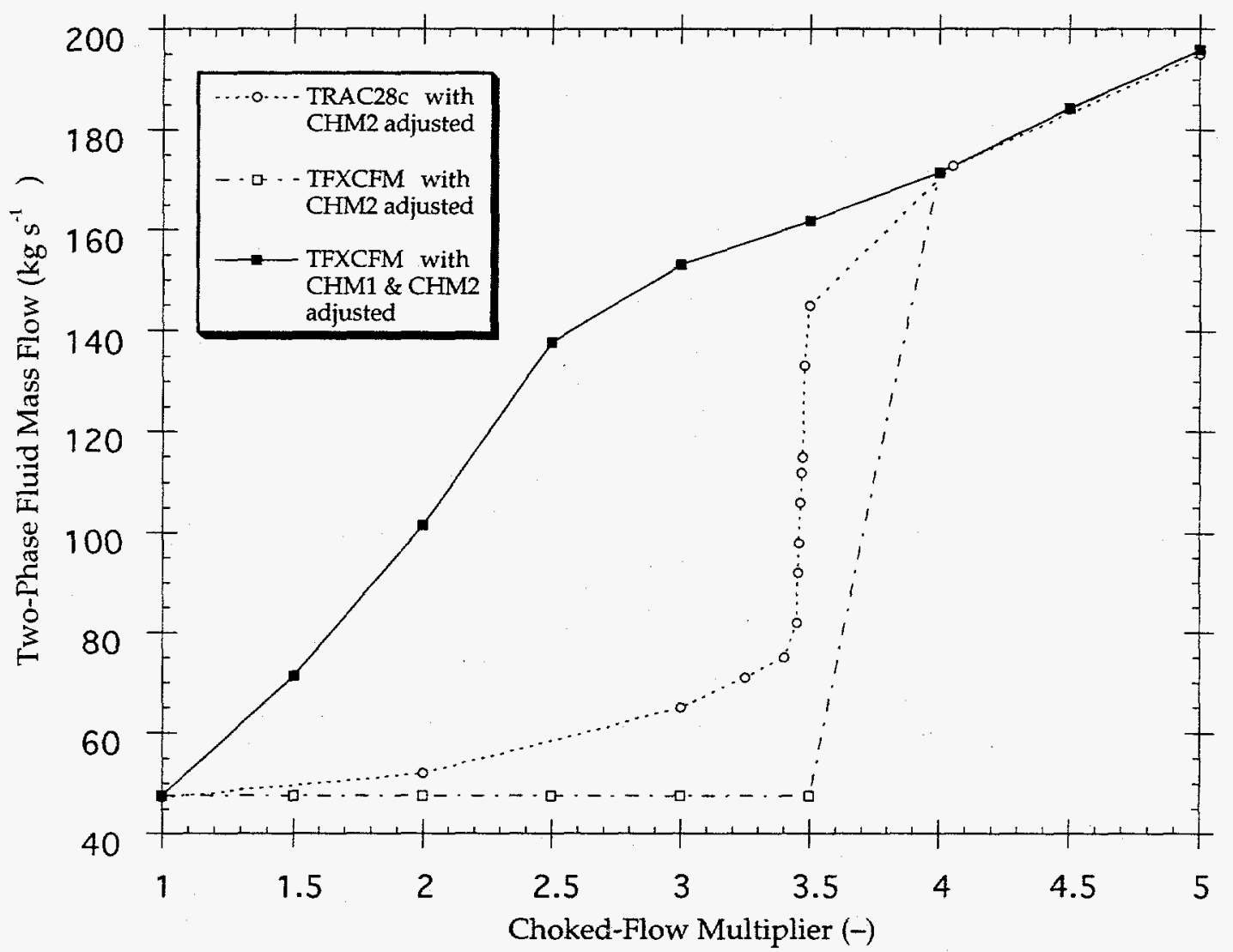

Fig. 1. Two-phase fluid mass flow vs the choked-flow multiplier. 
Then the two-phase choked-flow multiplier CHM2 was varied from 1.0 to 5.0 in 0.5 increments in the 1000-s input-data-file model and evaluated by TRAC-P Version 5.4.28 and TRAC-P Version 5.4.28 with update FXCFM. The later calculation gave the open-square data-point curve in Fig. 1. Results from both calculations are similar. The TRAC-P results evaluated by Scientech are the same for only CHM2 = 1.0, 4.0, 4.5, and 5.0. A tripling step change in the mass flow occurs at a larger value of CHM2 between 3.5 and 4.0. It is not understood why Scientech evaluates a gradual increase in the mass flow with TRAC-P Version $5.4 .28 \mathrm{c}$ for CHM2 varied from 1.0 to 3.4, whereas Los Alamos evaluates no change in mass flow for CHM2 varied from 1.0 to 3.5. It appears that the Scientech calculation evaluates a donorcell gas volume fraction $\alpha$ that increases to $\sim 0.03$ at CHM2 $=3.4$, whereas the Los Alamos calculation evaluates a constant $\alpha \sim 0.005$. That is because the choked-flow velocity is interpolated between the subcooled-liquid sonic velocity at $\alpha=0.01$ and the two-phase sonic velocity at $\alpha=0.10$ for $0.01 \leq \alpha \leq 0.10$. It is only the two-phase sonic velocity that gets multiplied by CHM2, so only the two-phase sonic velocity is increased when CHM2 is increased.

To increase the two-phase choked saturated mass flow in proportion to its chokedflow multiplier in TRAC-P, it appears that both the subcooled and two-phase choked-flow multipliers need to be increased. Figure 1 shows the two-phase fluid mass flow calculated by TRAC-P Version 5.4.28 with update FXCFM vs adjustment of both the subcooled choked-flow multiplier CHM1 and CHM2 plotted by the solidsquare data-point curve. Increasing both CHM1 and CHM2 defines a directly proportionaı dependence of $\dot{\mathrm{m}}=\mathrm{CHM \#}(51.2 \pm 3.9)$ for $1.0 \leq \mathrm{CHM} \# \leq 2.5$ and a reduced dependence of $\dot{\mathrm{m}}=82.9+\mathrm{CHM \#}^{*}(22.6 \pm 0.8)$ for $2.5 \leq \mathrm{CHM} \| 5.0$. Figure 2 shows the TRAC-P Version 5.4.28 with update FXCFM evaluated donor-cell gas volume fraction $\alpha$ increasing linearly when both CHM1 and CHM2 are adjusted, and increasing with a step change at $3.5<$ CHM2 $\leq 4.0$ when only CHM2 is adjusted. Why the donor-cell gas volume fraction doesn't increase linearly when only CHM2 is increased is not understood. Increasing both CHM1 and CHM2 together provides the near proportional dependence of $\mathrm{CHM \#}$ for $\#=1,2$ on the saturated two-phase mass flow and the donor-cell gas volume fraction that Scientech had expected.

The above Scientech test-problem analysis and results are discussed with further details in App. E. A final-analysis case is discussed on page E- 6 that accounts for half the difference between the RELAP-5 and TRAC-P saturated mass flows of $107.9 \mathrm{~kg} \mathrm{~s}^{-1}$ and $47.3 \mathrm{~kg} \mathrm{~s}^{-1}$, respectively. The TRAC-P model is changed to be more like the RELAP-5 model by moving the minimum-flow-area choke-flow interface from the TEE-component side-channel junction with the BREAK component to the internaljunction interface between the main-channel JCELL and the side-channel cell. Now the choked-flow interface donor-cell is the main-channel JCELL in both the RELAP5 and TRAC-P models. This remodeling increases the TRAC-P saturated mass flow at the choked interface from 47.3 to $71.6 \mathrm{~kg} \mathrm{~s}^{-1}$ based solely on different donor-cell properties. How one models the geometry of a break, which determines where choked flow occurs, is critical to obtaining an accurate prediction of the break's coolant mass flow. 


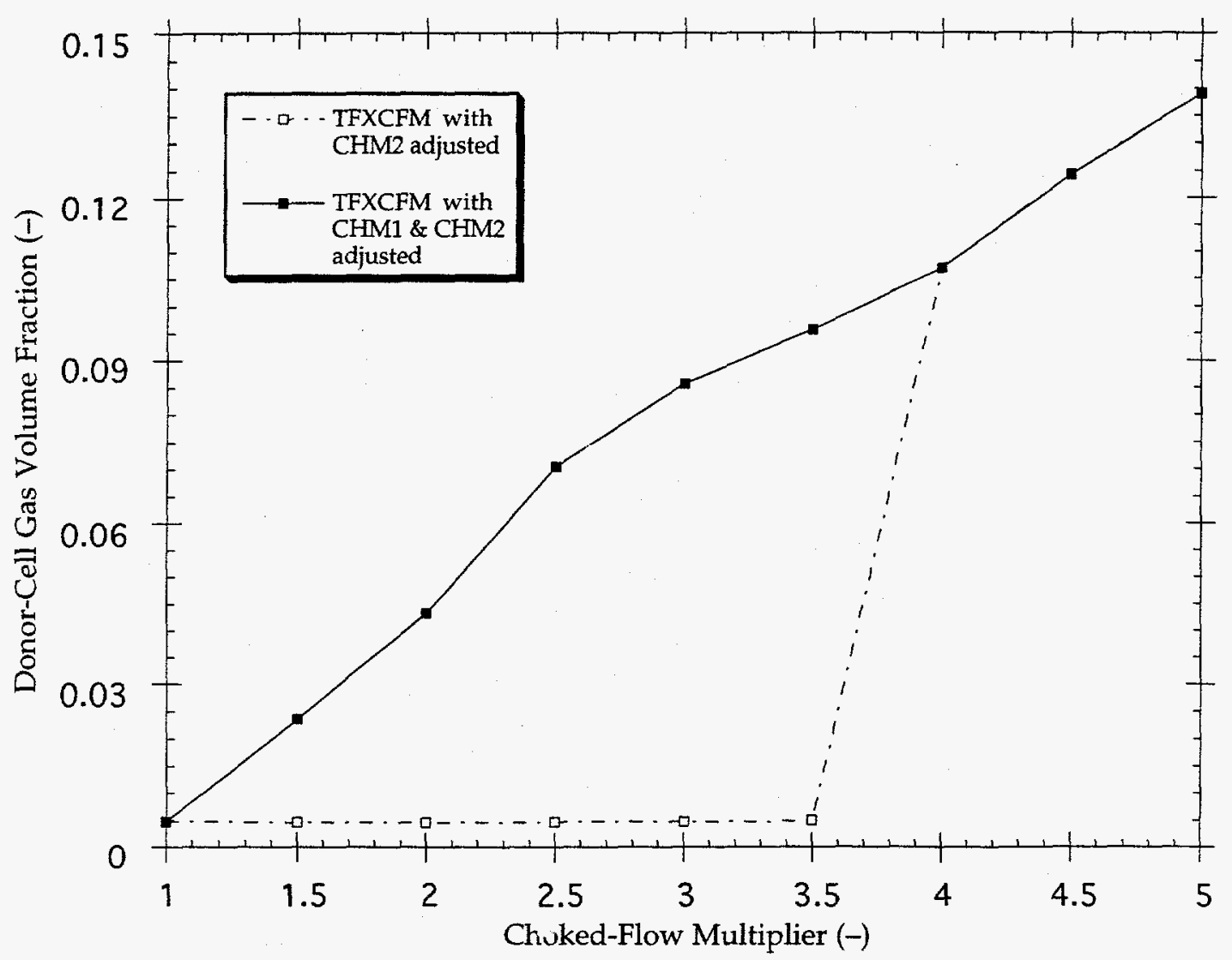

Fig. 2. Donor-cell gas volume fraction vs the choked-flow multiplier.

KAPL's request to document how the choked-flow multipliers are applied in TRAC$\mathrm{P}$ will be satisfied with the following description. All this is already documented in Sec. 7.2 of the TRAC-P Theory manual, which is difficult to understand because portions of the information are at various locations. The subcooled choked-flow multiplier CHM1 is applied as a factor by subroutine CHOKE to the subcooled sonic velocity evaluated by subroutine SOUND for a gas volume fraction $\alpha \leq 0.01$. This adjusted sonic velocity defines the sonic liquid velocity, and the sonic gas velocity is defined by the sonic liquid velocity times the slip. The two-phase choked-flow multiplier CHM2 is applied as a factor by subroutine CHOKE to the two-phase sonic velocity evaluated by subroutine SOUND for a gas volume fraction $\alpha \geq 0.10$. This adjusted sonic velocity defines the sonic gas velocity, and the sonic liquid velocity is defined by the sonic gas velocity divided by the slip. For $0.01 \leq \alpha \leq 0.10$, these sonic liquid velocities and sonic gas velocities at $\alpha=0.01$ and $\alpha=0.10$ are linearly interpolated. Then the sonic liquid and gas velocities are combined to define the sonic mixture velocity, which is compared with the predictor stabilizer mixture velocity (previously the basic mixture velocity) to test for choked flow. When the sonic mixture velocity is less than or equal to the predictor stabilizer mixture velocity, choked flow is assumed to occur and the sonic liquid velocity defines the liquid velocity and the sonic gas velocity defines the gas velocity. 


\subsection{SUMMARY AND CONCLUSIONS}

Scientech, KAPL, and Los Alamos National Laboratory observed solution errors and inappropriate programming in the TRAC-P choked-flow model that were reported in TRAC-P Trouble Report items 235, 259, and 260, respectively. The choked-flow model solution behavior was investigated using the KAPL, Marviken, Edwards, and Scientech critical-flow test problems. Five areas of correction changes in the chokedflow model programming were found and corrected by update FXCFM. Two of those areas address TRAC-P Trouble Report items 259 and 260. The other three areas were additional errors found during the investigation. TRAC-P Trouble Report item 235 was partially resolved by noting that geometry modeling of the break path significantly affects the magnitude of the evaluated choked mass flow and that both the subcooled and two-phase choked-flow multipliers need to be adjusted to proportionally adjust the saturated mass flow for donor-cell gas volume fractions. $<0.1$.

The update FXCFM corrections have the most effect on the pressure downstream of the choked-flow interface. This results in the corrections having little effect on the Marviken, Edwards, and Scientech critical-flow test problems because the chokedflow interface is the BREAK-component junction of the downstream-pressure boundary condition. This means that most of the choked-flow modeling in the past would be affected very little by the corrections of update FXCFM. The critical mass flow, which is the most important result, was found to be affected the least. 


\section{APPENDIX A}

\section{LISTINGS OF FILES LABCFM AND FXCFM}

\section{A.1. File LABCFM Listing}

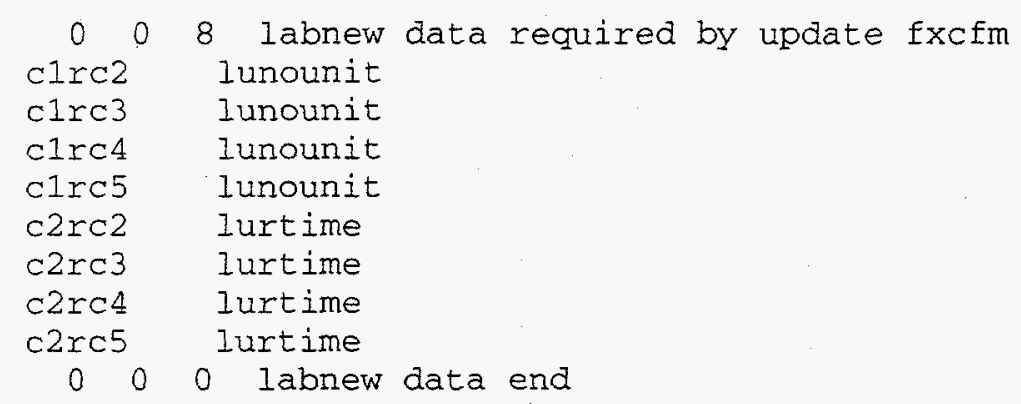

\section{A.2. File FXCFM Listing}

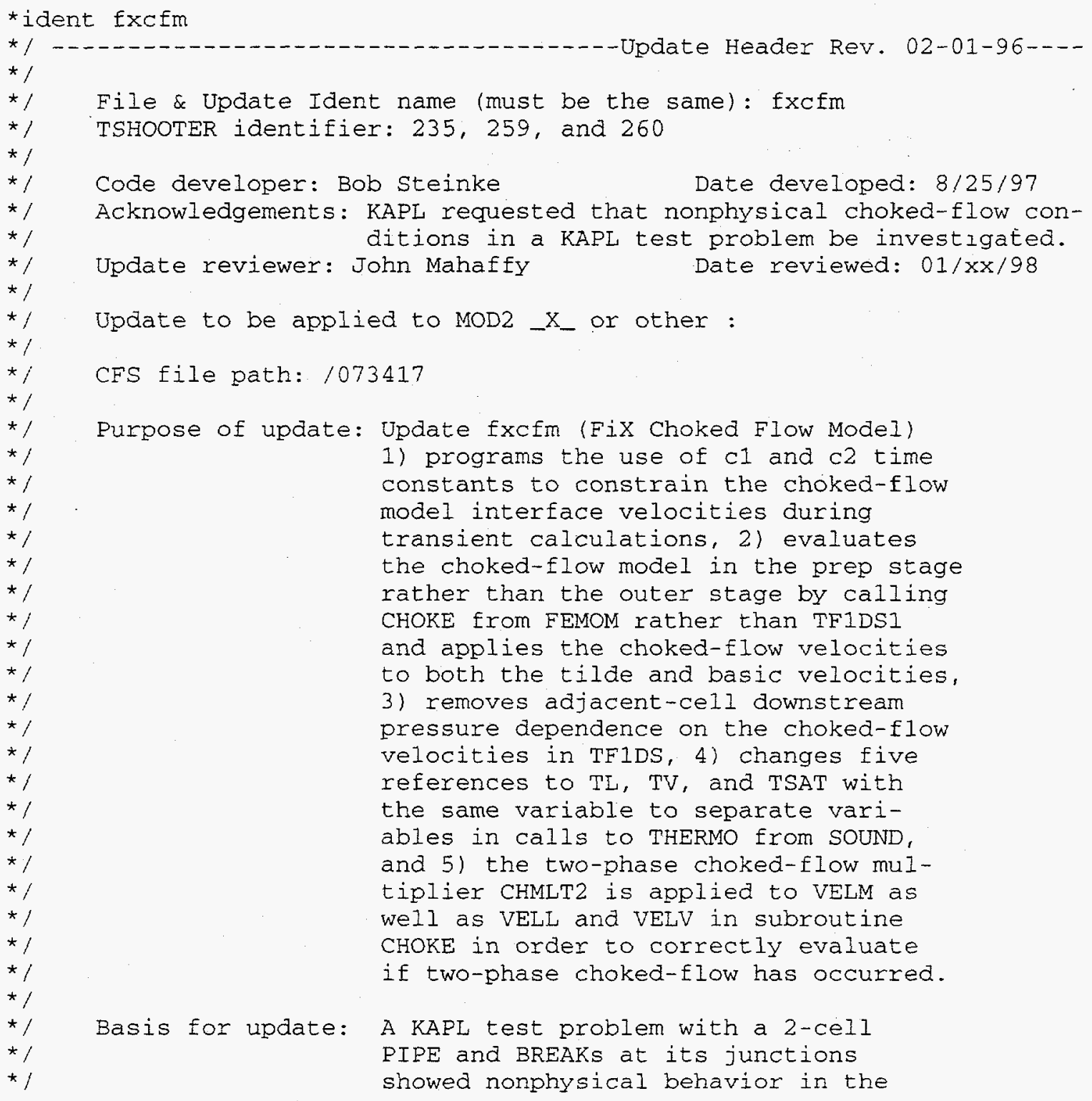




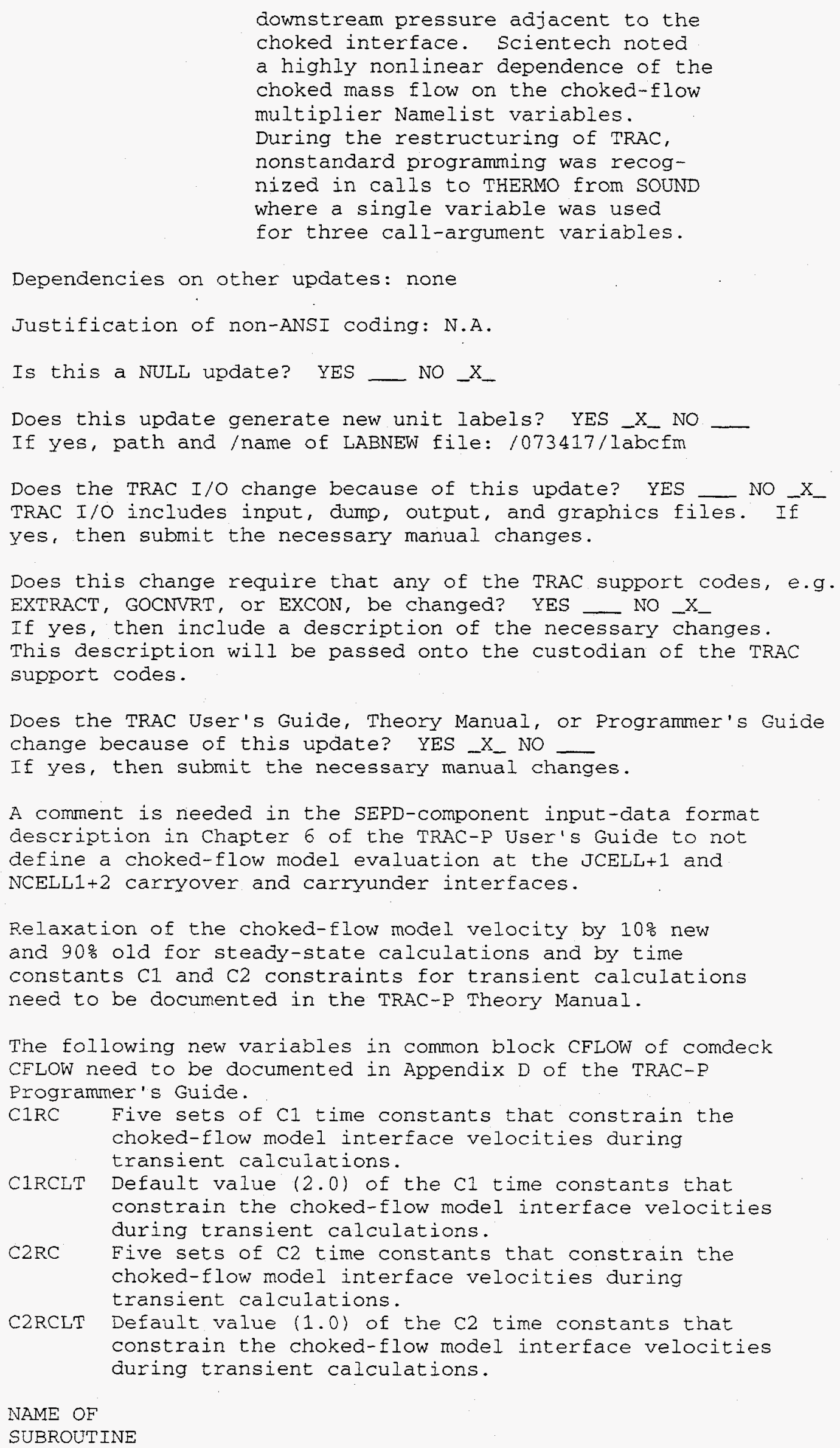

downstream pressure adjacent to the choked interface. Scientech noted a highly nonlinear dependence of the choked mass flow on the choked-flow multiplier Namelist variables. During the restructuring of TRAC, nonstandard programming was recognized in calls to THERMO from SOUND where a single variable was used for three call-argument variables.

Does the TRAC User's Guide, Theory Manual, or Programmer's Guide change because of this update? YES _. $X_{\text {_ }}$ NO

A comment is needed in the SEPD-component input-data format description in Chapter 6 of the TRAC-P User's Guide to not define a choked-flow model evaluation at the JCELL+1 and caryover and carryunder interfaces. and $90 \%$ old for st constants $\mathrm{C} 1$ and $\mathrm{C} 2$ constraints for transient calculations

The following new variables in common block CFLOW of comdeck ne TRAC-P Programmer's Guide.

C1RCLT Default value $(2.0)$ of the $c 1$ time constants that constrain the choked-flow model interface velocities during transient calculations. choked-flow model interface velocities during transient calculations. constrain the choked-flow model interface velocities during transient calculations. 
* $/$ OR COMDECK

* CHANGED

* 1

$\star /$

$* 1$

$\star /$

$\star /$

$\star /$

*/

* $/$

*

$* 1$

$\star /$

* 1

$* 1$

$\star /$

*

* 1

$\star 1$

$* 1$

* 1

* 1

$* 1$

*

* 1

$* 1$

$* 1$

$* 1$

$*$

$* 1$

* 1

$\star /$

$* 1$

$* 1$

$\star /$

$*$

$\star 1$

$\star /$

$\star /$

$* 1$

$* /$

*

$\star /$

$\star /$

$\star /$

$* 1$

*

$\star /$

* 1

$* 1$

$\star /$

$\star 1$

*/ comdeck cflow changes

*delete cflow. 2 , cflow. 4

dimension c1rc(5), c2rc (5), chm1 (5), chm2 (5)

common/cflow/ clrc, c1rclt,c2rc,

1 c2rclt, chm1, chm2, chmlt1, chmlt2

* 1

* / subroutine bits changes

* delete ifra. 42

data mskpk2/0000000000060000016000b/

* delete ifrd. 59
Adds new variables C1RCLT and C2RCLT and new arrays $\mathrm{C} 1 \mathrm{RC}(5)$ and $\mathrm{C} 2 \mathrm{RC}(5)$ to common block /CFLOW/. Sets bit 33 on in the mskpk2 mask for both -def ibm and def, ibm: changes comment statements entry on 1123 according $1 y$. Constrains the new choked-flow velocity between Vold*C1** $(-C 2 * D E L T)$ and Vold*C1** (C2*DELT) for transient calculations, reduces the velocity ivatives with respect to the donor-cell by the fraction 1.0-fder when the new calculations, and applies the saturatedier chamt 2 to the velocity VELL and vapor velocity VELV.

Evaluates the subroutine CHOKE arguments and alls CHOKE to evaluate the choked-flow velocity and $C 2 R C(I)$ for $I=2,5$ as C2RC2, C2RC3, C2RC4, and C2RC5. C1RC(I) and $C 2 R C$ (I) for $I=1,5$ are initialized to the values CIRCLT and C2RCLT, respectively.

A (LDFVDP) to the call FEMOM argument list. the value of TSAT.

dds logic to zero out adjacent-cell downstream sure dependence on the choked velocity at evaluation of its arguments and defines the choked-interface velocity by the tilde velocity. Turns off bit 33 when water packing changes a water-packed cell inflow liquid velocity to an outflow liquid velocity of 0.01 . Removes logic to not evaluate the choked-flow when type.eq. sepdh. and. isepcb.eq. 2 ; of a separator component. A comment is needed in the separator-component input-data format iption to not define a choked-flow model evaluation at the jcell+1 and ncel11+2 carryover and carryunder interfaces. 
c clear all bits except 11, 12, 13, 32, and 33 (called from inner)

*delete suntrac.266 data mskpk2/z'0000040180001000'/

* delete bits.112

data mskpk2/z0000040180001c00/

*delete bits.155,bits. 158

c al1 bits except $11,12,13,32,33$, and 43 hits 11,12 ,

c and 13 are water-packer flags and bits 32 and 33 are set

c by subroutines preper and femom during the prep stage)

$\star /$

* / subroutine blkdat changes

* delete dihorg. I

data icflow, ihor/1,1/

blkdat

data clrclt, c2rclt, chmlt1, chmlt $2 / 2.0,1.0,1.0,1.0 /$

$\star 1$

*/ subroutine choke changes

*insert choke. 3

c

*insert choke. 8

choke

* ca contrlir

*insert choke.38

c $\mathrm{cl} \quad \mathrm{c}$ relaxation constant

c c2 c2 relaxation constant

*insert choke.131

data fder $10.9 /$

* delete choke.133, choke.134

$c$ set relaxation constants and multipliers according to the

bits

c component-interface choke-flow model option ichoke=icflg

$\mathrm{C}$

$c 1=c 1 r c(i c h o k e)$

$c 2=c 2 r c($ ichoke)

* delete choke.663, choke.664

velm=chmlt2 * (alpv*rhov*velv+alpI*rhol*vell)/rhomc

vel l=velm*rhomc ( rhovc*alpc*slip+rholc* $(1.0-a l p c)$ )

* delete choke.849, choke. 855

c evaluate the choked-velocity derivatives

c with respect to the donor-cell pressure

*insert choke. 863

choke

timestep constrain the choked velocities

if (stdyst.gt.0) then

$\mathrm{vl}=0.1 * \mathrm{v} 1+0.9 * \mathrm{v} 10$

dfldp $=0.1 * d f I d p$

$\mathrm{VV}=0.1 * \mathrm{VV}+0.9 * \mathrm{VVO}$

dfvap $=0.1 * d f v d p$

else

fmax $=\operatorname{star}\left(c 1, c 2^{*}\right.$ delt $)$

$\mathrm{fmin}=1.0 / \mathrm{fmax}$

vmin $=f \min * v 10$

$v \max =\mathrm{fmax}^{*} \mathrm{vlo}$

if $(v 1 * v 10 . g t .0 .0)$ then

if $(a b s(v l) . l t . a b s(v m i n)) \quad v l=v m i n$

if $(a b s(v I) \cdot g t . a b s(v \max )) \quad v I=v \max$

if $(a b s(v l) . g t . a b s(v l o)\rangle$ then

$d f l d p=(1.0-f d e *(v l-v l o) /(\max -v l o)) * d f l d p$

else

$d f l d p=(1.0-f d e r *(v l o-v l) /(v 10-v m i n)) * d f l d p$ endif

endif

vmin $=$ fmin *vvo 


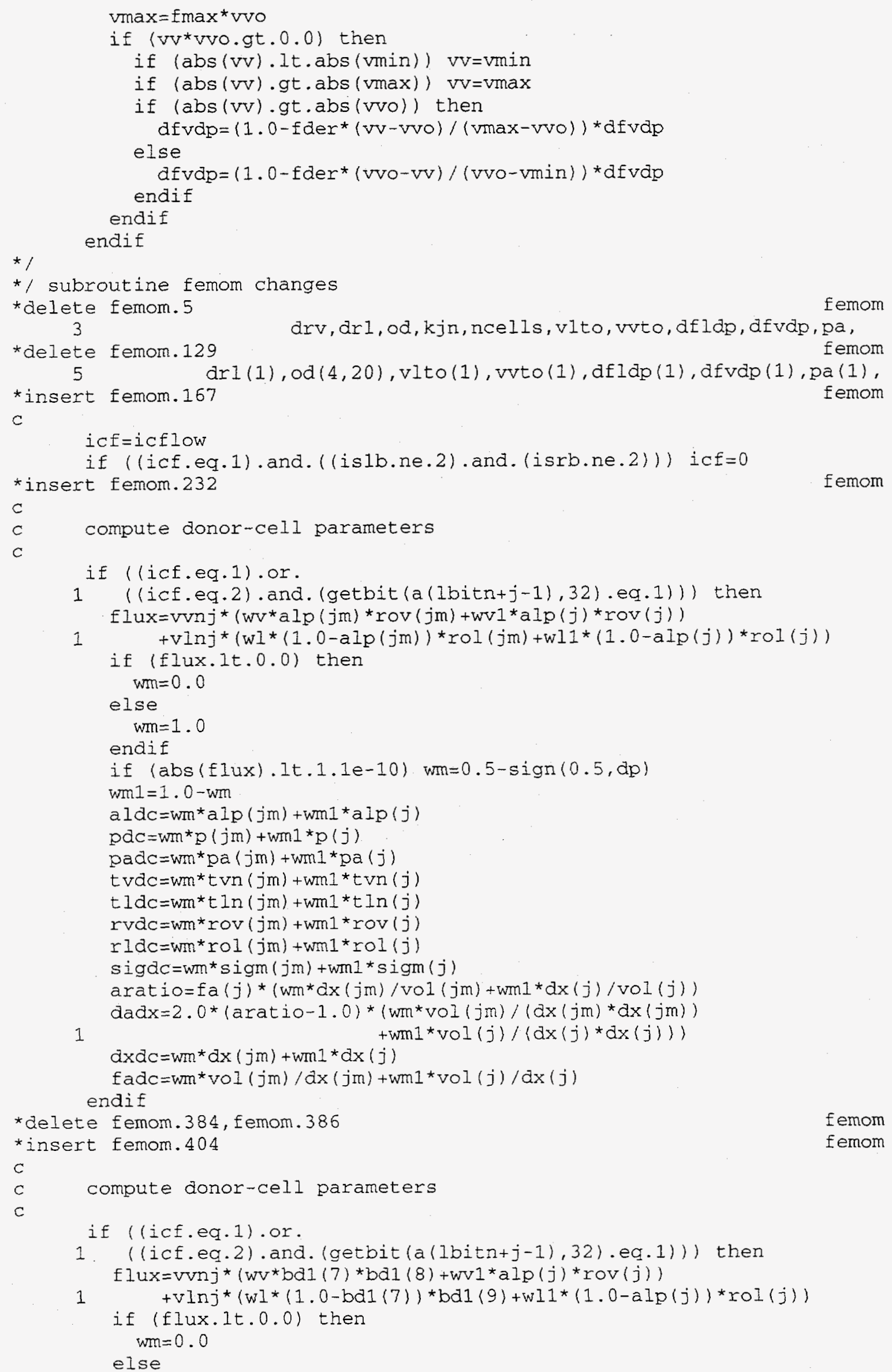




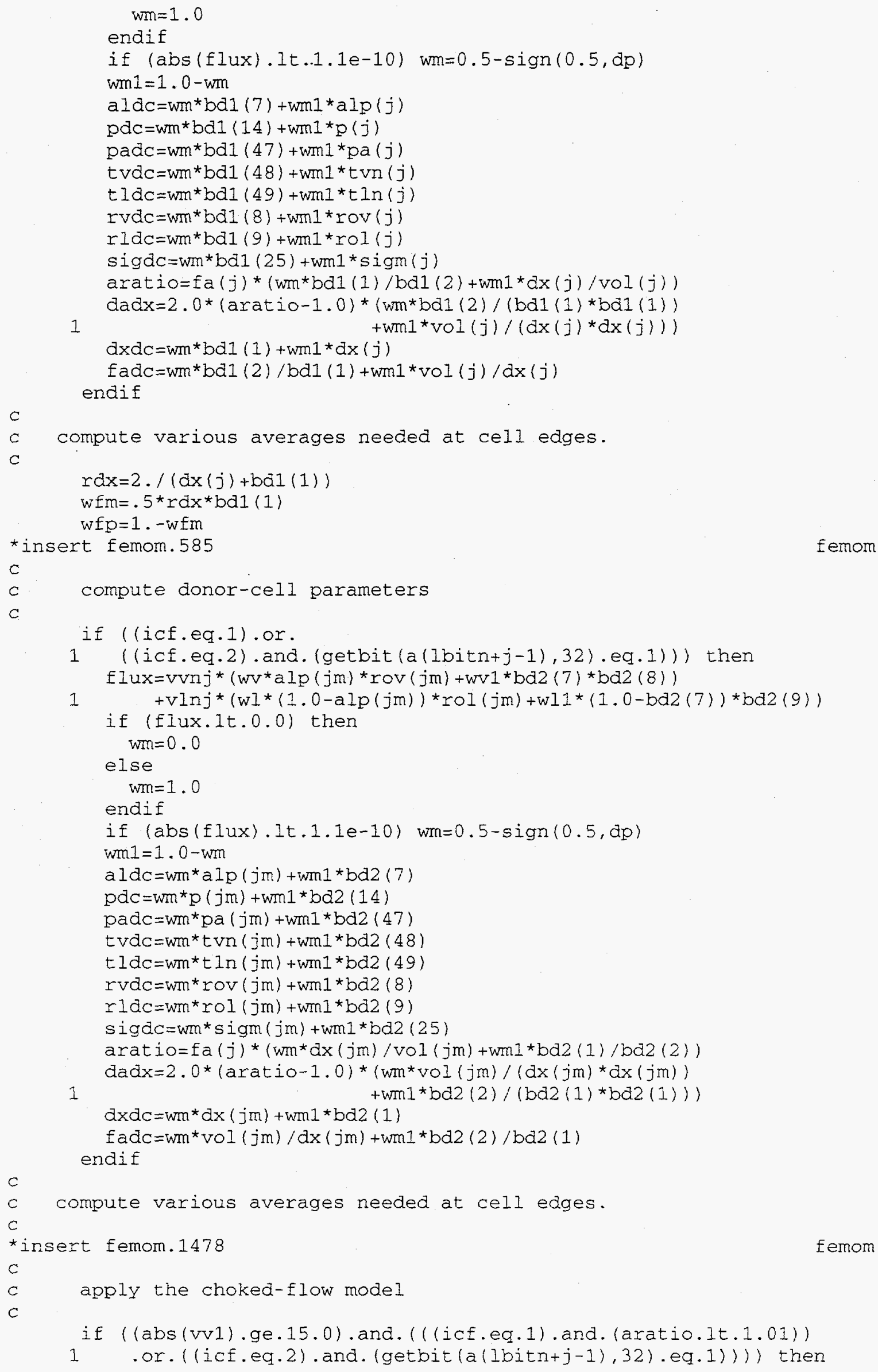




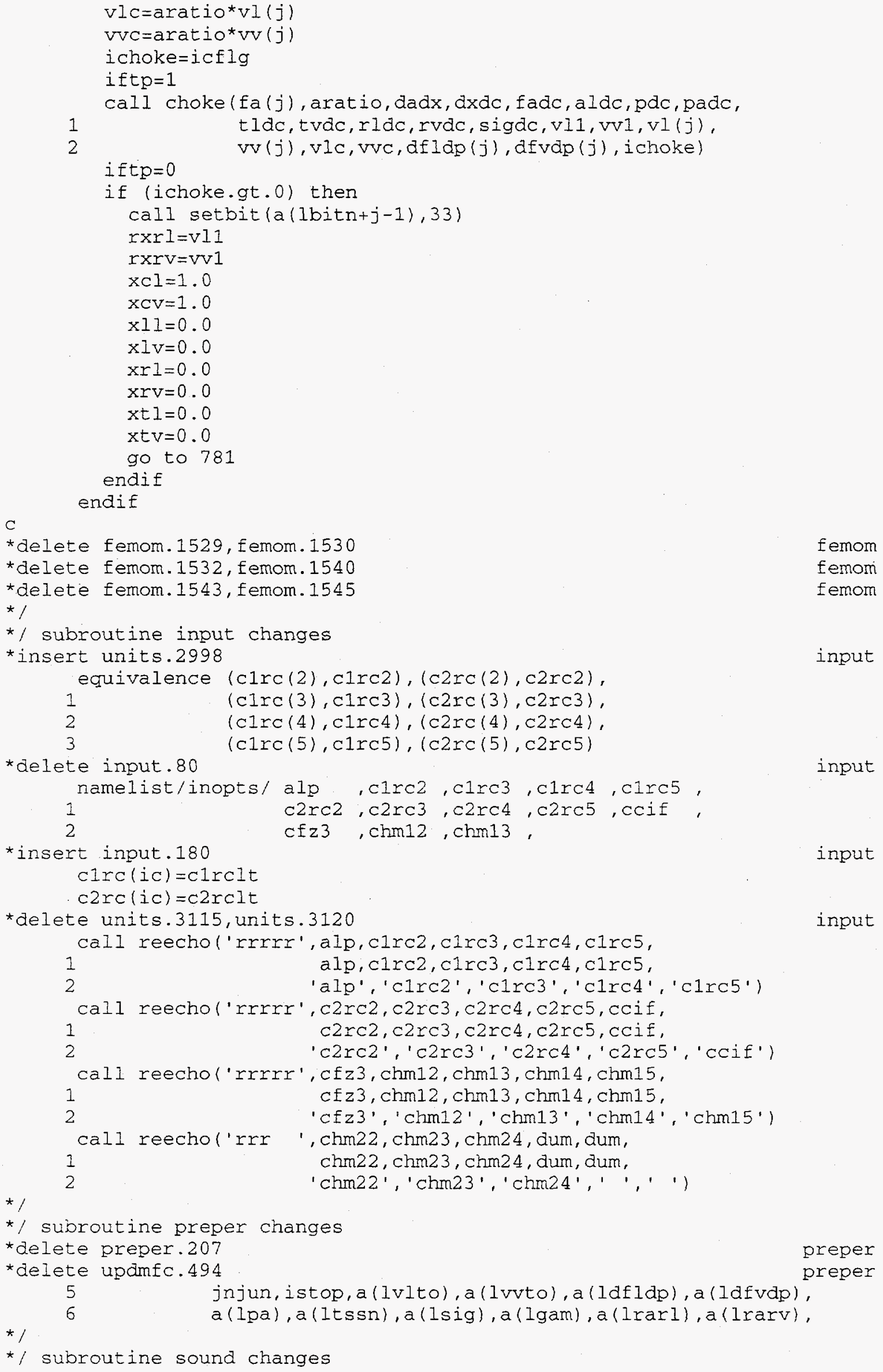


*insert sound. 53

$\operatorname{souna}$

tisat $=\operatorname{sattmp}(p)$

tvsat $=$ t lsat

*delete sound. 56 , sound. 57

sound

call thermo ( $p$, elsat, evsat, tlsat, tvsat, tsat, rhols, rhovs, pa,

1 rhoas, tssn, easat, der, $0,1,1$ )

*insert soind. 81

sound

tlsat $=$ sattmp $(p)$

tvsat $=$ Isat

*delete sound. 84 , sound. 85

sound

call thermo (p, elsat, evsat, tlsat, tvsat, tsat, rhols, rhovs, pasat

rhoas, tssn, easat, der, $0,1,1$ )

*insert sound. 214

tlsatc $=\operatorname{sattmp}(\mathrm{pc})$

tvsatc $=$ tlsatc

* delete sound.217, sound.218

sound

call thermo (pc, elc, evc, tlsatc, tvsatc, tc, rholc, rhovc, pac,

sound

1 rhoac, tssnc, eac, der, $0,1,1$ )

*insert sound. 235

tlc $=\operatorname{sattmp}(\mathrm{pc})$

*insert sound. 300

tlsatc $=$ sattmp $(\mathrm{pc})$

tvsatc $=$ t Isatc

*delete sound. 303 , sound. 304

call thermo (pc, elc, evc, tlsatc, tvsatc, tc, rholc, rhovc, pac,

1 rhoac, tssnc, eac, der, $0,1,1$ )

*insert sound. 533

tlcp=sattmp (pcp)

*insert sound. 555

tlsatc $=\operatorname{sattmp}(p c)$

tvsatc $=$ t lsatc

*delete sound.558, sound. 559

call thermo (pc, elc, evc, tlsatc, tvsatc, tc, rholc, rhove, pac,

1

rhoac, tssnc, eac, der, $0,1,1)$

*insert sound. 564

tlc $=$ t Isatc

*insert sound. 621

tic=sattmp $(p c)$

* 1

* / subroutine tflds changes

*delete tflas.25

logical ltest, lcfl, lcfr

*delete tflds.1081,tflds.1084

*insert tfids.1085

ICfl=getbit (bitn (jstart).33).ne.0

lcf $r=$ getbit (bitn (jstart +1$), 33)$.ne.0

if ((islb.eq.2) and. Icfl. and. (vln(jstart).ge.0.)) $\times 5=0$.

if $(1 \mathrm{cfr}$. and. $(\operatorname{vln}(j \mathrm{start}+1) .1 t .0)) \times 6=$.0 .

*insert tflds.1100

if (.not. Itest.and. Icfr. and. (vln (jstart +1$) \cdot$ ge.0.1) $\times 1=0$.

*insert tflds.1123

$1 \subset f l=l c f r$

lcfr $=$ getbit $($ bitn $(j+1), 33) \cdot$ ne. 0

$y 5=\operatorname{roln}(j)$

$y 6=\operatorname{rovn}(j)$

if (Icfl.and. $(\operatorname{vln}(j) \cdot g e .0)$.$) y 5=0$.

if (lcfr.and. $(\operatorname{vin}(j+1) .1 t .0)$.$) y 6=0$

*delete tflas. 1125

if (lcfl. and. ( $\ln (j) .1 t .0).) \quad x 4=0$.

$t f 1 d s$

$x 5=1 . /\left(1 .+\operatorname{czz} z \ln ^{*} \mathrm{y} 5+\mathrm{czzrh} * \mathrm{y} 6-\mathrm{x} 4 * \mathrm{x} 1\right)$

*insert tflds.1128

if ( $(j .1$ t.ncells $)$ and. lcfr. and. $(v \ln (j+I) \cdot g e .0).) \times 1=0$.

sound

sound

sound

sound

sound

sound.

sound

sound

tfids

tflds

$t f 1 d s$

tfids

$t+1 d s$

A-8 
*insert tfids.1164

$t f 1 d s$

if (getbit (bitn (ncells+1), 33) ne.0) and.

1 (vln(ncells+1).It.0.)) go to 1020

*insert tf1ds.1179

$t f 1 d s$

if ( (getbit (bitn (jstart), 33).ne.0). and.

1 (vln (jstart).ge.0.)) return

* delete tfids.1187

1050 if ( getbit (bitn (ncells +2$), 33)$.ne.0). and.

1 (vln (ncells+2). It.0.)) go to 1030

$\operatorname{dvb}(i i 03)=\operatorname{dvb}(i \mathrm{i03})+\operatorname{tsn}(\mathrm{msc})$

*

* subroutine tElas1 changes

* delete tf1ds1.112, tf1ds1:117

* delete tflds $1.135, t f 1 d s 1.150$

$s i g=w f m$ *sigma $(j m)+w f p{ }^{*} \operatorname{sigma}(j)$

*delete tflas1.244,tflas1.249

* delete tflas $1.275, t f 1 d s 1.290$

sig $=w f m * b d 1(25)+w f p * \operatorname{sigma}(j)$

*delete tf1ds1.430,tf1as1.435

* delete tflds1.458,tflds1.473

sig $=w f p * b d 2(25)+w f m * s i g m a(j m)$

*insert tflas1.559

if (getbit(bitn(j),33).eq.1) go to 150

* delete ccflfx.10

capc $=\operatorname{sqrt}\left(\operatorname{sig} /\left(g c^{*}\right.\right.$ delrho $\left.)\right)$

*insert tf1ds1.805

tflas 1

tflds 1

tflds 1

tflas 1

$t f 1 d s 1$

tflas 1

$\operatorname{tflas} 1$

$t \pm 1 d s 1$

tf1dsI

go to 155

$\mathrm{C}$

c apply the choked-flow model evaluated in subroutine femom

c which defined $v i t(j), \operatorname{vvt}(j), \operatorname{dfldp}(j)$, and $\operatorname{dfvap}(j)$

C

150 continue

$\operatorname{vln}(j)=\operatorname{vlt}(j)$

$\operatorname{vvn}(j)=\operatorname{vvt}(j)$

* delete tilas 1.807

tflas 1

tflas 1

*delete tfias 1.849

*insert tflds1.857

call offbit (bitn(j), 33)

* delete tflds 1.896

tflas 1

*insert tflas 1.904

tf $1 \mathrm{ds} 1$ call offbit (bitn $(j) ; 33$ )

*delete tflds1.934,tf1ds1.959

tflds 1

$\operatorname{tf1ds} 1$

$\star /$

*compile cflow, bits,blkdat, choke, femom, input, preper, sound, tflds, tflds 1

$\star /$

$*$ 


\section{APPENDIX B}

\section{EVALUATING THE KAPL CHOKED-FLOW TEST PROBLEM}

\section{B.1. INTRODUCTION}

KAPL uses transient-calculation test problems having a two-cell PIPE, one-cell PIPE, or two-cell VALVE with a high-pressure ( 680.0 psia) BREAK at one junction and a low-pressure (14.7 to 600.0 psia) BREAK at the other junction to test the choked-flow model in TRAC-P. Choked (critical) flow occurs at the positive interface of cell 1 (between cells 1 and 2) where the interface flow area is reduced to $70 \%$ of the otherwise constant flow area of the flow channel. The low-pressure boundary condition has a step-change increase every $100 \mathrm{~s}$, first by $35.3 \mathrm{psi}$ to $50.0 \mathrm{psia}$ at $100 \mathrm{~s}$ and later in 50.0 psi increments to 100.0 psia at $200 \mathrm{~s}, 150.0$ psia at $300 \mathrm{~s}, \ldots$, and $600.0 \mathrm{psia}$ at $1200.0 \mathrm{~s}$. As the low-pressure boundary condition pressure is increased, at some point choked flow will no longer occur. The fluid is water vapor at a temperature of $500.0^{\circ} \mathrm{F}$ upstream of the choked interface. At a pressure of $680.0 \mathrm{psia}$, the saturation temperature is $499.79^{\circ} \mathrm{F}$. A saturated condition occurs at the choked interface.

In the two-cell PIPE and VALVE test problems, KAPL observed that the adjacent downstream-cell pressure of the choked-flow interface falls below the pressure of the low-pressure boundary condition. This behavior is shown in Fig. B.1 for the two-cell PIPE test problem. KAPL asked that the cause of this nonphysical behavior be investigated and corrected in TRAC-P Version 5.4.28. This error was recorded as trouble-report item 259. All further testing will be done on the two-cell PIPE test problem.

\section{B.2. ANALYSES AND RESULTS}

The error investigation, correction, and testing process for KAPL was done in three stages. In the first stage, the time-delay procedure of averaging $10 \%$ of a newly predicted choked velocity with $90 \%$ of the old velocity from the previous timestep to define the present-timestep choked velocity was found programmed at the end of subroutine CHOKE for both steady-state and transient calculations. This time-delay procedure is appropriate only for steady-state calculations because it is timestep-size dependent and introduces significant time lag. A more appropriate physically based time-delay procedure is needed for transient calculations. At this point, it was felt that too much time lag in the choked-interface velocity could be causing the 
adjacent downstream-cell pressure rise to lag the low-pressure boundary-condition pressure rise enough to cause the observed nonphysical behavior.

This was corrected for transient calculations by constraining the newly predicted choked velocity $V$ to lie in the range $V_{0}{ }^{*} C 1^{* *}\left(-C 2^{*} \Delta t\right)$ to $V_{0}{ }^{*} C 1^{* *}\left(+C 2^{*} \Delta t\right)$ where $V_{o}$ is the old velocity from the previous timestep, $\mathrm{C} 1$ and $\mathrm{C} 2$ are constants to be defined, and $\Delta t$ is the current timestep size. This time-constant constraining procedure with $\mathrm{C} 1=2$ and $\mathrm{C} 2=10 \mathrm{~s}^{-1}$ currently is used in TRAC-P for thermal-hydraulic coefficients evaluated for transient calculations during the prep stage.

In addition to the choked velocity $V$, the $d V / d P_{d}$ derivative of the choked velocity with respect to its donor-cell pressure (used in the Jacobian-matrix semi-implicit solution) also needs a time-delay procedure applied to it for numerical stability. For steady-state calculations, $V_{n}=0.1^{*} \mathrm{~V}+0.9^{*} \mathrm{~V}_{\mathrm{o}}$ and $\mathrm{dV}_{\mathrm{n}} / \mathrm{dP}_{\mathrm{d}}=0.1^{*} \mathrm{dV} / \mathrm{dP}_{\mathrm{d}}$ such that $\mathrm{V}_{\mathrm{n}}\left(\mathrm{P}_{\mathrm{d}}\right)=0.1^{*} \mathrm{~V}\left(\mathrm{P}_{\mathrm{d}}\right)+0.9^{*} \mathrm{~V}_{\mathrm{o}}$ where $\mathrm{V}_{\mathrm{n}}\left(\mathrm{P}_{\mathrm{d}}\right)=\mathrm{V}_{\mathrm{n}}+\left(\mathrm{dV} \mathrm{V}_{\mathrm{n}} / \mathrm{d} \mathrm{P}_{\mathrm{d}}\right)^{*} \Delta \mathrm{P}_{\mathrm{d}}$ and $\mathrm{V}\left(\mathrm{P}_{\mathrm{d}}\right)=\mathrm{V}+$ $\left(\mathrm{dV} / \mathrm{dP} \mathrm{P}^{*} \Delta \mathrm{P}_{\mathrm{d}}\right.$. For transient calculations where $\mathrm{V}_{\mathrm{o}}{ }^{*} \mathrm{C} 1^{* *}\left(-\mathrm{C} 2^{*} \Delta \mathrm{t}\right) \leq \mathrm{V} \leq \mathrm{V}_{\mathrm{o}}{ }^{*} \mathrm{C} 1^{* *}$ $\left(+C 2^{*} \Delta t\right)$ defines $V_{n}=V$, we linearly vary $d V_{n} / d P_{d}$ from $d V_{n} / d P_{d}=d V / d P_{d}$ when $V=V_{0}$ to $d V_{n} / d P_{d}=0.1^{*} d V / d P_{d}$ when $V=V_{0}{ }^{*} C 1^{* *}\left( \pm C 2^{*} \Delta t\right)$. The full derivative value is used when the newly predicted choked velocity hasn't changed from its value in the previous timestep, whereas $10 \%$ of the derivative value is used when the choked velocity is being constrained at one of its limits.

The effect on pressure and mass flow (in the two-cell PIPE test problem) of applying the above time-constant constraint to the choked velocity and its derivative is shown in Figs. B.2, B.3, and B.4 for $\mathrm{C} 1=2.0$ and $\mathrm{C} 2=10.0,0.1$, and $0.001 \mathrm{~s}^{-1}$, respectively. Figure B.1 shows the original base-case results where the steady-state calculation $\mathrm{V}_{\mathrm{n}}=0.1^{*} \mathrm{~V}+0.9^{*} \mathrm{~V}_{\mathrm{o}}$ and $\mathrm{dV}_{\mathrm{n}} / \mathrm{dP}_{\mathrm{d}}=0.1^{*} \mathrm{dV} / \mathrm{dP}_{\mathrm{d}}$ time-delay procedure is used. We find that changing the time-delay procedure to a more appropriate form for transient calculations has no effect on correcting the underpredicted pressure in the adjacent downstream cell. The $\mathrm{C} 2=0.001 \mathrm{~s}^{-1}$ case in Fig. B.4 shows too much time delay in the mass-flow results.

The second stage of the error investigation, correction, and testing process involved finding that the choked-flow model was being applied only to the basic motion equations in the outer-iteration stage and not to the stabilizer motion equations in the prep stage. The intent of the existing programming in subroutine FEMOM was to define the previous-timestep choked basic velocity to be the present-timestep corrector stabilizer velocity. This was done if the $33 \mathrm{rd}$ bit in BITN(J) is 1 signifying that the Jth interface had choked flow during the previous timestep. It turns out 
that all the bits of BITN $(\mathrm{J})$ are 0 in subroutine FEMOM because subroutine PREPER calls subroutine CLEAR to reset all the bits of BITN(J) to 0 before calling subroutine FEMOM. Fortunately, the previous-timestep bit information in BITN $(J)$ was stored in $\operatorname{BIT}(\mathrm{J})$ before the bits of BITN(J) were reset to 0. Having subroutine FEMOM test $B I T(J)$ rather than $B I T N(J)$ would correct this intended programming.

Figures B.5 through B.8 show the effect of the BITN(J)-replaced-by-BIT(J) correction in subroutine FEMOM upon the cases in Figs. B.1 through B.4, respectively. The choked-interface adjacent downstream-cell pressure is now computed correctly. Low-pressure boundary-condition pressures of 550 and 600 psia now calculate lesser mass flows that are not choked. There are four 100-s time intervals during which the computed mass flow oscillates each timestep between two different levels. These levels differ less in Figs. B.5 and B. 8 than in Figs. B.6 and B.7 because of increased time dampening from 10 and $90 \%$ averaging and $C 1=2.0$ and $C 2=0.001 \mathrm{~s}^{-1}$ time-constant constraint.

At this point, it may appear that the needed correction has been made (replacing $\operatorname{BITN}(\mathrm{J})$ with BIT(J) to test for choked flow in subroutine FEMOM). That is true only if we were to accept the approximation of defining the present-timestep corrector stabilizer velocity with the choked basic velocity from the previous timestep. This timestep-wise inconsistent definition of the choked stabilizer velocity by the basic velocity is shown in the titles of Figs. B.1 to B. 8 to increase the number of timesteps required for the 1300 -s solution from $\sim 5800$ to $\sim 10400$ timesteps. The perturbing effect of applying inconsistent choked stabilizer and basic velocities during a timestep has reduced the timestep size determined by TRAC-P internally by an average factor of $0.56(5800 / 10400)$.

The correct approach, to be programmed instead, evaluates the choked-flow model in subroutine FEMOM by calling subroutine CHOKE and applies its choked velocity to both the corrector stabilizer velocity and the basic velocity of the timestep. The predictor stabilizer velocity is evaluated in the usual way by subroutine FEMOM. Then subroutine CHOKE is called by subroutine FEMOM to evaluate the sonic velocity. If the sonic velocity is less than the predictor stabilizer velocity for the timestep, choked flow is assumed and the corrector stabilizer velocity during the prep stage and the basic velocity during the outer-iteration stage are defined by the sonic velocity. The choked-velocity derivative, with respect to its donor-cell pressure, is evaluated by subroutine CHOKE as well and is used in the Jacobianmatrix semi-implicit solution of the outer-iteration stage. If there is water packing in the adjacent downstream cell of a choked interface during the outer-iteration B-3 
stage, its choking flag is turned off (bit 33 of BITN(J) is reset to 0), the choked-velocity flow direction is reversed and its magnitude is reduced to $0.01 \mathrm{~m} \mathrm{~s}^{-1}$, and the choked vapor-velocity derivative is redefined by its liquid-velocity derivative. The result of applying a consistent choked-flow velocity to the corrector stabilizer velocity and basic velocity is shown in Figs. B.9 through B.12 for the cases in Figs. B.5 through B.8. The correct pressure and mass-flow results are slightly different but similar. The largest change is that now $\sim 2940$ rather than $\sim 10,400$ timesteps are required to evaluate the 1,300-s solution. The average timestep size determined by TRAC-P internally has increased by a factor of $3.5(10,400 / 2,940)$.

The third stage of the error investigation, correction, and testing process involved eliminating the adjacent downstream-cell pressure dependence on the choked velocity in the Jacobian-matrix semi-implicit solution of the outer-iteration stage. The choked velocity is dependent only on the upstream donor-cell pressure through its $d V_{n} / d P_{d}$ derivative. Normal dependence of an interface velocity on both its upstream and downstream adjacent-cell pressures existed in TRAC-P without special logic to eliminate adjacent downstream-cell pressure dependence when the interface velocity is choked. An error doesn't occur when the adjacent downstream cell of a choked-flow interface is a BREAK-component cell. Generally, choked flow is modelea at the junction of a BREAK component so that such cases are not affected by this error. Cases, such as the KAPL two-cell PIPE test problem, where the choked interface is not at the junction of a BREAK component, are effected by this error.

The logic to eliminate adjacent downstream-cell pressure dependence on an interface choked velocity has been programmed in subroutine TF1DS by update FXCFM. The programming is different for an internal interface of a component and for a junction interface between components. For the internal interface $I$ of a component with $\mathrm{N}$ cells (where $1<\mathrm{I}<\mathrm{N}+1$ ) that has a velocity $\mathrm{V}_{\mathrm{I}}$ that is choked, the I-1th row of the component's pressure-matrix equation

$$
-c_{\text {left }, I-1}^{\prime} \cdot \delta p_{\mathrm{I}-2}+\left(1+c_{\text {left }, I-1}^{\prime}+c_{\text {right }, I-1}^{\prime}\right) \cdot \delta p_{\mathrm{I}-1}-c_{\text {right }, I-1}^{\prime} \cdot \delta p_{I}=b_{I-1}^{\prime}-0 \cdot \Delta p_{1}+0 \cdot \Delta p_{N+1}
$$

needs to have $+c_{\text {right,I-1 }}$ set to 0 if $V_{I}<0$ or $-c_{\text {right,I-1 }}$ set to 0 if $V_{I} \geq 0$, and the Ith row of the component's pressure-matrix equation

$$
-c_{\text {left }, I}^{\prime} \cdot \delta p_{\mathrm{I}-1}+\left(1+c_{\text {left,I }}^{\prime}+c_{\text {right,I }}^{\prime}\right) \cdot \delta p_{I}-c_{\text {right,I }}^{\prime} \cdot \delta p_{\mathrm{I}+1}=b_{I}^{\prime}-0 \cdot \Delta p_{1}+0 \cdot \Delta p_{N+1}
$$


needs to have $-c_{\text {left,I }}$ set to 0 if $V_{I}<0$ or $+c_{\text {left,I }}$ set to 0 if $V_{I} \geq 0$. For the junction interface $\mathrm{J}$ between cell 1 of the component and cell $\mathrm{M}=1$ or $\mathrm{N}_{\text {left }}$ of the adjacent component that has a velocity $\mathrm{V}_{\mathrm{J}}$ of the component that is choked, the networkmatrix equation

$$
\Delta \mathrm{p}_{1}=\delta \mathrm{p}_{1}-\delta \mathrm{p}_{\mathrm{M}}
$$

needs to have $-\delta p_{M}$ set to 0 if $\mathrm{V}_{\mathrm{J}}<0$ or $\delta \mathrm{p}_{1}$ set to 0 if $\mathrm{V}_{\mathrm{J}} \geq 0$. For the junction interface $\mathrm{J}$ between cell $\mathrm{N}$ of the component and cell $\mathrm{M}=1$ or $\mathrm{N}_{\text {right }}$ of the adjacent component that has a velocity $\mathrm{V}_{\mathrm{J}}$ of the component that is choked, the networkmatrix equation

$$
\Delta \mathrm{p}_{\mathrm{N}+1}=\delta \mathrm{p}_{\mathrm{M}}-\delta \mathrm{p}_{\mathrm{N}}
$$

needs to have $-\delta \mathrm{p}_{\mathrm{N}}$ set to 0 if $\mathrm{V}_{\mathrm{J}}<0$ or $\delta \mathrm{p}_{\mathrm{M}}$ set to 0 if $\mathrm{V}_{\mathrm{J}} \geq 0$. In Appendix $\mathrm{A}$, update FXCFM changes *delete tf1ds. 25 through *insert tf1ds.1128 on page A- 8 to program the logic for internal interfaces and changes *insert tf1ds.1164 through *delete tf1ds.1187 on page A-9 to program the logic for junction interfaces.

Figures B.13 through B.16 show the results of removing $\delta \mathrm{p}_{1}$ dependence on the $\mathrm{V}_{2}<$ 0 choked velocity for the cases in Figs. B.9 through B.12. There is not much difference in the results except for the mass-flow levels in some of the 100-s time intervals that don't appear to oscillate for the $\mathrm{C} 2=10.0$ and 0.1 cases in Figs. B.14 and B.15. Had the oscillation occurred during the time interval, their mass flows would have lain at different limits of the oscillation.

Six variations of the two-cell PIPE KAPL test problem were created to test the correct programming of the internal- and junction-interface logic in subroutine TF1DS by update FXCFM. Component-cell diagrams of those cases are shown in Fig. B.17. Base case 1 is the two-cell PIPE KAPL test problem with $\mathrm{C} 1=2.0$ and $\mathrm{C} 2=1.0$. Testing in later appendices will determine these time-constant values to be the recommended default values. Cases 2 and 3 change the two-cell PIPE to a four-cell PIPE by halving the DX and VOL input data. All three of these cases model the choked interface by an internal interface with a different number of component cells and with a reversed direction of cell and interface numbering. Cases 4 through 7 change the four-cell PIPE to two two-cell PIPEs. The choked interface is now the junction interface between these two PIPEs. Among these four cases, all combinations of reversing the direction of cell and interface numbering of each of 
the two PIPEs is defined. Correct programming of the internal- and junctioninterface logic in subroutine TF1DS should result in these six cases (with a total of four cells in one or two PIPEs) determining the same solution.

Figure B.18 shows the pressure and mass flow results from the two-cell PIPE base case 1, whereas Figs. B.19 and B.20 show the results from the four-cell PIPE cases 2 and 3 . There are four differences in these results: (1) averaging the two-cell pressures on each side of the choked interface gives a pressure slightly different from the single-cell pressure, (2) the two-cell PIPE choked mass flow of 26.68 $( \pm 0.18) \mathrm{kg} \mathrm{s}^{-1}$ is slightly greater than the $26.51( \pm 0.09) \mathrm{kg} \mathrm{s}^{-1}$ choked mass flow of the four-cell PIPE with double the oscillation amplitude, (3) the mass-flow oscillations occur in different 100-s time intervals, and (4) the low-pressure boundary condition of 550 psia evaluates no choking with the two-cell PIPE and choking with the fourcell PIPE. These slight differences are assumed because of a discretization error in donor-cell convection. Figures B.21 through B.24 give the same results as Figs. B.19 and B.20, indicating that the logic reprogramming in subroutine TF1DS by update FXCFM is done correctly.

Halving of the mass-flow-oscillation amplitude when doubling the number of cells prompted the creation of two more case variations: doubling the number of cells in case 2 to create case 8 with 8 cells in PIPE 2, and doubling the number of cells in case 8 to create case 9 with 16 cells in PIPE 2. Doubling the number of cells in each of these cases involved halving their DX and VOL input data. The input and output data from cases 1 to 9 are defined by files IN\# and OUT\# for \# $=1,2, \ldots, 9$. Cases 8 and 9 determined choked mass flows of $26.44( \pm 0.06)$ and $26.43( \pm 0.04) \mathrm{kg} \mathrm{s}^{-1}$, respectively. These mass-flow results are shown in Fig. B.25 for cases 1, 2, 8, and 9. Two observations can be made: (1) modeling more cells between the choked interface and the upstream-pressure boundary condition reduces the amplitude of the massflow oscillation and (2) doubling the number of cells doubles the number of timesteps and increases the calculative effort by a factor of four. Progressively doubling the number of cells without changing the cell size gives similar results. Having more cells between the BREAK-component pressure boundary condition and a choked-flow interface provides more degrees of freedom in the numerical solution. This dampens the oscillation in the choked mass flow caused by the explicit evaluation of the choked-flow velocity by subroutine CHOKE. 

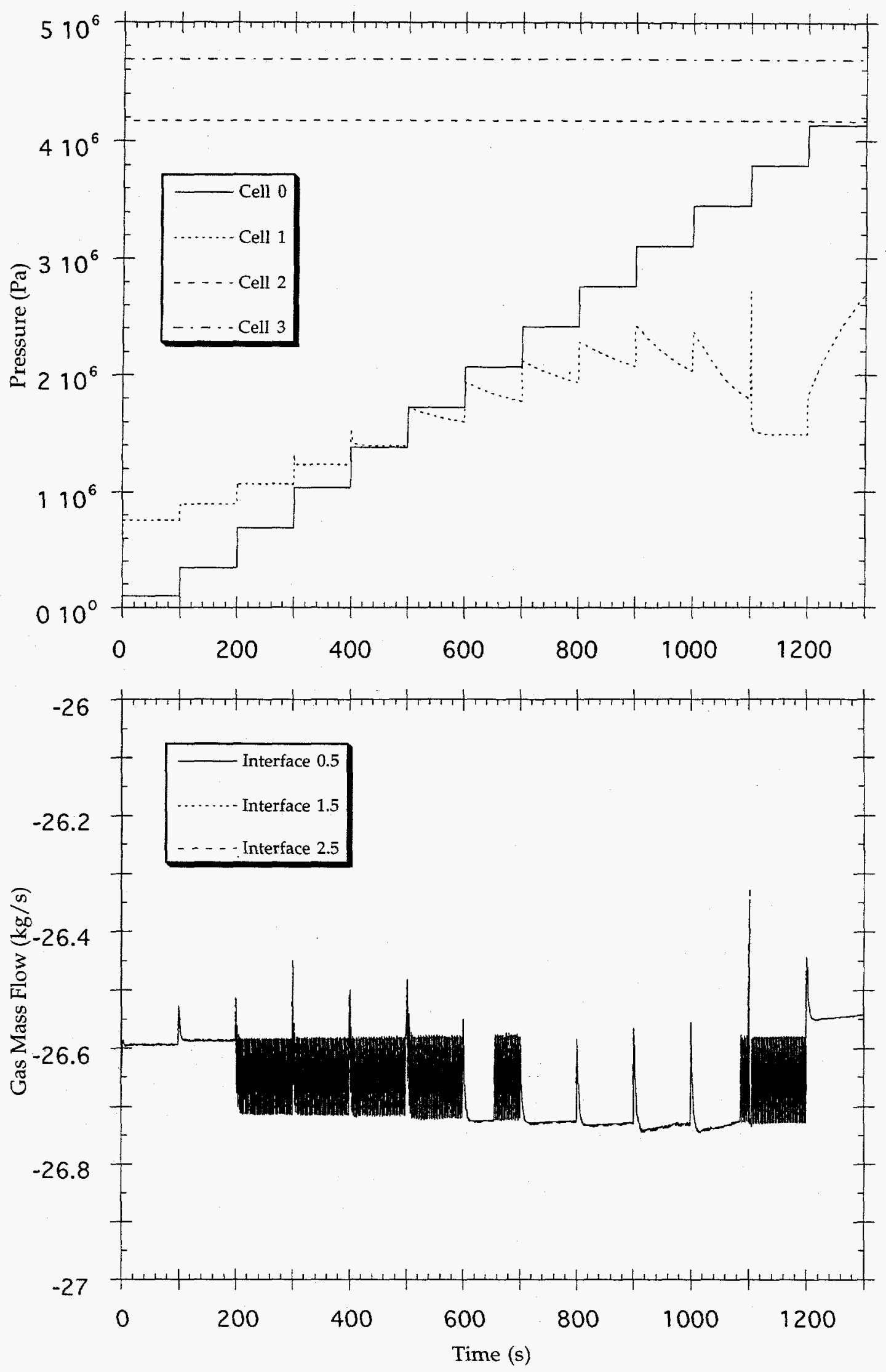

Figure B.1. Gas pressure and mass flow vs time [10/90 SS weighting, CHOKE called in TF1DS1 with BITN in FEMOM, and with $\delta \mathrm{p}_{1}$ dependence (5823 \#ts)]. 

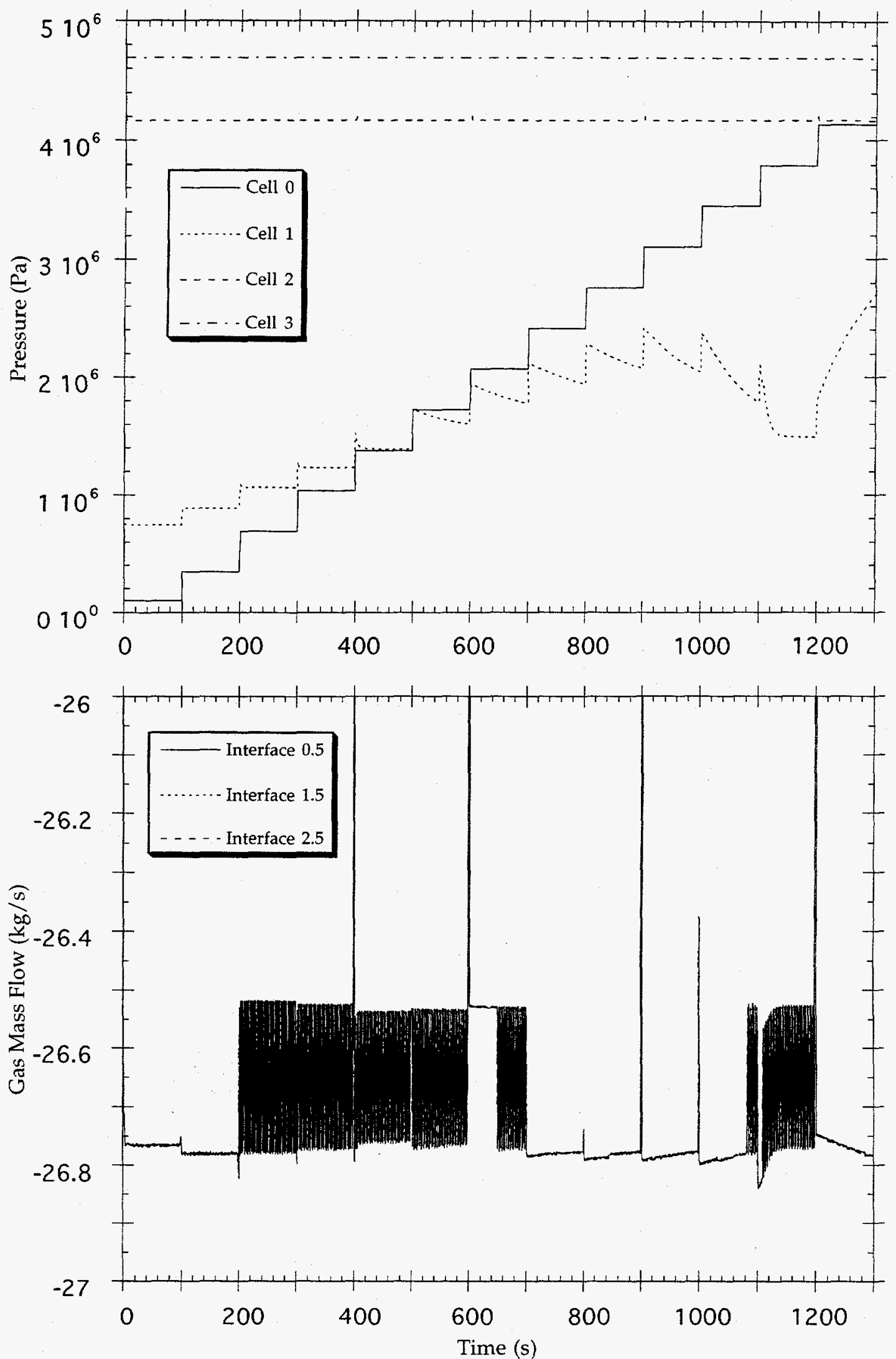

Figure B.2. Gas pressure and mass flow vs time [2/10.0 TR weighting, CHOKE called in TF1DS1 with BITN in FEMOM, and with $\delta \mathrm{p}_{1}$ dependence (5798 \#ts)]. 

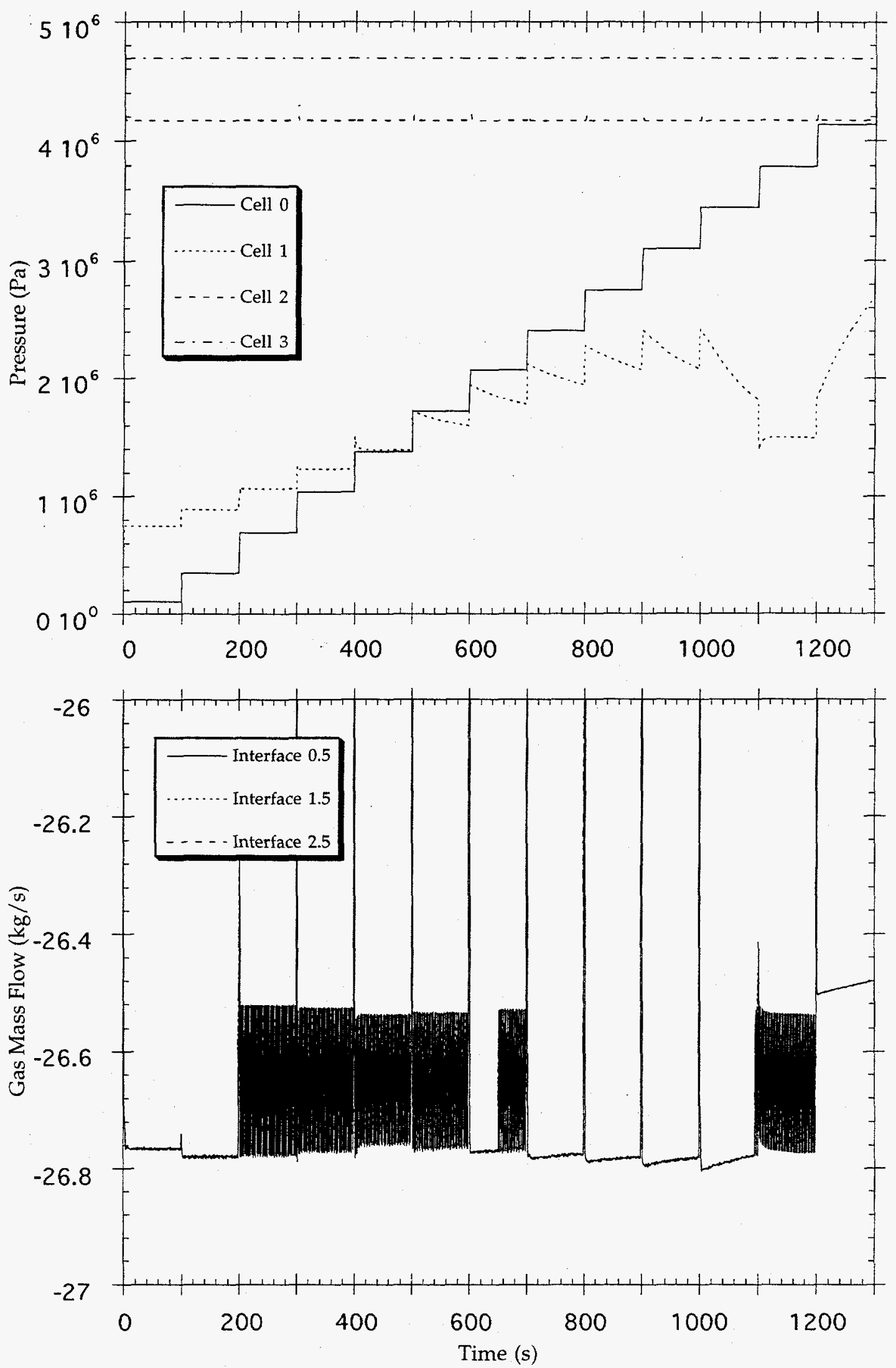

Figure B.3. Gas pressure and mass flow vs time [2/0.1 TR weighting, CHOKE called in TF1DS1 with BITN in FEMOM, and with $\delta \mathrm{p}_{1}$ dependence (5790 \#ts)]. 

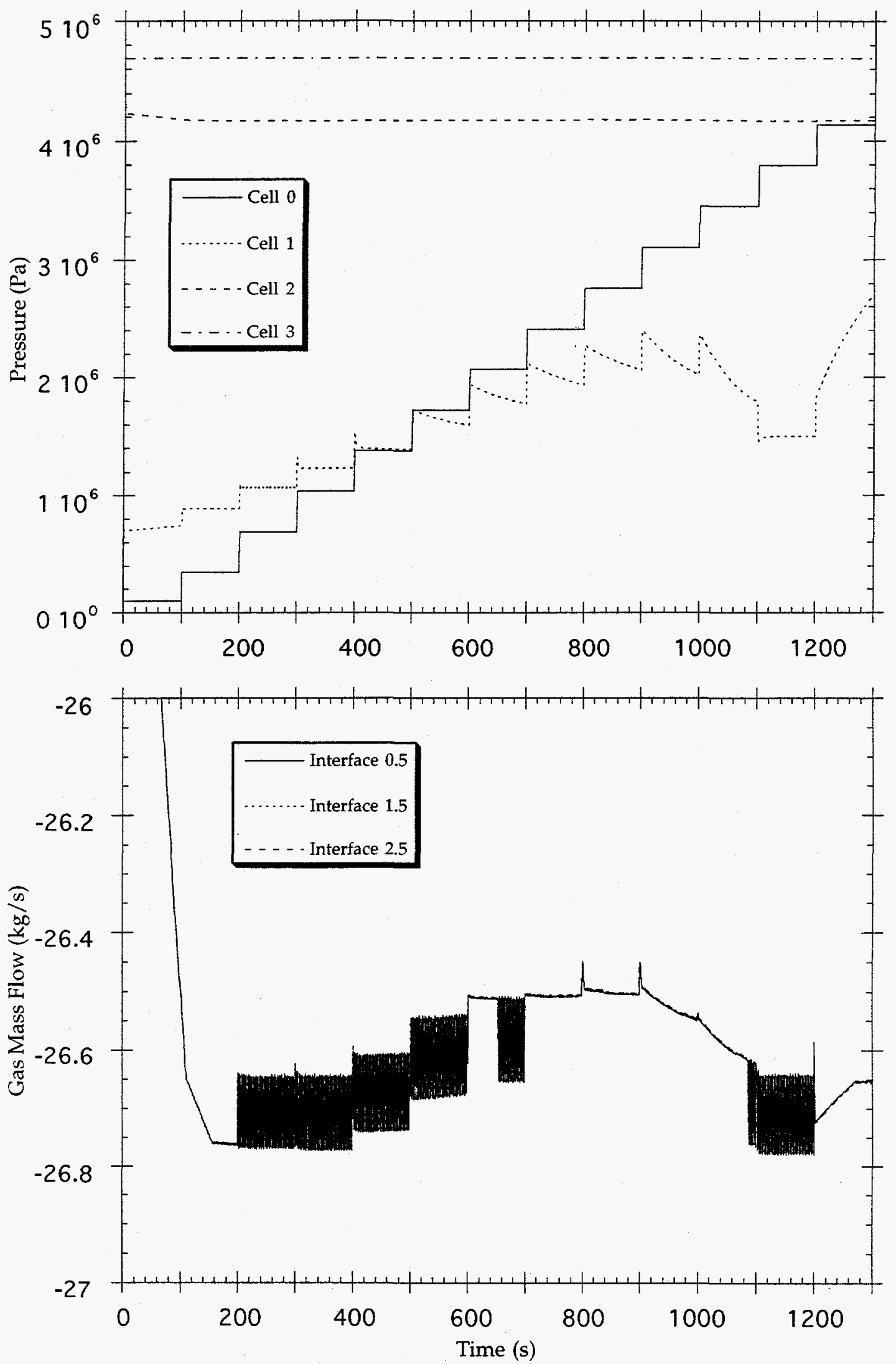

Figure B.4. Gas pressure and mass flow vs time [2/0.001 TR weighting, CHOKE called in TF1DS1 with BITN in FEMOM, and with $\delta \mathrm{p}_{1}$ dependence (5801 \#ts)]. 

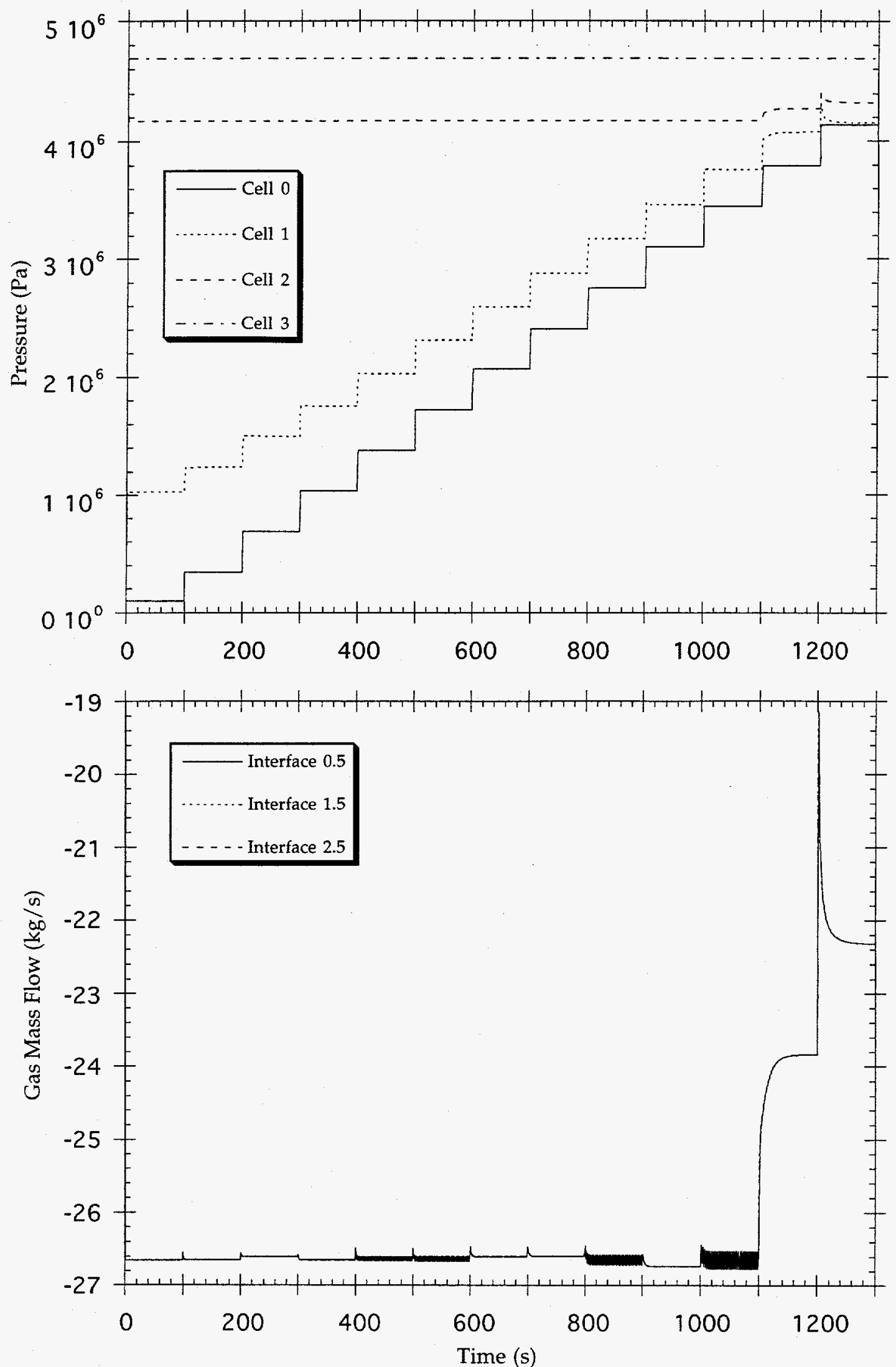

Figure B.5. Gas pressure and mass flow vs time [10/90 SS weighting, CHOKE called in TF1DS1 with BIT in FEMOM, and with $\delta \mathrm{p}_{1}$ dependence (10357 \#ts)]. 

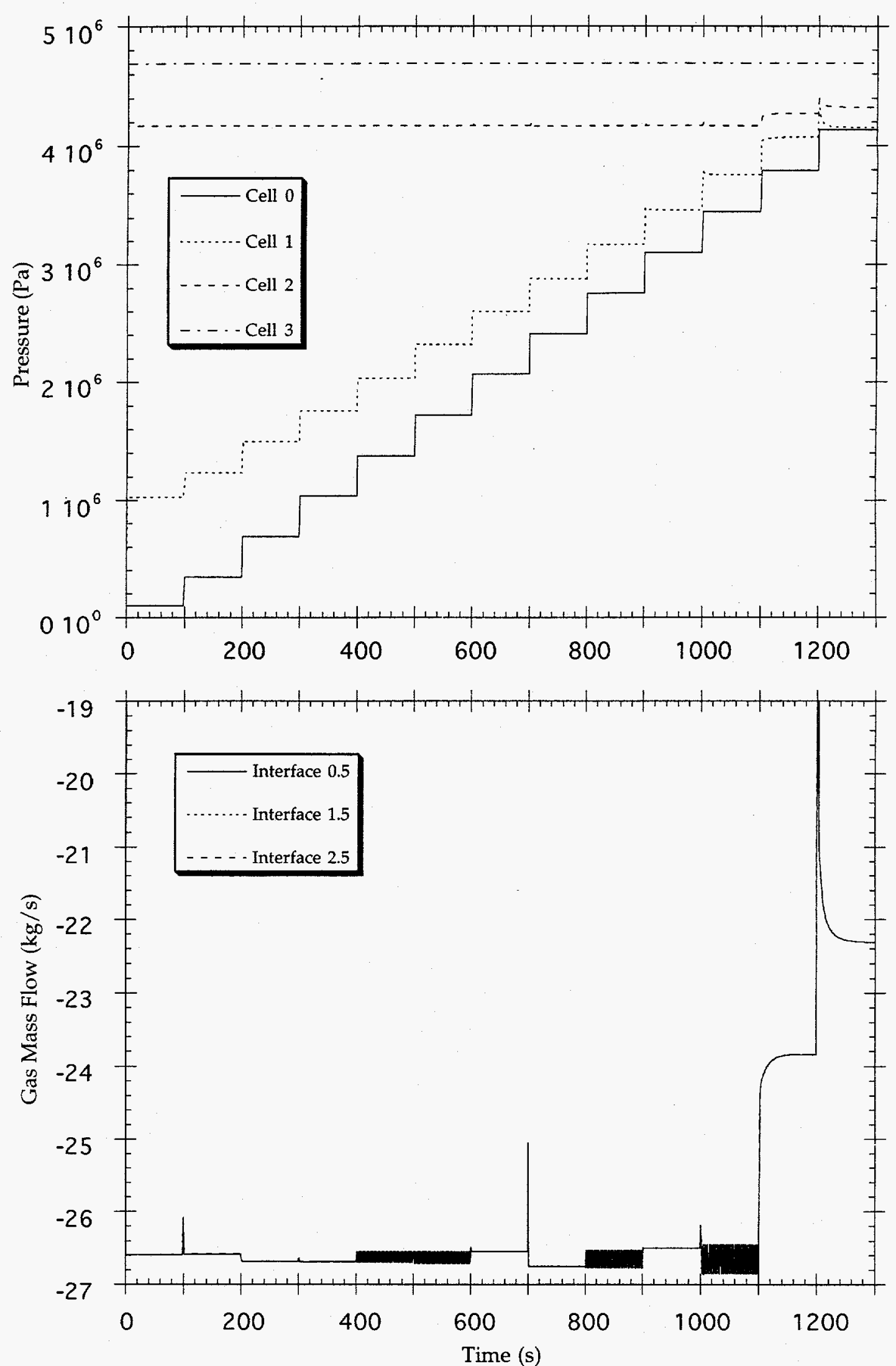

Figure B.6. Gas pressure and mass flow vs time [2/10.0 TR weighting, CHOKE called in TF1DS1 with BIT in FEMOM, and with $\delta \mathrm{p}_{1}$ dependence (14380 \#ts)]. 

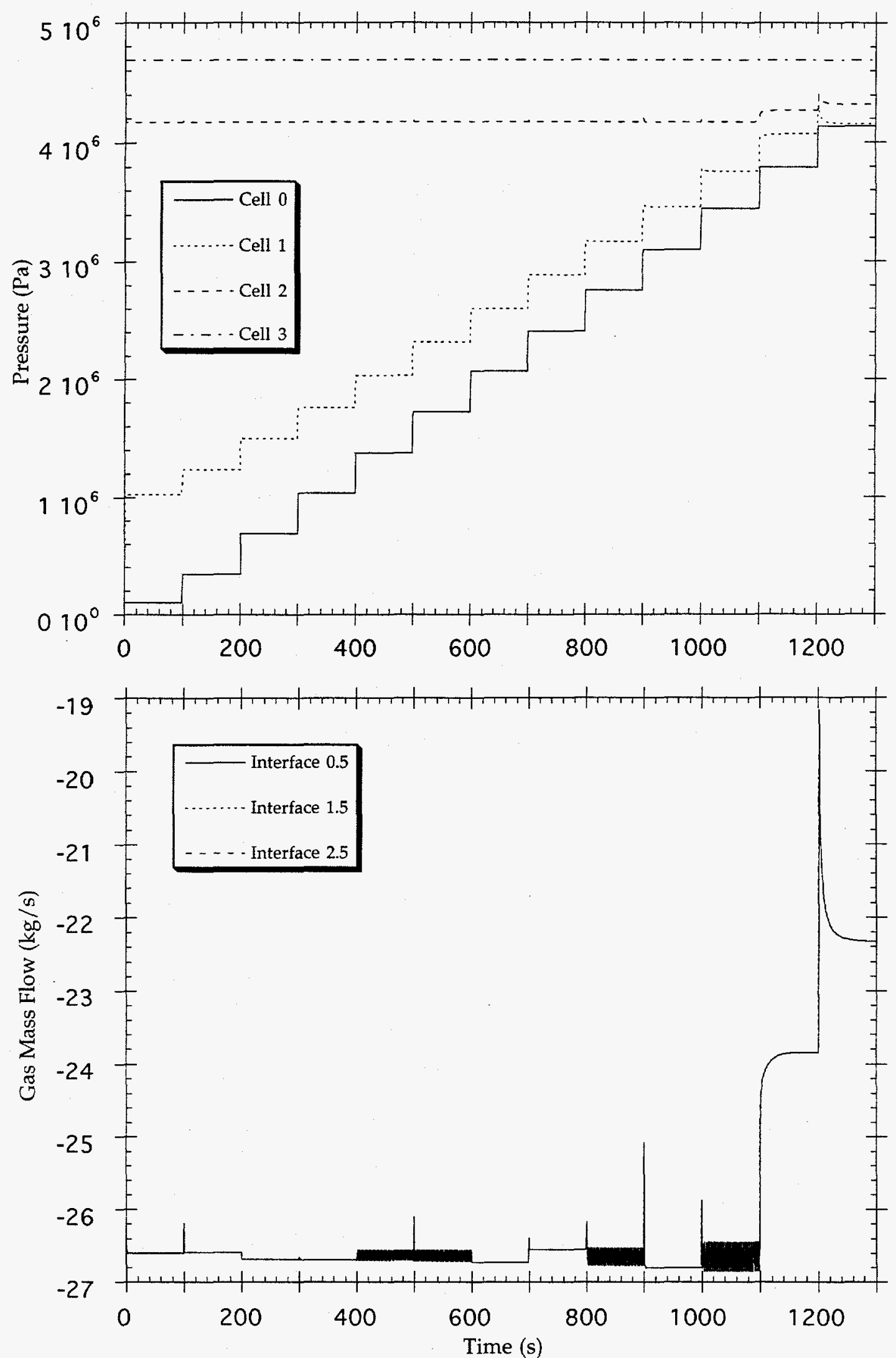

Figure B.7. Gas pressure and mass flow vs time [2/0.1 TR weighting, CHOKE called in TF1DS1 with BIT in FEMOM, and with $\delta p_{1}$ dependence (10375 \#ts)]. 

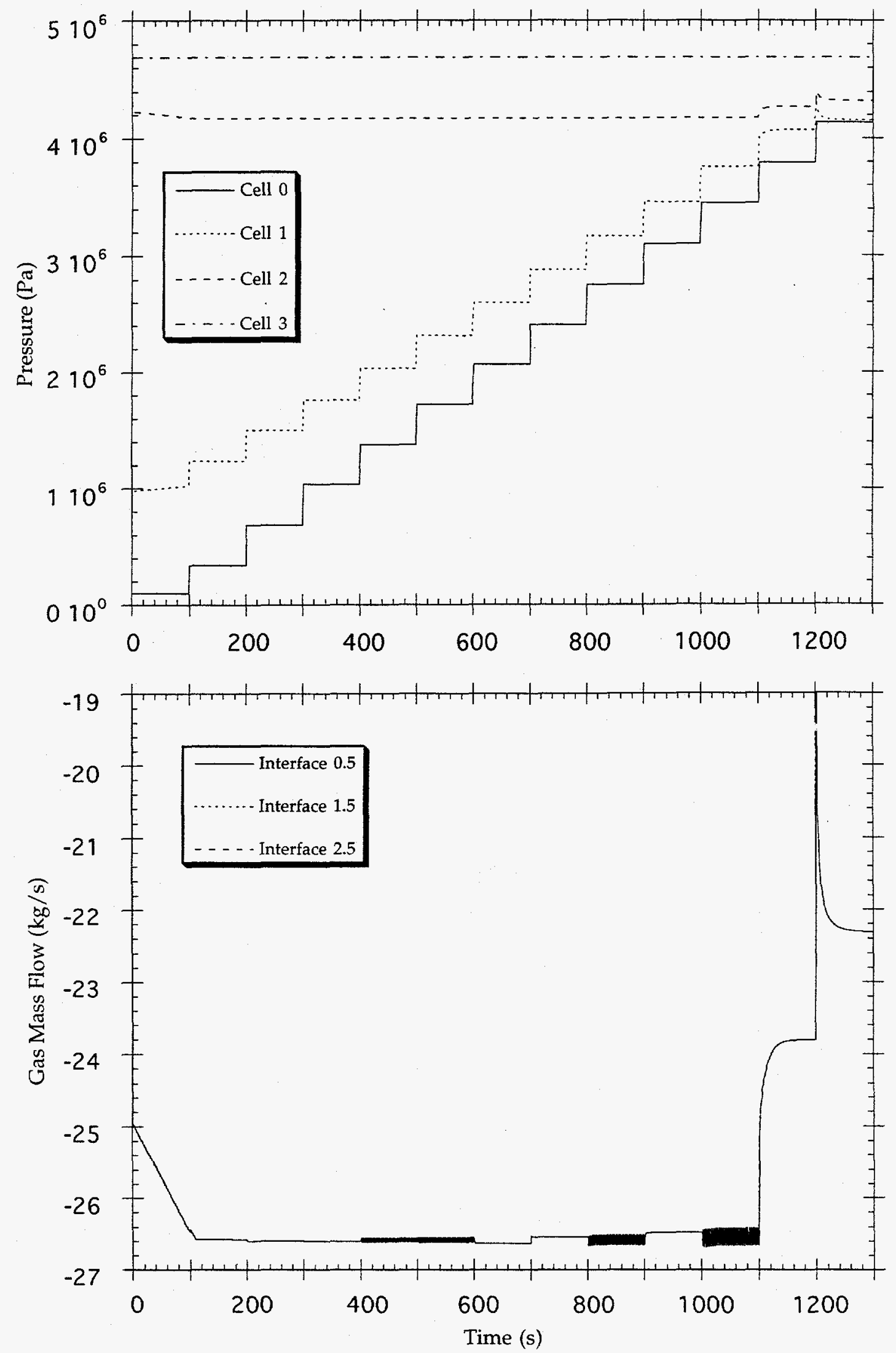

Figure B.8. Gas pressure and mass flow vs time [2/0.001 TR weighting, CHOKE called in TF1DS1 with BIT in FEMOM, and with $\delta p_{1}$ dependence (10486 \#ts)]. 

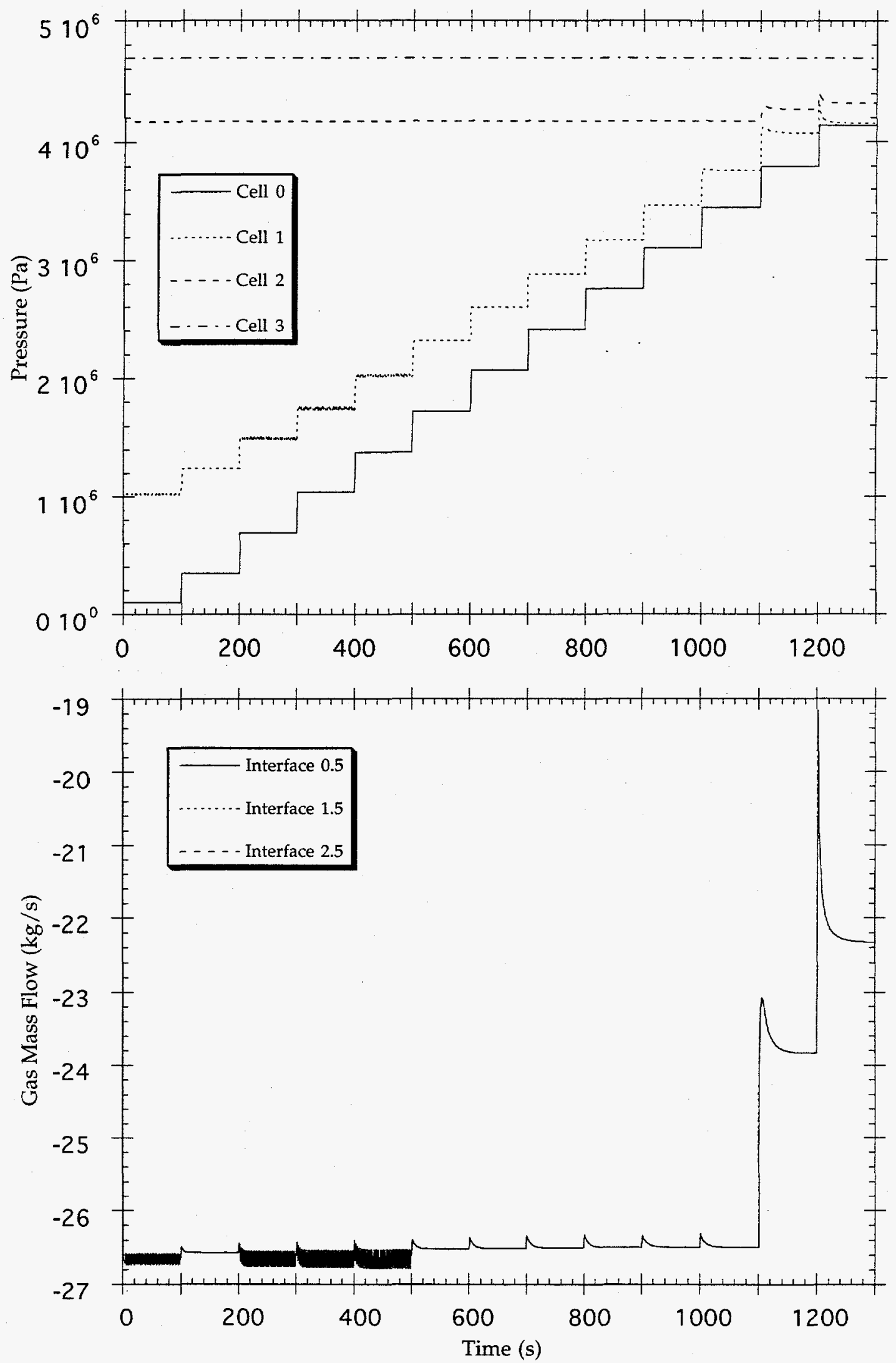

Figure B.9. Gas pressure and mass flow vs time [10/90 SS weighting, CHOKE called in FEMOM \& set in FEMOM and TF1DS1, and with $\delta \mathrm{p}_{1}$ dependence (2937 \#ts)]. 

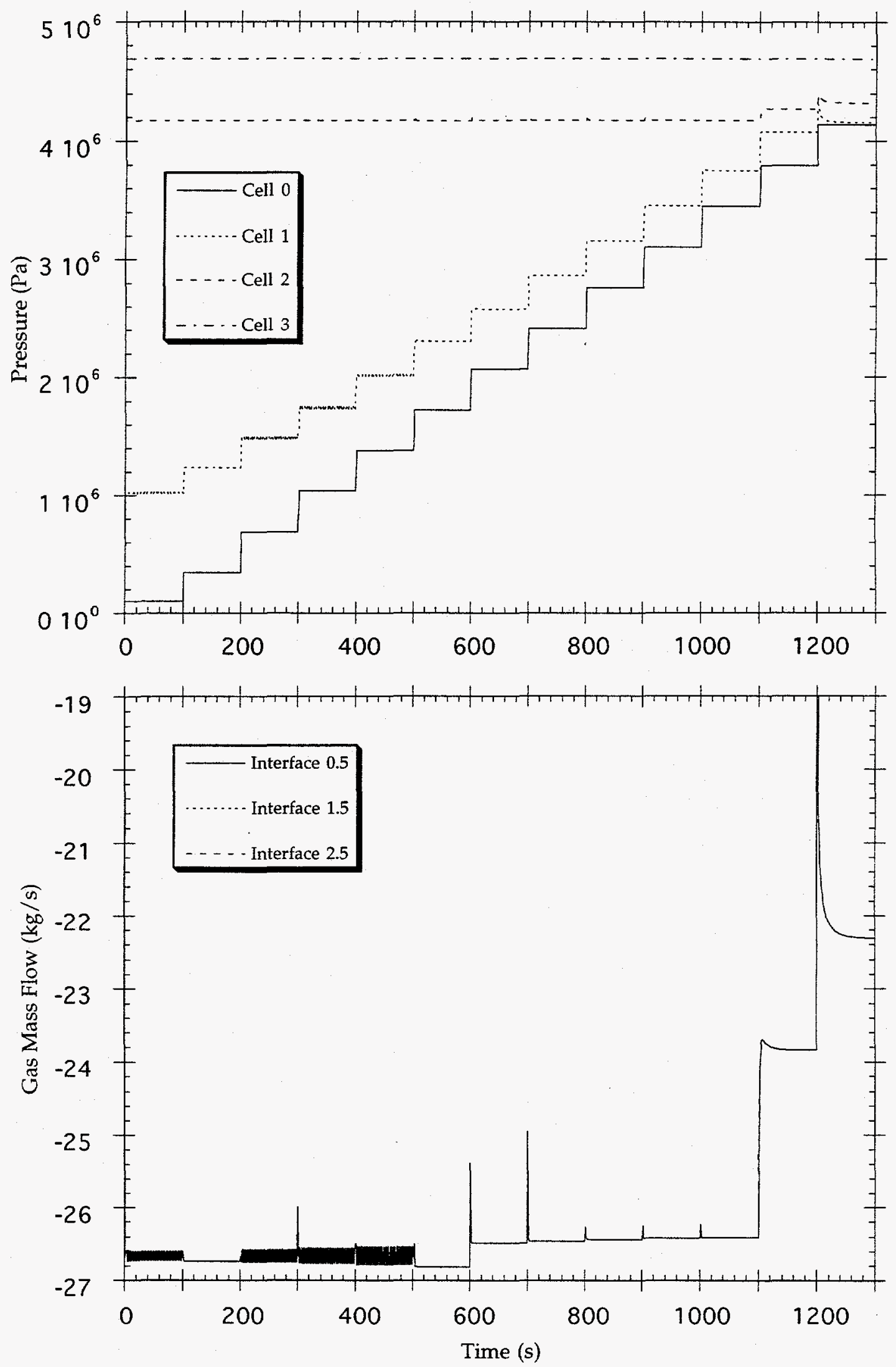

Figure B.10. Gas pressure and mass flow vs time [2/10.0 TR weighting, CHOKE called in FEMOM \& set in FEMOM and TF1DS1, and with $\delta \mathrm{p}_{1}$ dependence (2941 \#ts)]. 

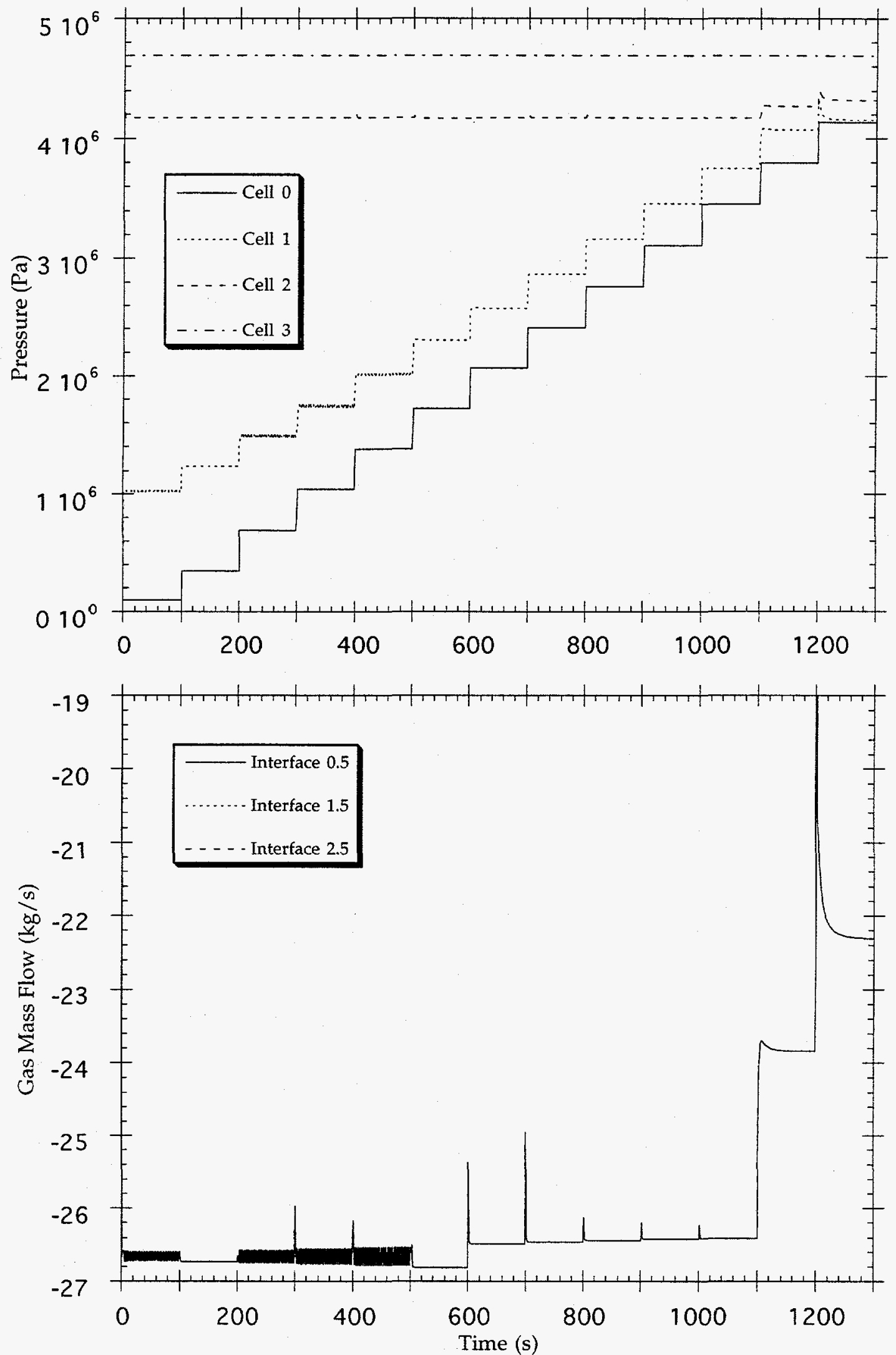

Figure B.11. Gas pressure and mass flow vs time [2/0.1 TR weighting, CHOKE called in FEMOM \& set in FEMOM and TF1DS1, and with $\delta p_{1}$ dependence (2941 \#ts)]. 

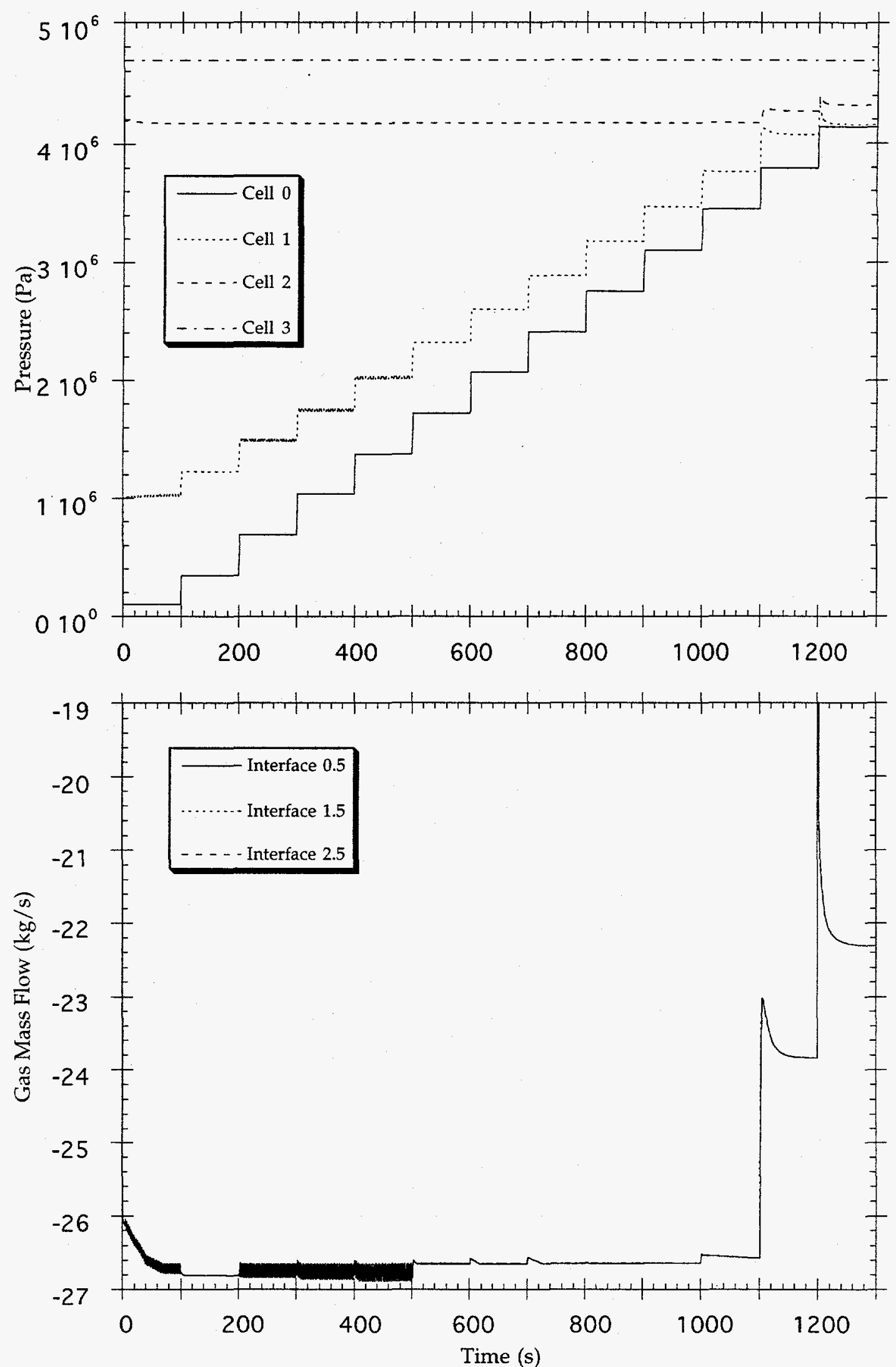

Figure B.12. Gas pressure and mass flow vs time [2/0.001 TR weighting, CHOKE called in FEMOM \& set in FEMOM and TF1DS1, and with $\delta \mathrm{p}_{1}$ dependence (2942 \#ts)]. 

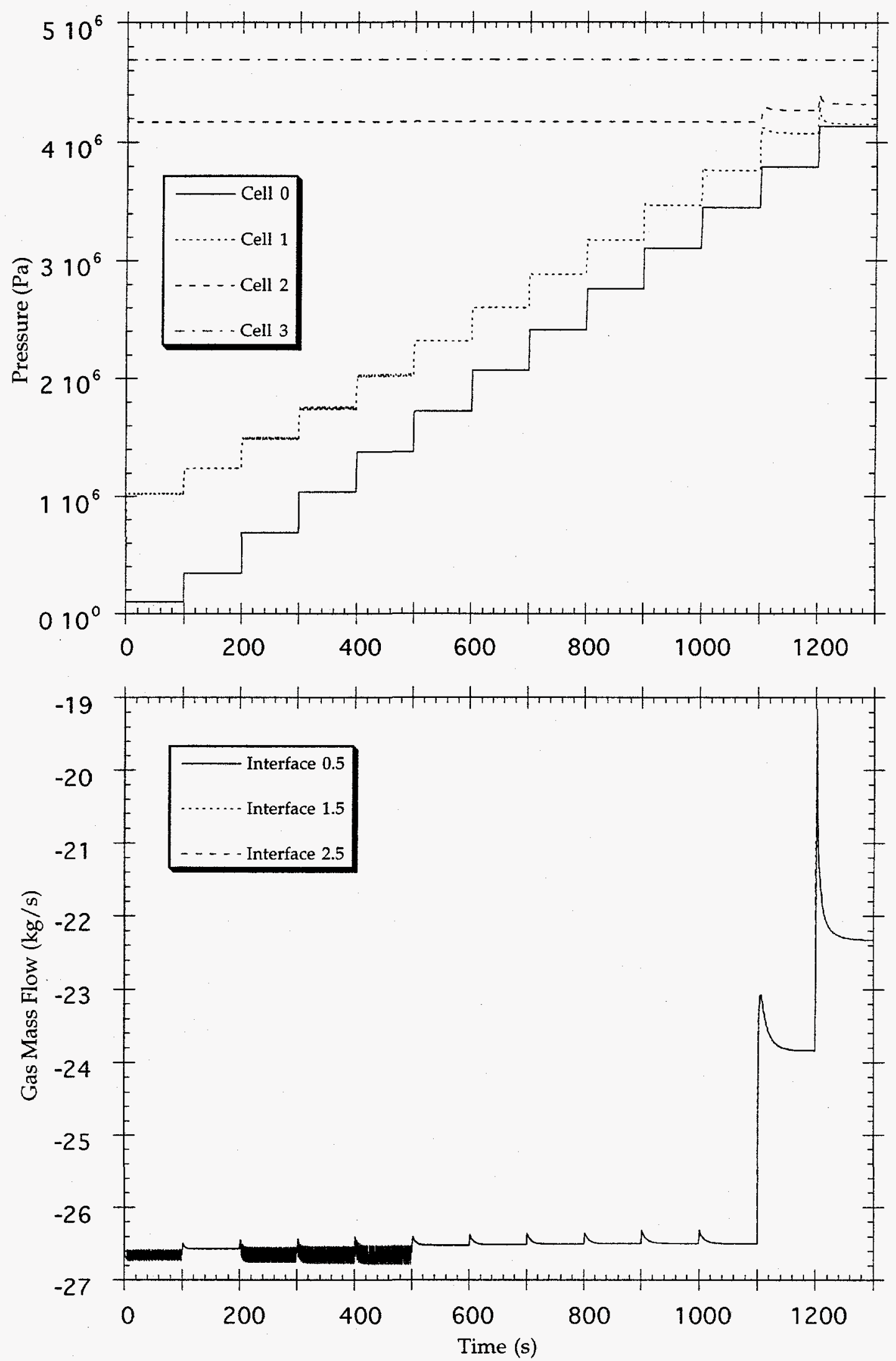

Figure B.13. Gas pressure and mass flow vs time [10/90 SS weighting, CHOKE called in FEMOM \& set in FEMOM and TF1DS1, without $\delta \mathrm{p}_{1}$ dependence (2937 \#ts)]. 

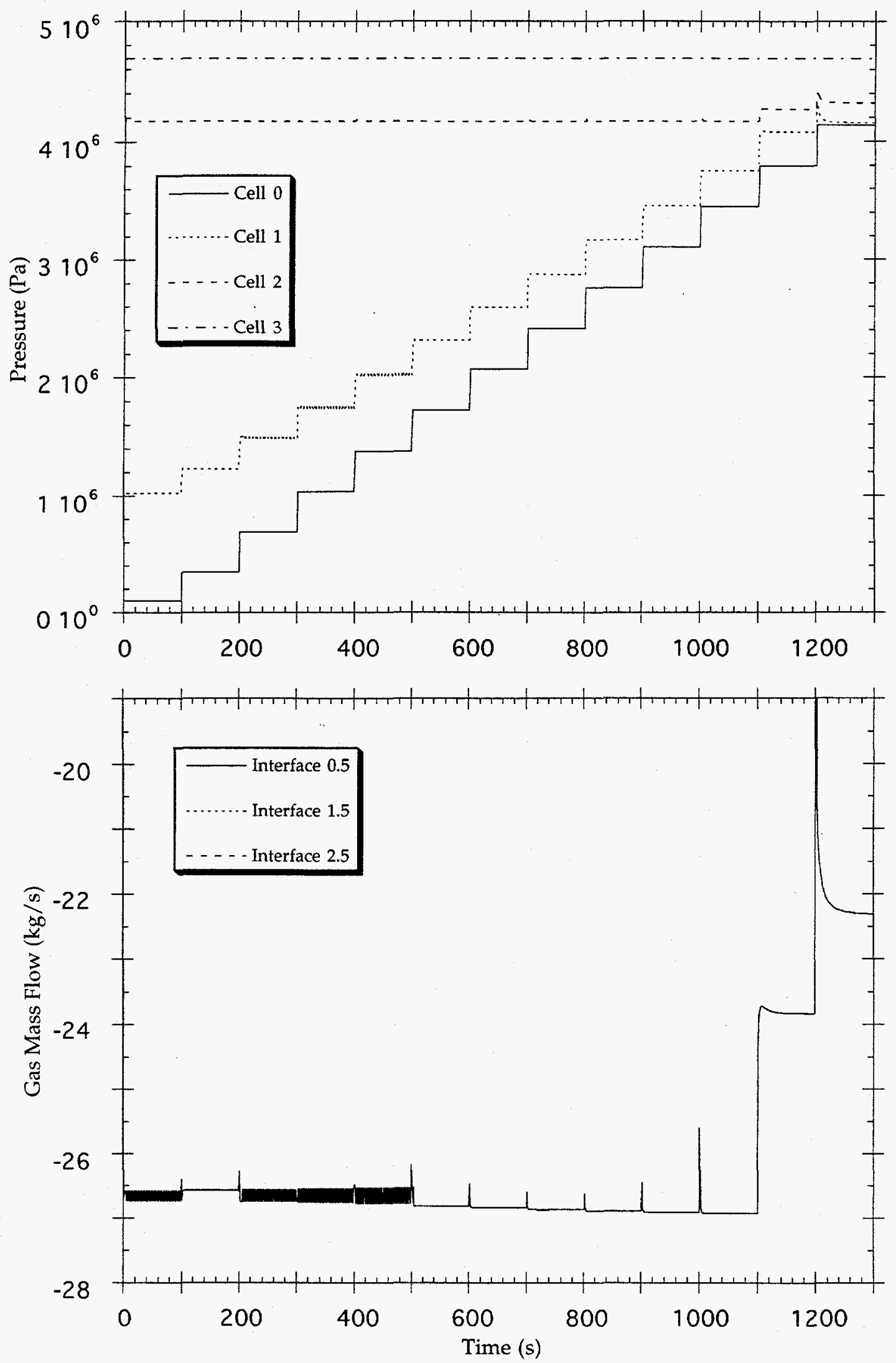

Figure B.14. Gas pressure and mass flow vs time [2/10.0 TR weighting, CHOKE called in FEMOM \& set in FEMOM and TF1DS1, without $\delta \mathrm{p}_{1}$ dependence (2978 \#ts)]. 

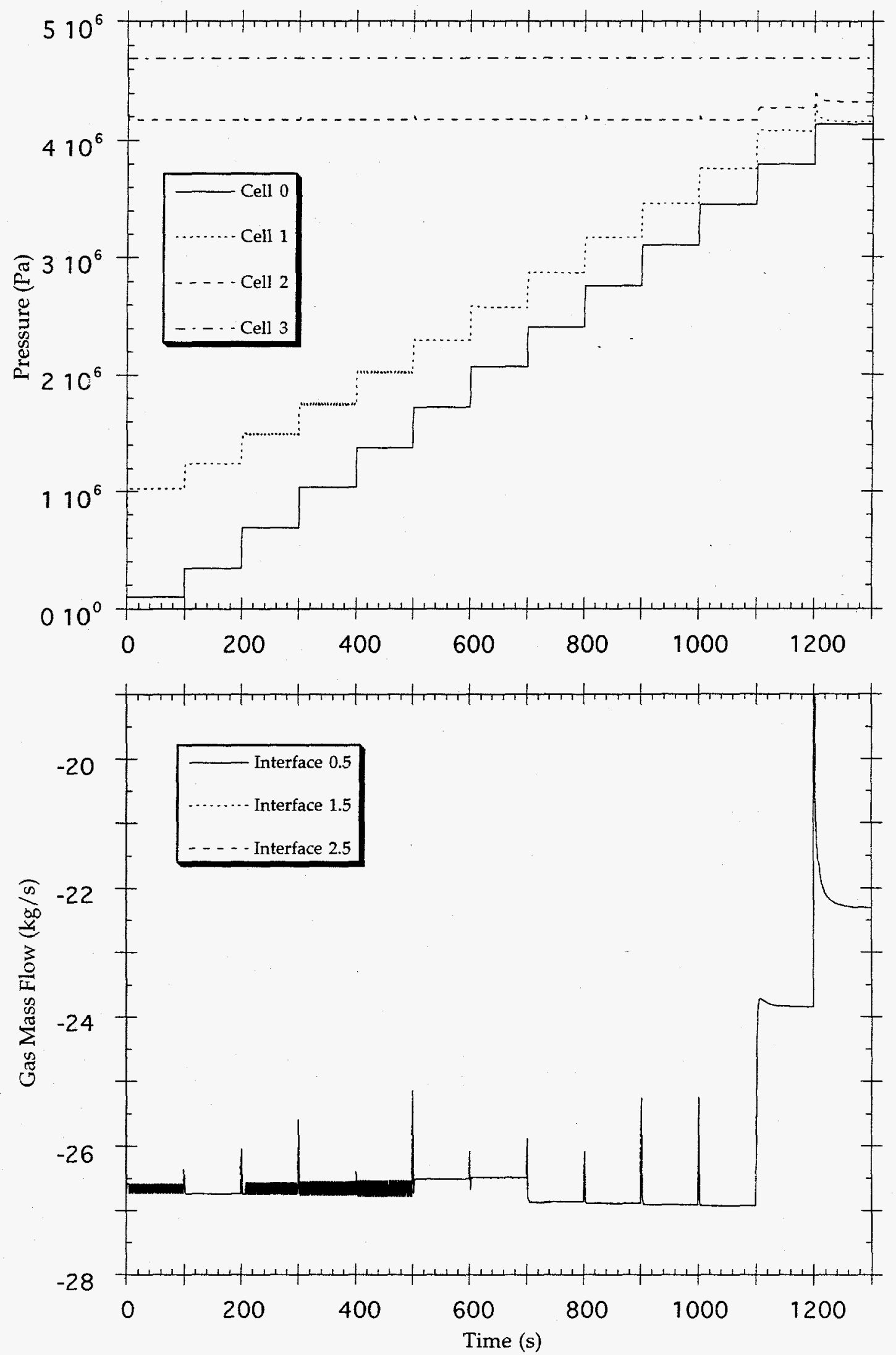

Figure B.15. Gas pressure and mass flow vs time [2/0.1 TR weighting, CHOKE called in FEMOM \& set in FEMOM and TF1DS1, without $\delta \mathrm{p}_{1}$ dependence $\left.(2978 \# \mathrm{ts})\right]$. 

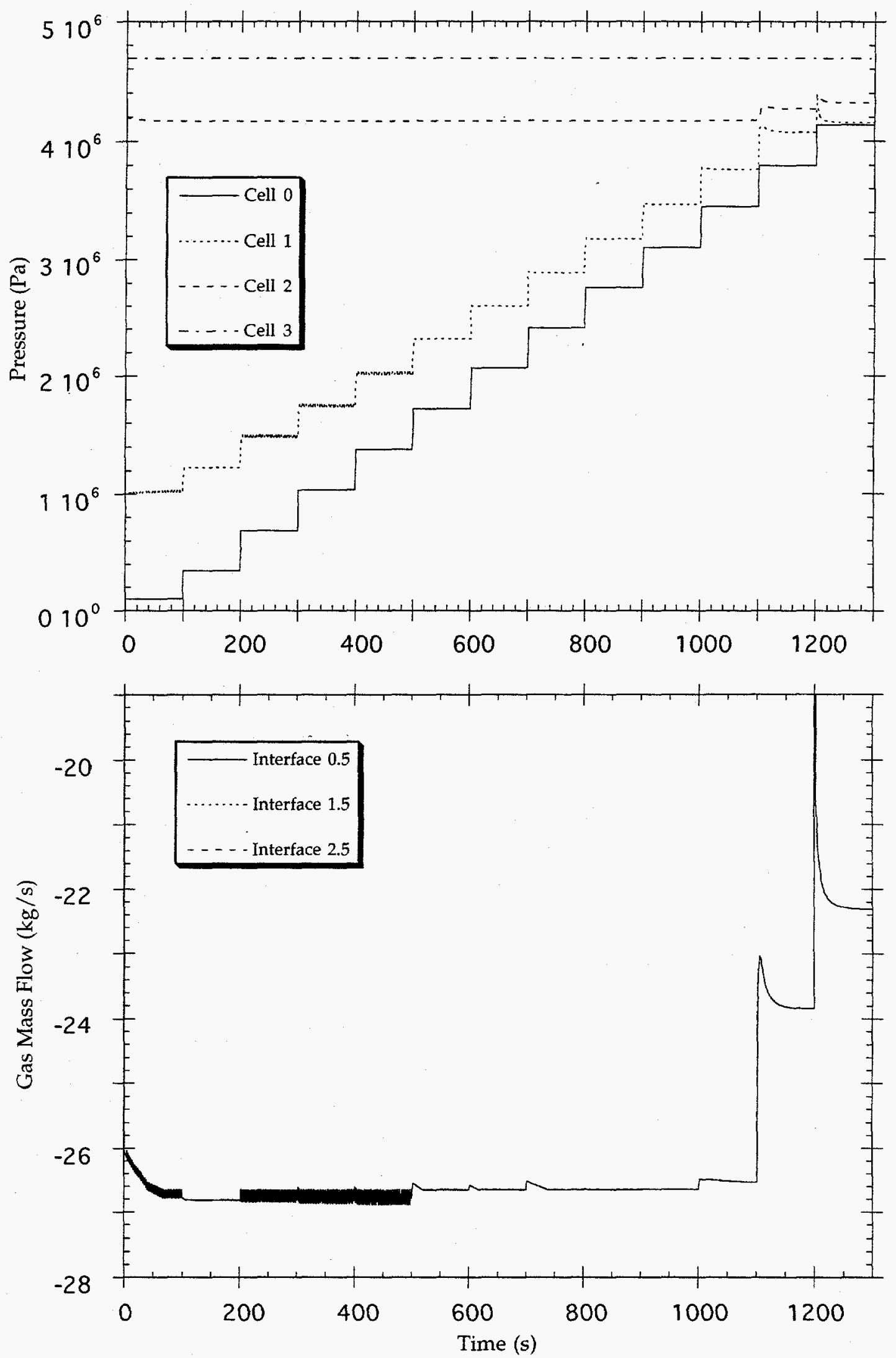

Figure B.16. Gas pressure and mass flow vs time [2/0.001 TR weighting, CHOKE called in FEMOM \& set in FEMOM and TF1DS1, without $\delta \mathrm{p}_{1}$ dependence (2942 \#ts)]. 
KAPL

Case 1

Case 3

Case 4

Case 5

Case 6

Case 4 With

Case 7
PIPE 3

Reversed

PIPE 2 changed from 2 cells to 4 cells

Case 2 PIPE 2

Reversed

Case 2 PIPE 2

Made Into

PIPEs 2 and 3

Case 4 With

Both PIPEs

Reversed

Case 4 With

PIPE 2

Reversed
Interface 0.5

1.5

2.5
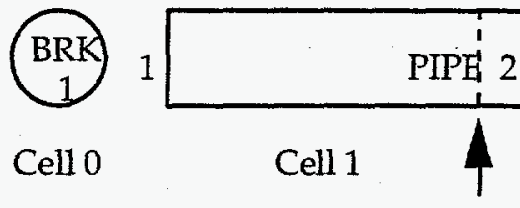

Cell 0

Choked Interface

Cell 2

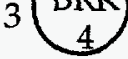

Cell 3

BRK
1

Cell 0

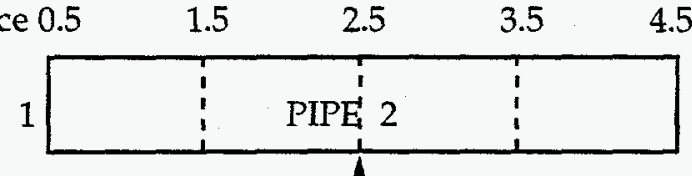

BRK

Cell 5

Choked Interface
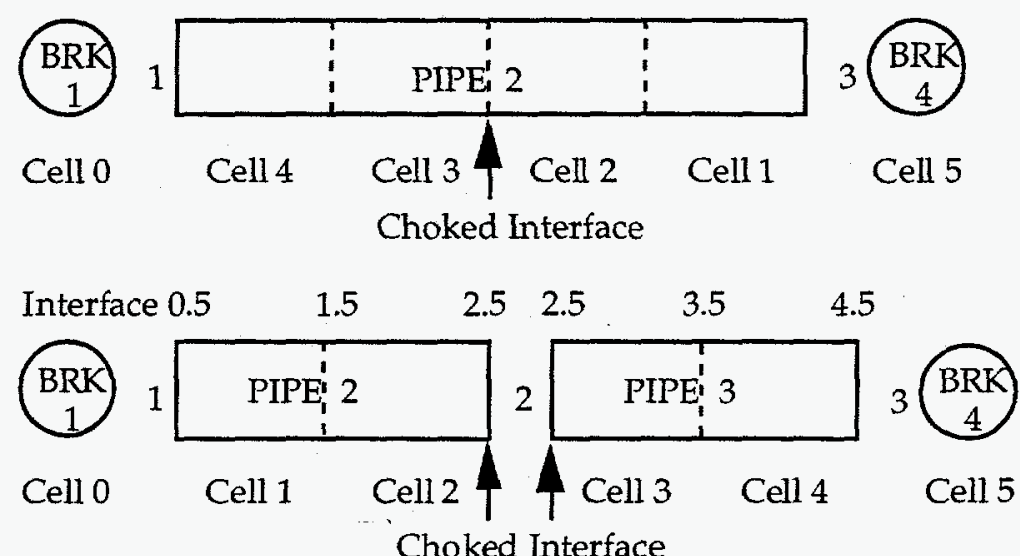

Choked Interface

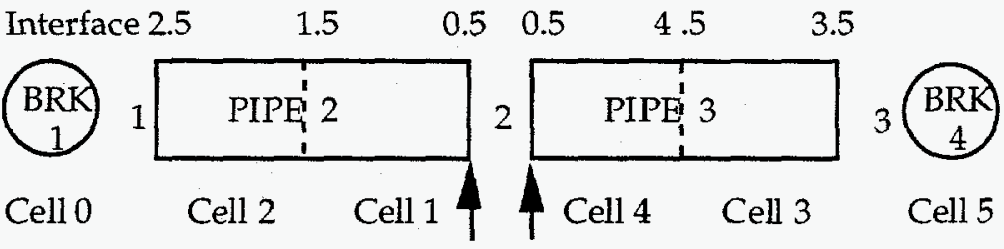

Choked Interface

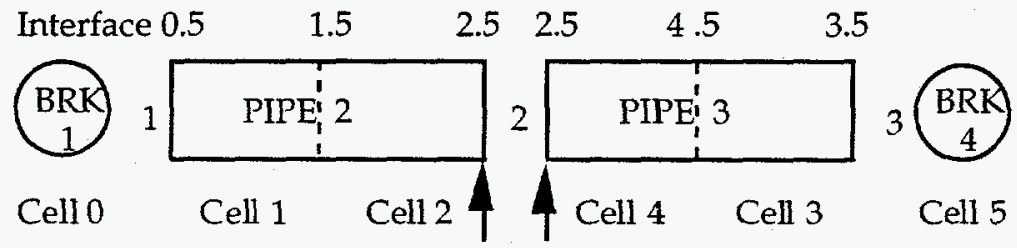

Choked Interface

$\begin{array}{llllll}\text { Interface } 2.5 & 1.5 & 0.5 & 0.5 & 3.5 & 4.5\end{array}$

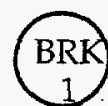

Cell 0
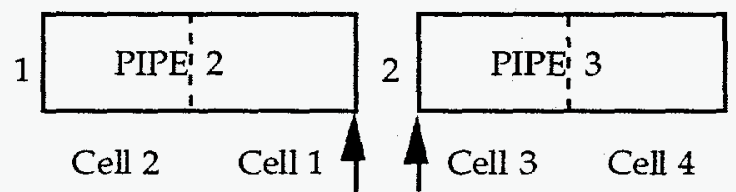

3<smiles>[R18]C[R17]</smiles>

Cell 5

Choked Interface

Figure B.17. KAPL Test Problem With the Choked-Flow Interface at a PIPE Component Internal Interface and at a Junction Between Two PIPE Components. 

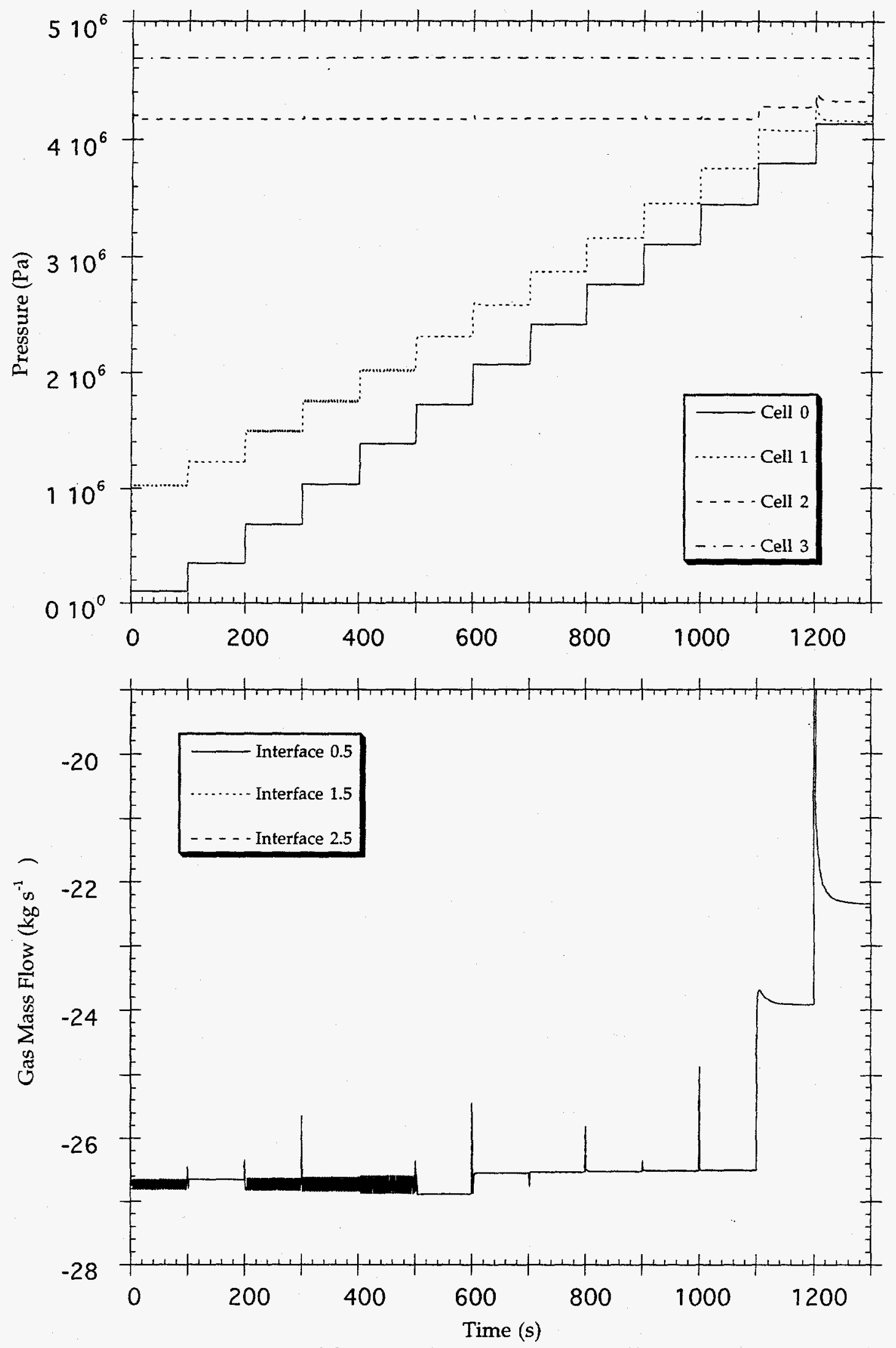

Figure B.18. KAPL test problem with BREAK1, 2-cell PIPE2, BREAK4 (TRAC-P Version 5.4.29 + pending KAPL updates+update FXCFM) [2984 \#ts]. 

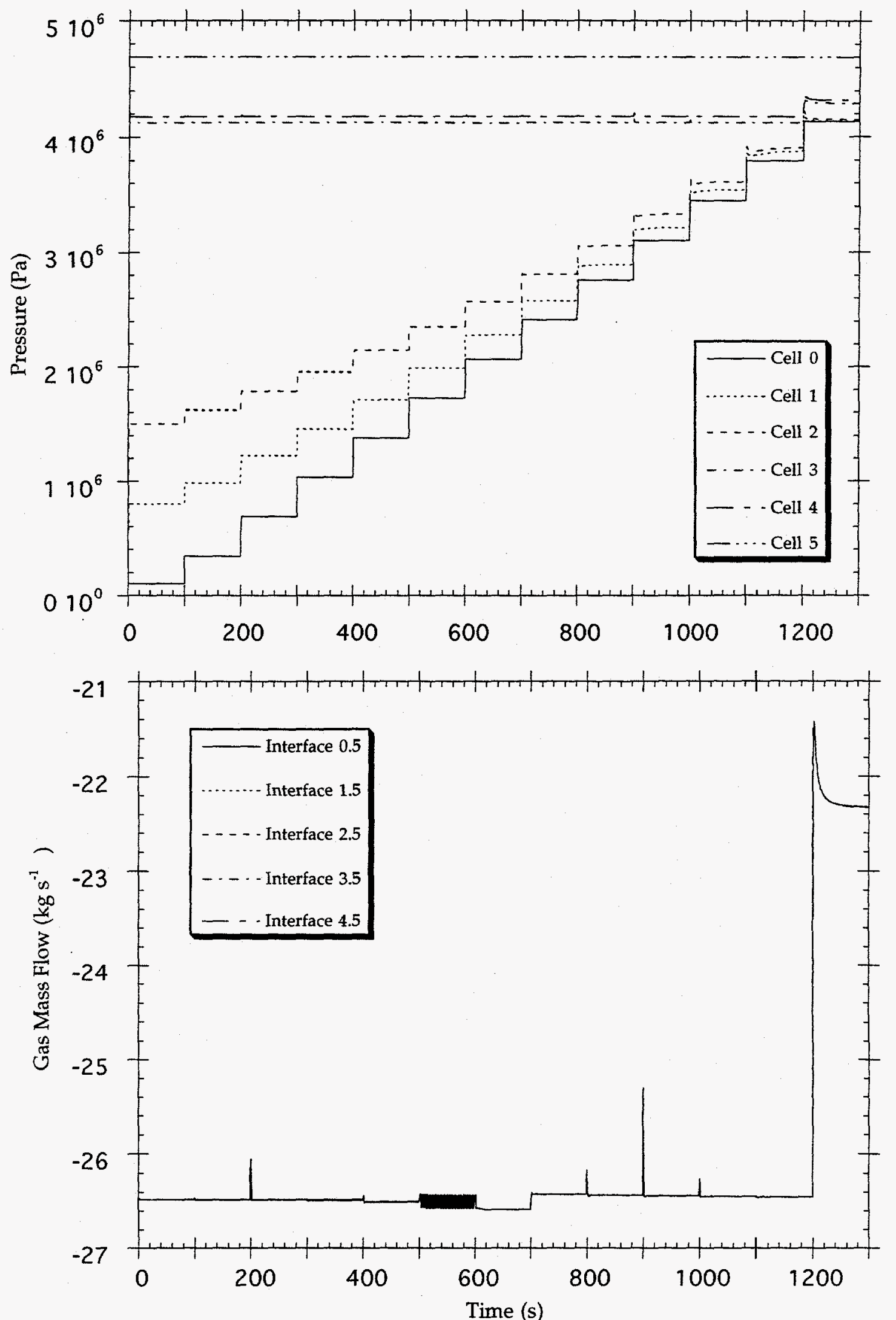

Figure B.19. KAPL test problem with BREAK1, 4-cell PIPE2, BREAK4 (TRAC-P Version 5.4.29 + pending KAPL updates+update FXCFM) [6630 \#ts]. 

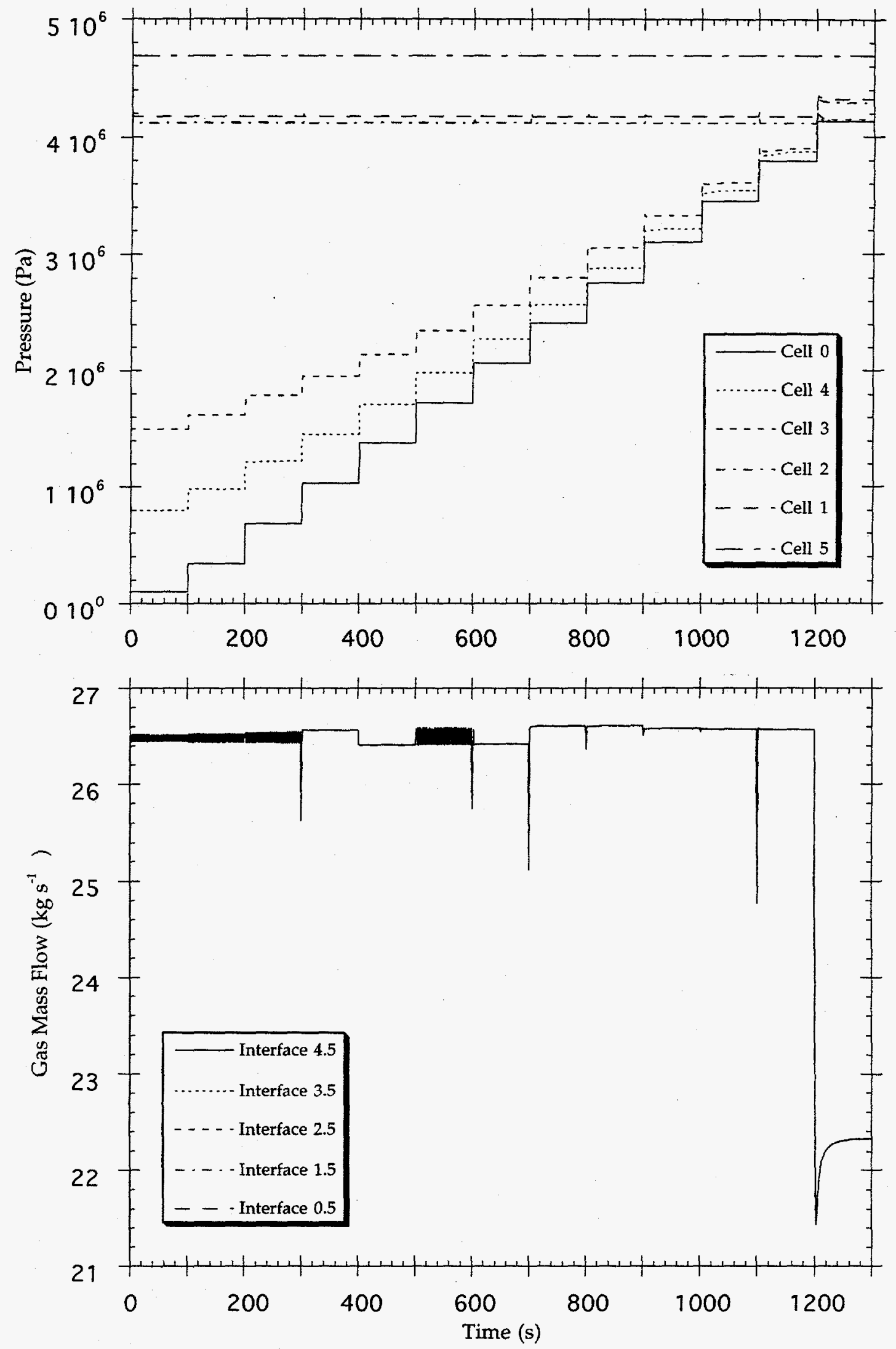

Figure B.20. KAPL test problem with BREAK1, 4-cell PIPE2 Rev., BREAK4 (TRAC-P Version 5.4.29 + pending KAPL updates+update FXCFM) [6740 \#ts]. 

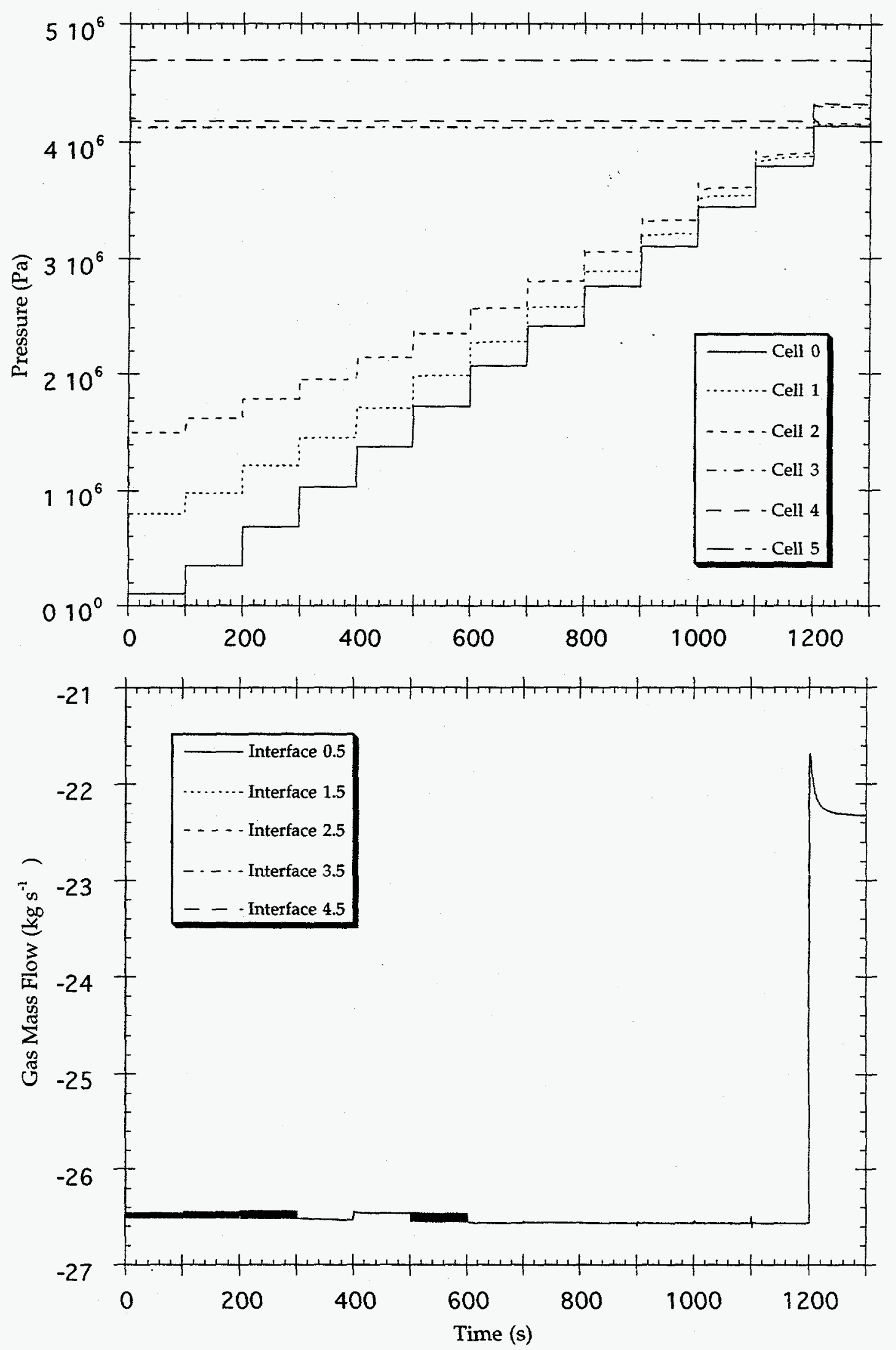

Figure B.21. KAPL test problem with BREAK1, 2-cell PIPE2, 2-cell PIPE3, BREAK4 (TRAC-P Version 5.4.29 + KAPL updates+update FXCFM) [6595 \#ts]. 

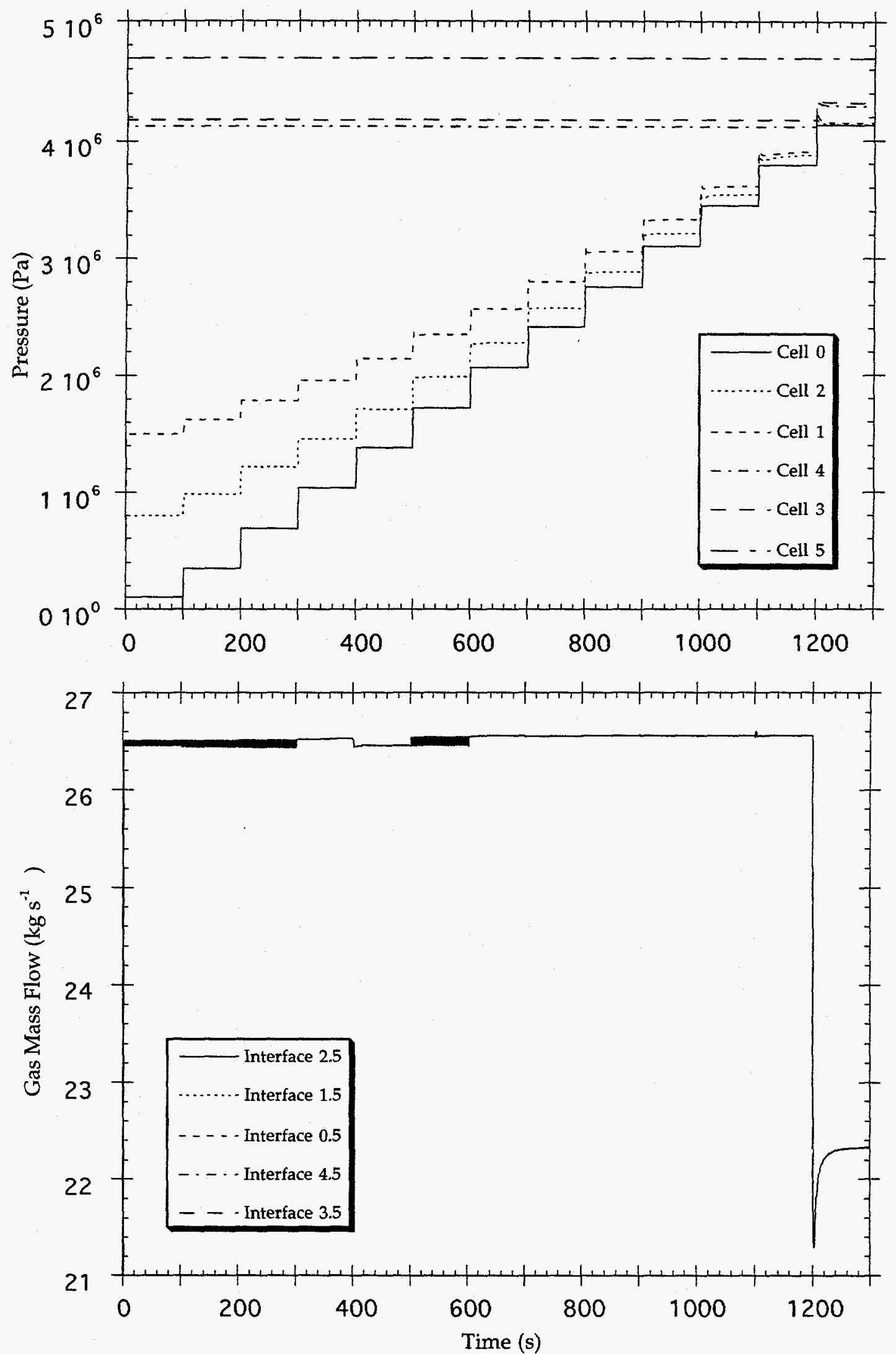

Figure B.22. KAPL test problem with BREAK1, 2-cell PIPE2R, 2-cell PIPE3R, BREAK4 (TRAC-P Version 5.4.28 + KAPL updates+update FXCFM) [6595 \#ts]. 

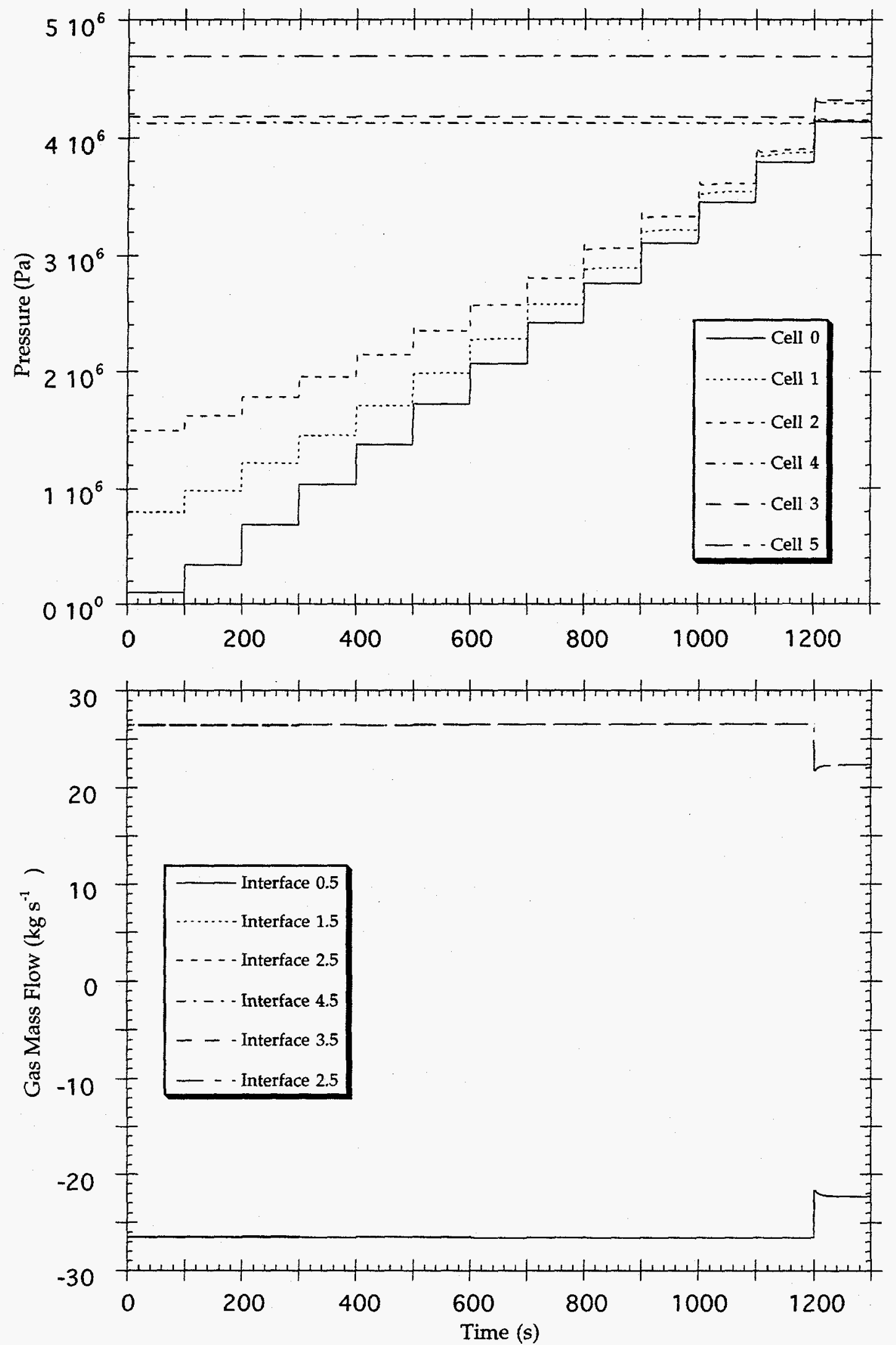

Figure B.23. KAPL test problem with BREAK1, 2-cell PIPE2, 2-cell PIPE3R, BREAK4 (TRAC-P Version 5.4.29 + KAPL updates+update FXCFM) [6594 \#ts]. 

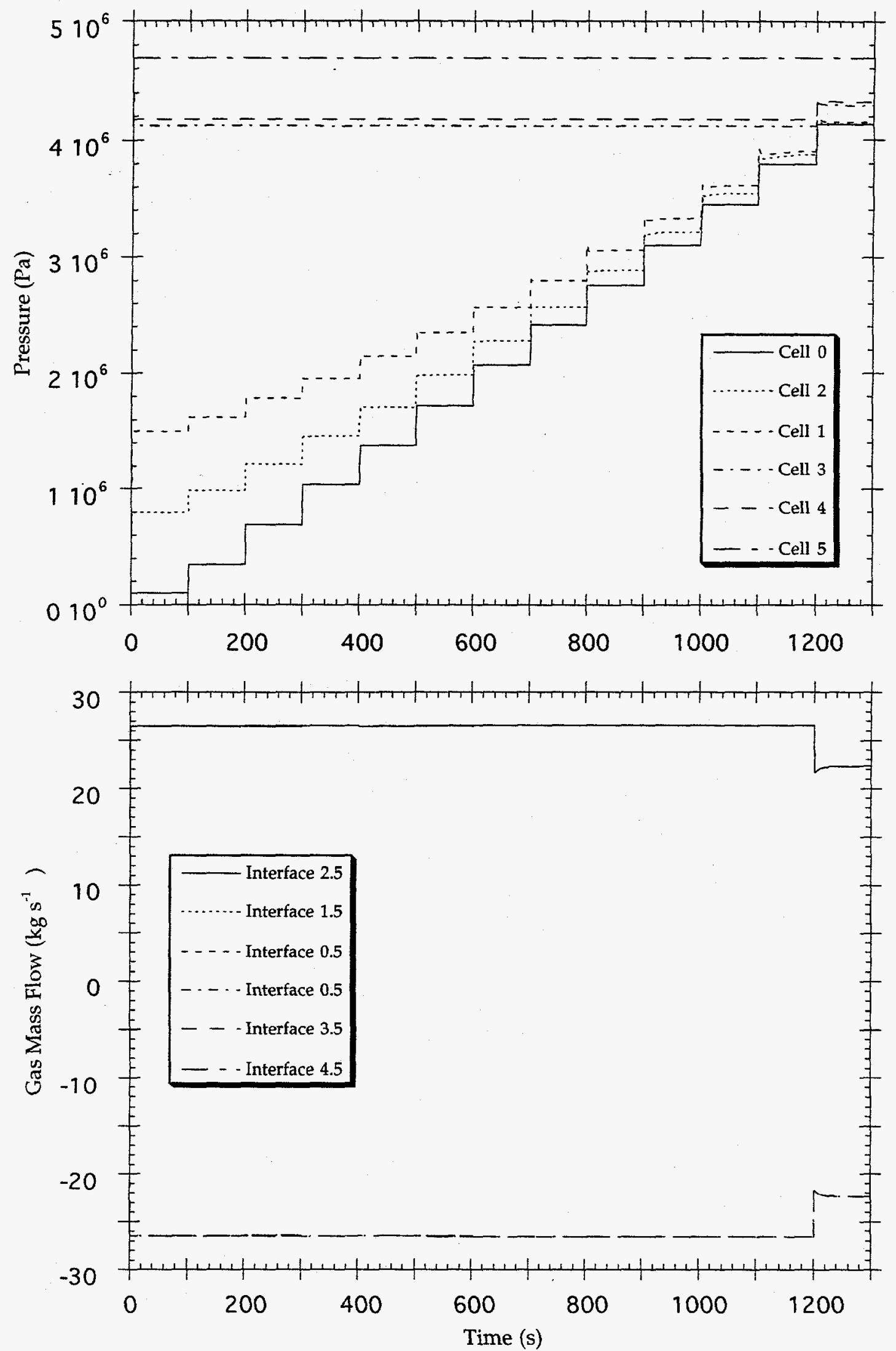

Figure B.24. KAPL test problem with BREAK1, 2-cell PIPE2R, 2-cell PIPE3, BREAK4 (TRAC-P Version 5.4.28 + KAPL updates+update FXCFM) [6594 \#ts]. 

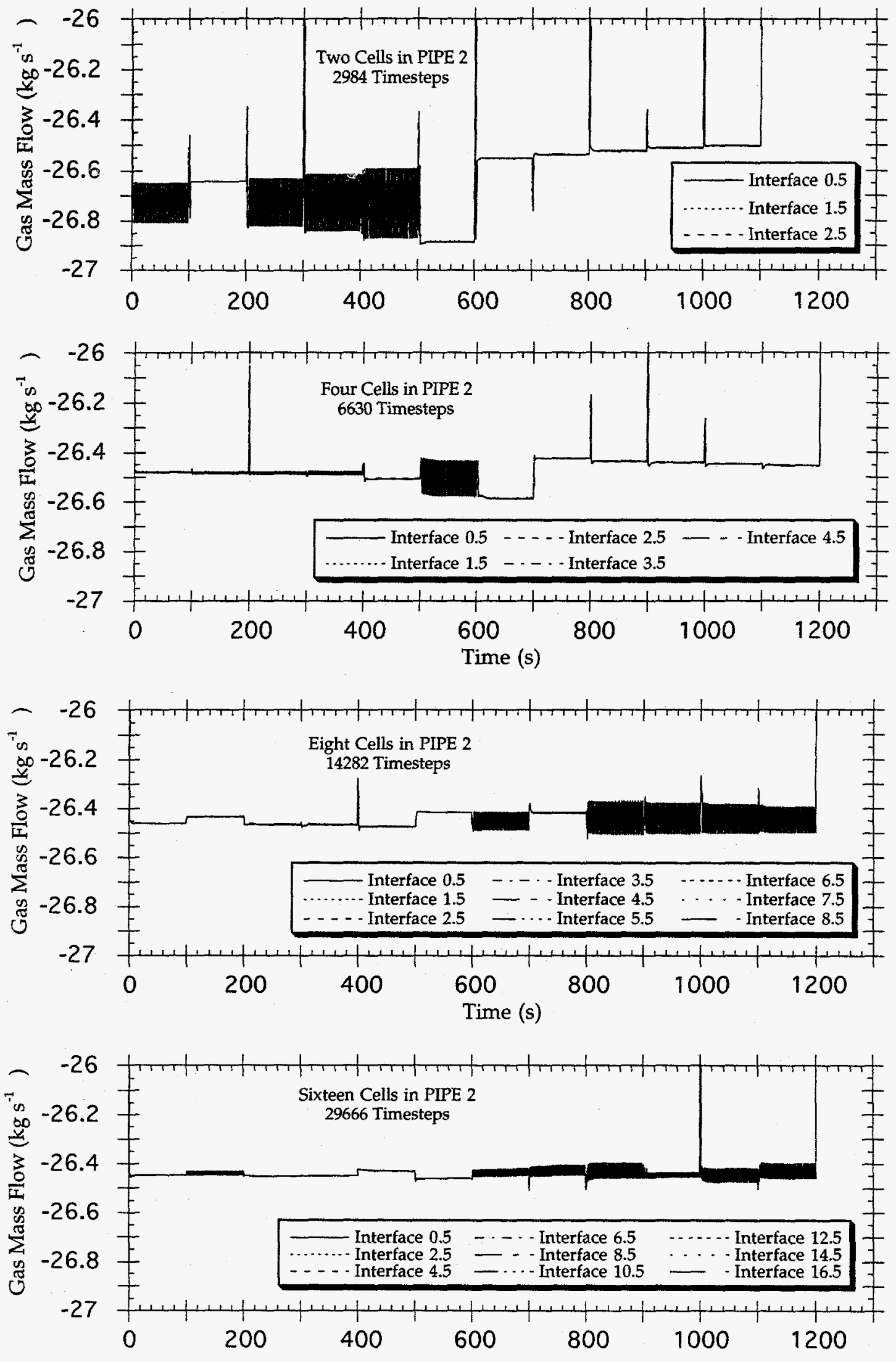

Time (s)

Figure B.25. KAPL test problem with BREAK1, 2-, 4-, 8-, and 16-cell PIPE2, BREAK4 (TRAC-P Version 5.4.28+KAPL updates+update FXCFM). 


\section{APPENDIX C \\ FOLLOW UP ON CONCERNS FROM THE CHOKED-FLOW MODEL CORRECTION TECHNICAL DESIGN REVIEW}

The choked-flow model correction technical design review on October 21, 1997, was attended by Brent Boyack, Paul Giguere, Jim Lime, Rich Smith, Jay Spore, Jim Steiner, and Bob Steinke. Seven concerns were noted in the choked-flow-model correction results that need further investigation. Those concerns and their investigated results are discussed below. Feedback is needed on the bold-type questions in responses 1 and 3.

Concern 1: What is causing the oscillations in choked flow and pressure in the KAPL test problem? Perform timestep debugging to investigate this. Evaluate subcooled liquid, superheated vapor, and all noncondensable gas to see if the oscillations go away.

Response 1: Evaluating the KAPL test problem with TRCOUT-file large edits every timestep showed oscillations in the upstream donor-cell pressure and the choked velocity from timestep to timestep. A larger beginning-oftimestep donor-cell pressure determines a larger choked velocity and mass flow. This evaluates a smaller end-of-timestep donor-cell pressure, which in the next timestep (as the beginning-of-timestep donor-cell pressure) evaluates a smaller choked velocity and mass flow. The semi-implicitness of the choked-velocity derivative with respect to donor-cell pressure in the outer-iterative solution doesn't seem to be able to do much to dampen the effect of explicitness in the choked-velocity evaluation. Using V(new)*(1-exp($\left.\left.10^{*} \Delta t\right)\right)+V(\text { old })^{*} \exp \left(-10^{*} \Delta t\right)$ weighting, in addition to the time-constant constraints, gave only enough dampening to half the oscillation amplitude. As you may recall from the pressure and mass flow vs problem time plots, only 3 or 4 of the 100 -s intervals of constant downstream BREAK pressure had $\sim 0.4 \%$ amplitude oscillations. The other 100-s intervals didn't appear to be oscillating in the plots; however, the large edits do show oscillations occurring with $\sim 0.005 \%$ amplitude oscillations. I don't understand why certain 100-s intervals have much smaller amplitude oscillations than other 100-s intervals and why the magnitude of the smaller amplitude oscillations lie at the extreme of the larger amplitude oscillation range. The KAPL test problem has slightly superheated vapor in the donor cell that becomes subcooled vapor at the choked interface and in the downstream cell. Condensation of liquid and the choked-interface liquid velocity has the largest amplitude of oscillation from timestep to timestep. There is no significant oscillation in the donor-cell pressure and choked velocity for highly subcooled liquid or highly superheated vapor. Oscillations begin to appear when the level of donor-cell subcooling or superheating gets within 20 to $30 \mathrm{~K}$ of the saturation temperature. I 
didn't create a test problem with all noncondensable gas, but would expect that no oscillation in its choked flow condition based on the highly subcooled liquid or highly superheated vapor cases above that involves phase change. Do I need to investigate these oscillations further to understand the cause? This would probably require a significant further effort. [A later effort found that increasing the number of mesh cells between the high-pressure BREAK cell and the choked-flow interface decreased the magnitude of the oscillations.]

Concern 2: Jay Spore expressed concern that the pressure and mass flow oscillations didn't diminish in the plots as they should for small values of $\mathrm{C} 2$ [where the choked velocity is constrained between $\mathrm{V}(\mathrm{old}){ }^{*} \mathrm{C} 1^{* *}\left(-\mathrm{C} 2^{*} \Delta \mathrm{t}\right)$ and $\mathrm{V}(\text { old })^{*} \mathrm{C} 1^{* *}\left(+\mathrm{C} 2^{*} \Delta \mathrm{t}\right)$ with $\left.\mathrm{C} 1=2\right]$.

Response 2: For small values of $C 2\left(0.1,0.001\right.$ and $\left.0.00001 \mathrm{~s}^{-1}\right)$ both $V($ new) at the donor-cell pressure and V1(new) at $99 \%$ of the donor-cell pressure were being constrained by $\mathrm{V}(\text { old })^{*} \mathrm{C} 1^{* *}\left(-\mathrm{C} 2^{*} \Delta \mathrm{t}\right)$ or $\mathrm{V}(\mathrm{old})^{*} \mathrm{C} 1^{* *}\left(+\mathrm{C} 2^{*} \Delta \mathrm{t}\right)$ in subroutine CHOKE. This resulted in the choked-velocity derivative with respect to the donor pressure, $\Delta \mathrm{V} / \Delta \mathrm{P}($ donor cell $)=100.0 *\{\mathrm{~V}($ new $)$ $-\mathrm{V} 1$ (new) $/ \mathrm{P}$ (donor cell) to be 0 because $\mathrm{V}($ new $)=\mathrm{V} 1$ (new) when both values are constrained. However, this did not result in the choked velocity only changing very little throughout the 1300-s transient when the downstream BREAK pressure did step changes every $100 \mathrm{~s}$. The choked velocity was able to make step changes at the start of each 100-s time interval because the reduced mass flow spikes at the start of each 100-s interval evaluated unchoked flow, which allowed the velocity to approach the choked velocity before being constrained by the chokedflow model. Constraining V(new) and V1(new) before its pressure derivative is evaluated removed the semi-implicitness of the choked velocity's donor-cell pressure dependence. To restore that semiimplicitness, I moved the pressure-derivative evaluation before the choked-velocity time-constant constraint at the end of subroutine CHOKE so that only the magnitude of the choked velocity is constrained between $\mathrm{V}(\text { old })^{*} \mathrm{C} 1^{* *}\left(-\mathrm{C} 2^{*} \Delta \mathrm{t}\right)$ and $\mathrm{V}(\text { old })^{*} \mathrm{C} 1^{* *}\left(+\mathrm{C} 2^{*} \Delta \mathrm{t}\right)$. The KAPL test problem was then evaluated for $C 2=1000,100,10,1,0.1$, $0.01,0.001$, and 0.0001 . The gas mass flow $\left(\mathrm{kg} \mathrm{s}^{-1}\right)$ vs problem time(s) plots from those eight cases are shown in Figs. C.1 through C.8. Note in the $\mathrm{C} 2=0.1,0.01,0.001$, and 0.0001 plots in Figs. C.5 through C. 8 that after a few seconds the interface-1.5 gas mass flow ramps from 0 to $\sim 20 \mathrm{~kg} \mathrm{~s}^{-1}$ before choking is evaluated to occur. Its subsequent ramp is constrained by the value of $\mathrm{C} 2$. For $\mathrm{C} 2=0.1$ and 0.01 , it reaches pseudo steady-state conditions for the upstream donor-cell pressure with a mass flow of 26.5 to $27.0 \mathrm{~kg} \mathrm{~s}^{-1}$. For C2 $=0.001$ and 0.0001 , it doesn't reach pseudo steady-state conditions because of a significant time delay. 
Concern 3: Rich Smith wanted to know if the choked-flow multipliers were being applied correctly and how they were being applied. This needs to be documented.

Response 3: Subroutine SOUND evaluates the sonic velocity, and subroutine CHOKE applies a choked-flow multiplier to that sonic velocity. There are two choked-flow multiplier defined through Namelist; CHM1, which is applied to the subcooled-liquid sonic velocity, $\mathrm{CHM}{ }^{*} \mathrm{~V}$ (sonic) $=\mathrm{VL}$, with the vapor velocity defined by $\mathrm{VV}=\mathrm{VL} * \mathrm{SLIP}$ and CHM2, which is applied to the two-phase fluid or single-phase gas $(\alpha>0.999)$ sonic velocity, $\mathrm{CHM} 2^{*} \mathrm{~V}$ (sonic) $=\mathrm{VV}$, with the liquid velocity defined by $\mathrm{VL}=\mathrm{VV} / \mathrm{SLIP}$. For $0.01<\alpha<0.1$, the liquid and vapor velocities based on the CHM1*subcooled-liquid sonic velocity and CHM2*twophase fluid sonic velocity are averaged together based on a linear weighting over this $\alpha$ gas volume fraction range.

$* * * *$ NOTE ${ }^{* * * *}$, I think there is an error in applying CHM2 (actually CHMLT2) in subroutine CHOKE to the two-phase sonic velocities between statements 52 CONTINUE and 40 CONTINUE. The mixture sonic velocity VELM is evaluated and then based on VELM; the liquid sonic velocity VELL and gas sonic velocity VELV are evaluated with CHMLT2 applied as a factor. CHMLT2 is not applied to VELM before it is then used in the statement IF(ABS(VM) .LT.ABS(VELM)) RETURN to determine if choking does not occur. CHMLT2 needs to be applied to VELM before this choked-flow test is performed. I have not yet made this correction in FXCFM. Is this an error that needs to be corrected in update FXCFM? [This error was later corrected in update FXCFM as its fifth area of correction.]

Concern 4: Check that the DFLDP and DFVDP choked-flow velocity derivatives with respect to the donor-cell pressure are not used as temporary storage arrays between subroutine FEMOM and subroutine TF1DS1 during the timestep solution of TRAC-P.

Response 4: I checked the TRAC-P source that all uses of arrays DFLDP and DFVDP are for their velocity derivatives with respect to pressure. I also programmed temporary write statements in subroutines FEMOM, TF1DS1, and TF1DS to verify that their choked-interface values determined by subroutine CHOKE were the same when these three subroutines are evaluated. It was this output that showed their derivative values being 0.0 when choking occurred and $C 2$ was small enough to constrain the values of both VL and VL1 and both VV and VV1. This resulted in reprogramming the choked-velocity constraint criterion that is described in Response 2.

Concern 5: Paul Giguere said that during backups to the beginning of subroutine OUTER, BITN masking to not reset certain bits to 0 is done by entry ON1123 in subroutine BITS. The choked-flow bit 33 of BITN, set in 
subroutine FEMOM rather than subroutine TF1DS1, now needs to be protected from being reset to 0 during such a backup.

Response 5: Paul was correct on this. I have programmed FXCFM to not reset bit 33 of BITN during backups to the beginning of subroutine OUTER. In looking at the bit mask and from further discussion with Paul, I became aware that for def,IBM, bit 43 is not being reset to 0 but for -def,IBM, bit 43 is being reset to 0 by the ON1123 entry in BITS. Bits 42 and 43 are flags for vapor and liquid, respectively, reaching (crossing) saturation in subroutine HTIF during the timestep. If bit 43 is not reset to 0 for def,IBM, why isn't the same done for bit 42 ? Why isn't bit 43 not reset to 0 for -def,IBM? Paul and I feel that not resetting bit 43 to 0 for def,IBM is an error that needs to be corrected. On a backup to the beginning of subroutine OUTER, both bits 42 and 43 should be reset to zero because subroutine HTIF is called again and needs to redetermine if the vapor and liquid reach (cross) saturation. Rich Smith requested that this bit- 43 error not be corrected in update FXCFM because it is a separate issue. Trouble report item 261 has been generated on this error. [An update needs to be programmed to correct this bit-43 error.]

Concern 6: Trying to create the Scientech test problem's input-data files at Los Alamos gave TRAC-P Version 5.4.28 results inconsistent with troublereport item 235 results reported by Don Palmrose. We need to get the actual input-data files for the Scientech test problems to investigate these problems with the corrections of update FXCFM.

Response 6: A request is being make by Jim Lime to Don Palmrose for the inputdata files for these test problems.

Concern 7: Investigate the cause of oscillatory behavior, reduced timestep size, and a single-case-evaluation abort of the Marviken and Edwards blowdown test problems evaluated by Jim Steiner and Jim Lime.

Response 7: The Marviken and Edwards blowdown test problems showed less robust numeric, whereas the KAPL test problem showed more robust numeric with the corrections of update FXCFM. I assumed that was caused by something happening in the Marviken and Edwards test problems that was not happening in the KAPL test problem. The first consideration was that water packing is occurring in the former problems, but is not happening in the later problem. Moving the call to subroutine CHOKE from subroutine TF1DS1 to subroutine FEMOM meant that now water packing was not affecting the application of choking. An IF test to not evaluate the choked-flow model in subroutine TF1DS1 based on a water-packing backup being done was now not being applied. A two-line correction in subroutine TF1DS1 was made to update FXCFM to again override the effect of applying choking when a water-packing backup is effected by choking. Jim Lime 
reevaluated Marviken Case 24, which had aborted before, with this correction and reported that Case 24 now ran OK. I don't know if halving DTMIN and DTMAX was still in the input data that was used in this reevaluation. Jim Lime said that he and Jim Steiner would wait for any further changes I would be making to update FXCFM (discussed above) and a successful evaluation of the Scientech test problems before reevaluating all the Marviken and Edwards blowdown test problems with the corrections of update FXCFM. [Using the actual Scientech input-data files (see Appendix D) and update FXCFM with the corrections of responses $2,3,5$, and 7 showed similar robustness as in the KAPL test problem. Then with a further constraint applied to the choked-velocity derivative with respect to its donor-cell pressure, the oscillations in the Marviken and Edwards blowdown test-problem results were traced to using too large a value $\left(10.0 \mathrm{~s}^{-1}\right)$ for the $C 2$ time constant. $\mathrm{C} 2=0.1 \mathrm{~s}^{-1}$ and smaller values eliminated the oscillations.] 


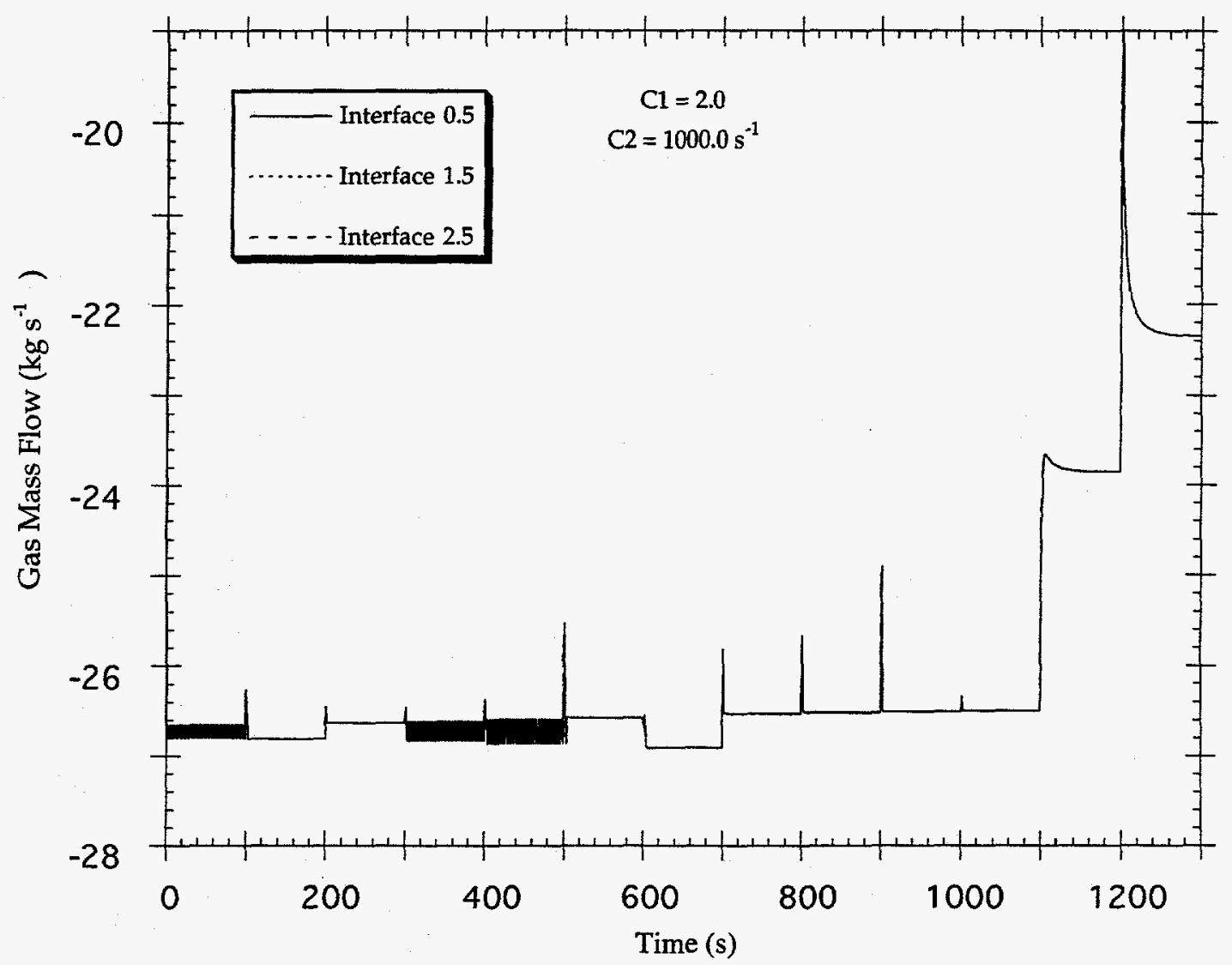

Fig. C.1. KAPL test problcin gas mass flow vs time for $\mathrm{C} 1=2.0$ and $\mathrm{C} 2=1000.0 \mathrm{~s}^{-1}$.

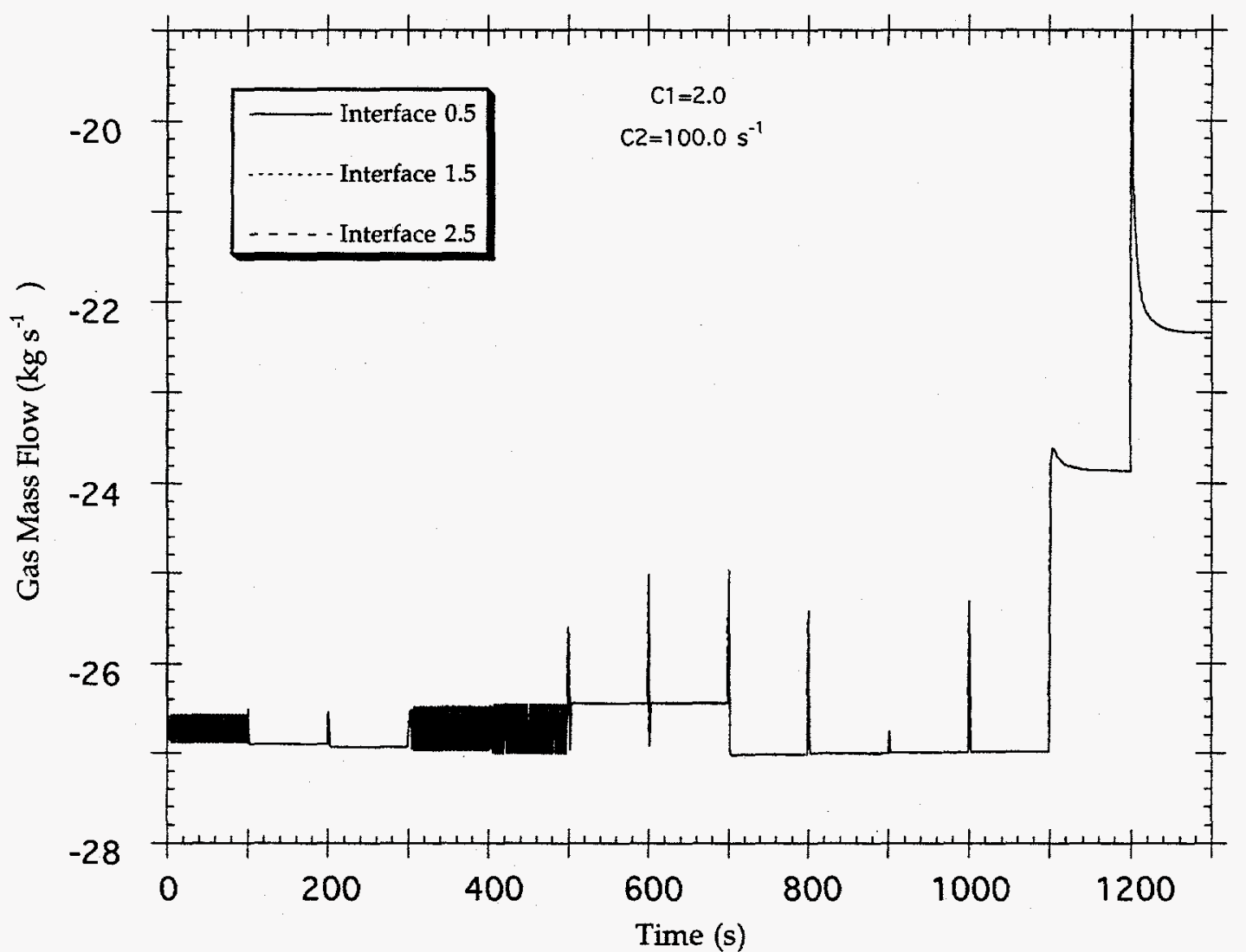

Fig. C.2. KAPL test problem gas mass flow vs time for $\mathrm{C} 1=2.0$ and $\mathrm{C} 2=100.0 \mathrm{~s}^{-1}$. C-6 


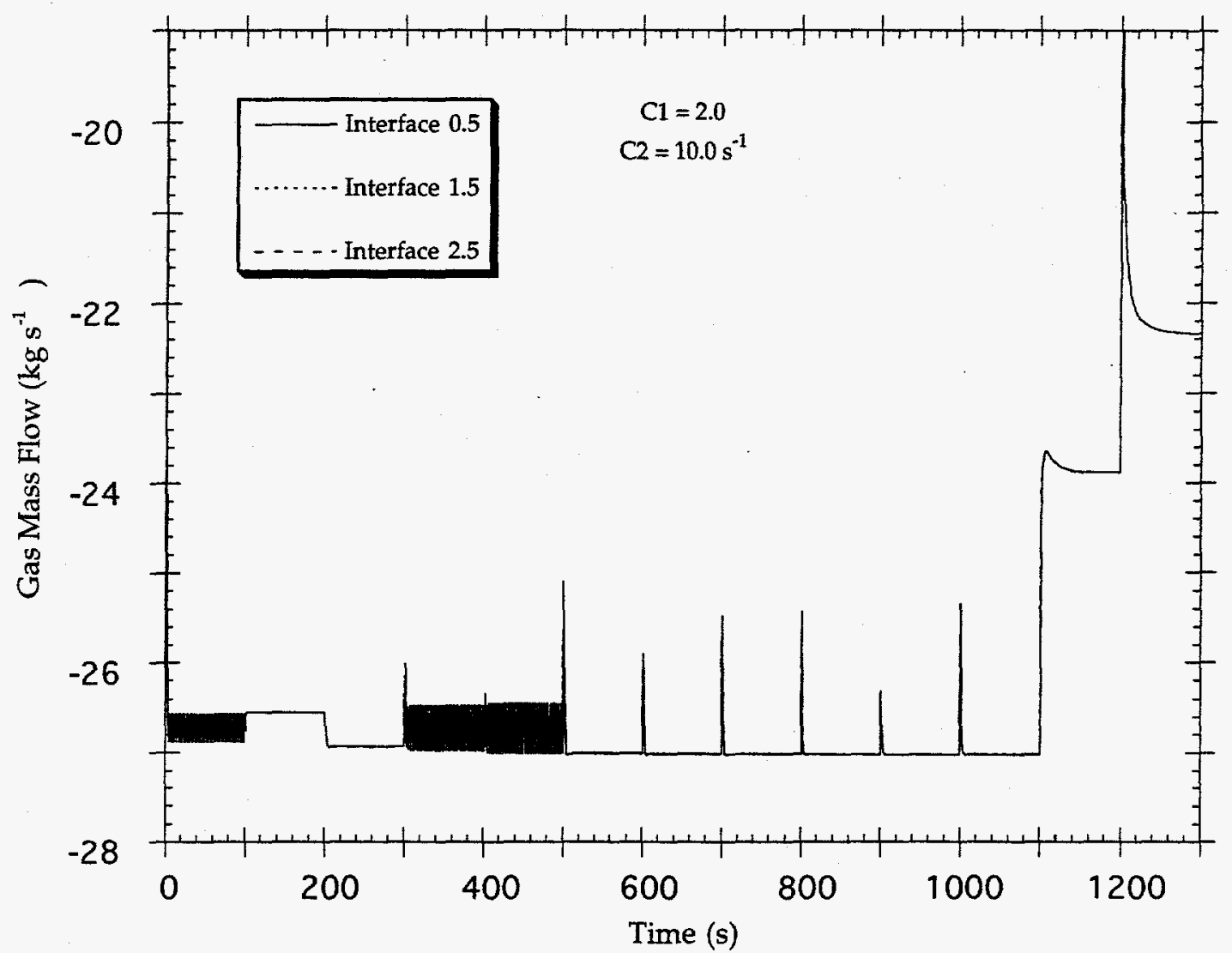

Fig. C.3. KAPL test problem gas mass flow vs time for $\mathrm{C} 1=2.0$ and $\mathrm{C} 2=10.0 \mathrm{~s}^{-1}$.

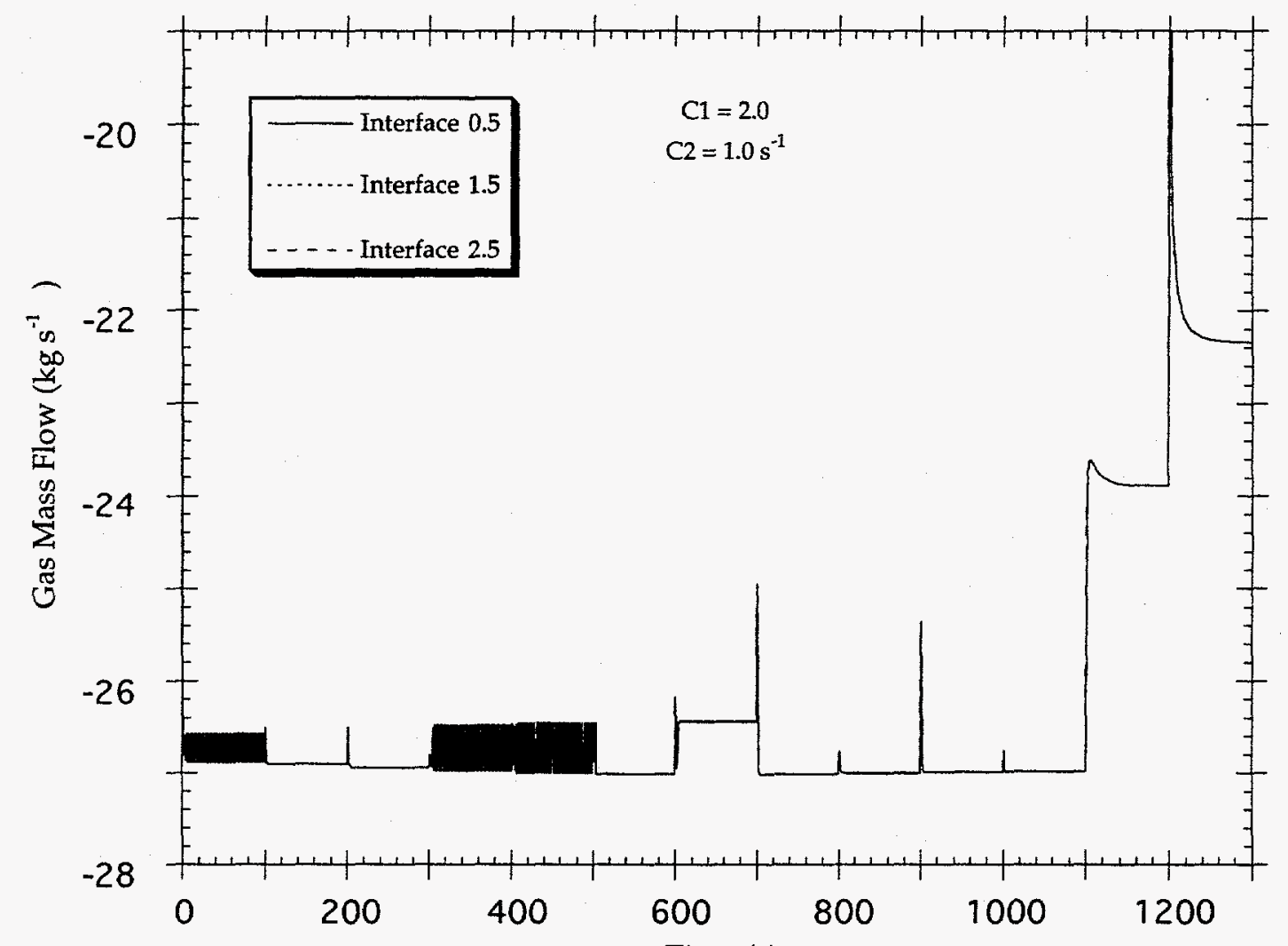

Time (s)

Fig. C.4. KAPL test problem gas mass flow vs time for $\mathrm{C} 1=2.0$ and $\mathrm{C} 2=1.0 \mathrm{~s}^{-1}$. 


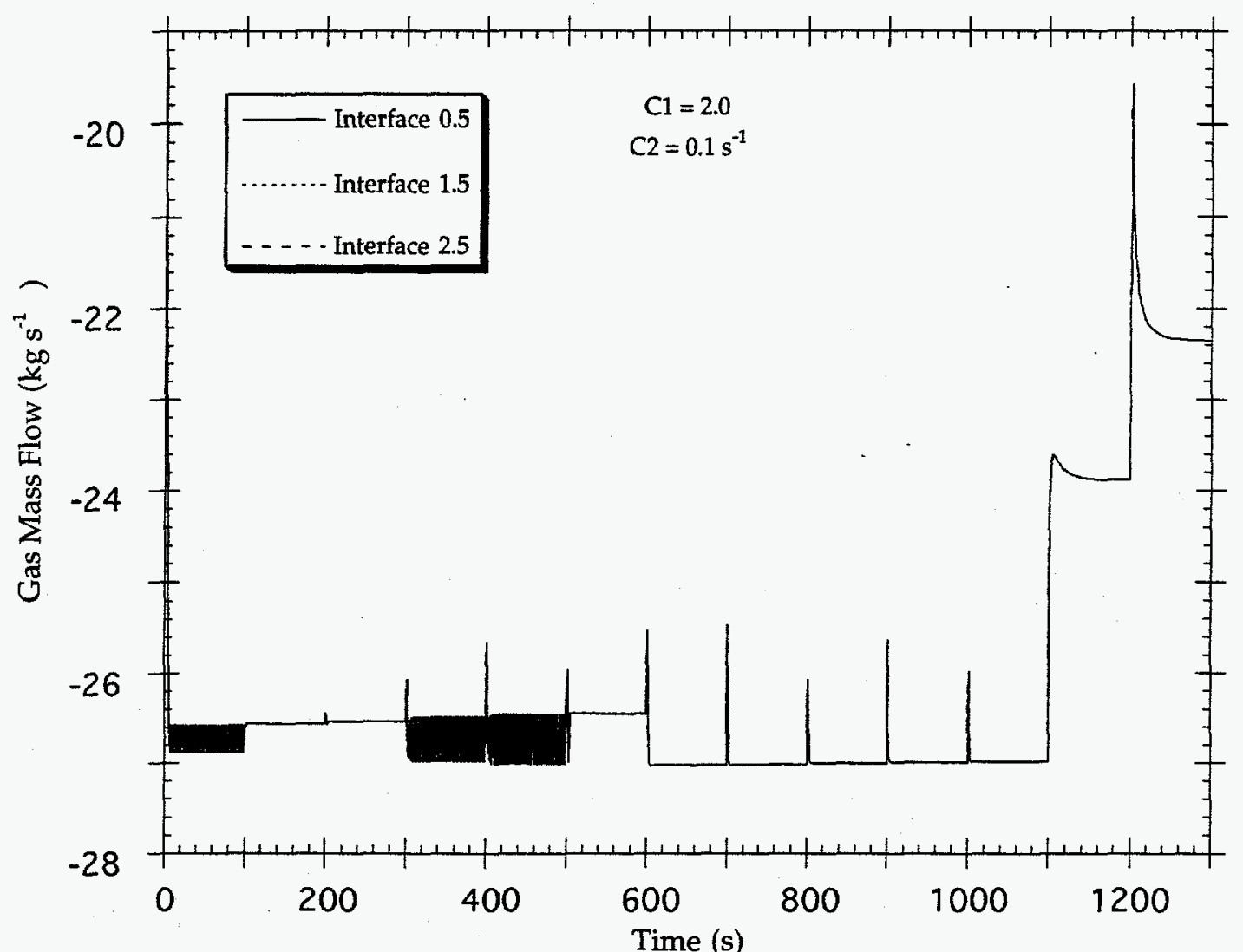

Fig. C.5. KAPL test problem gas mass flow vs time for $\mathrm{C} 1=2.0$ and $C .2=0.1 \mathrm{~s}^{-1}$.

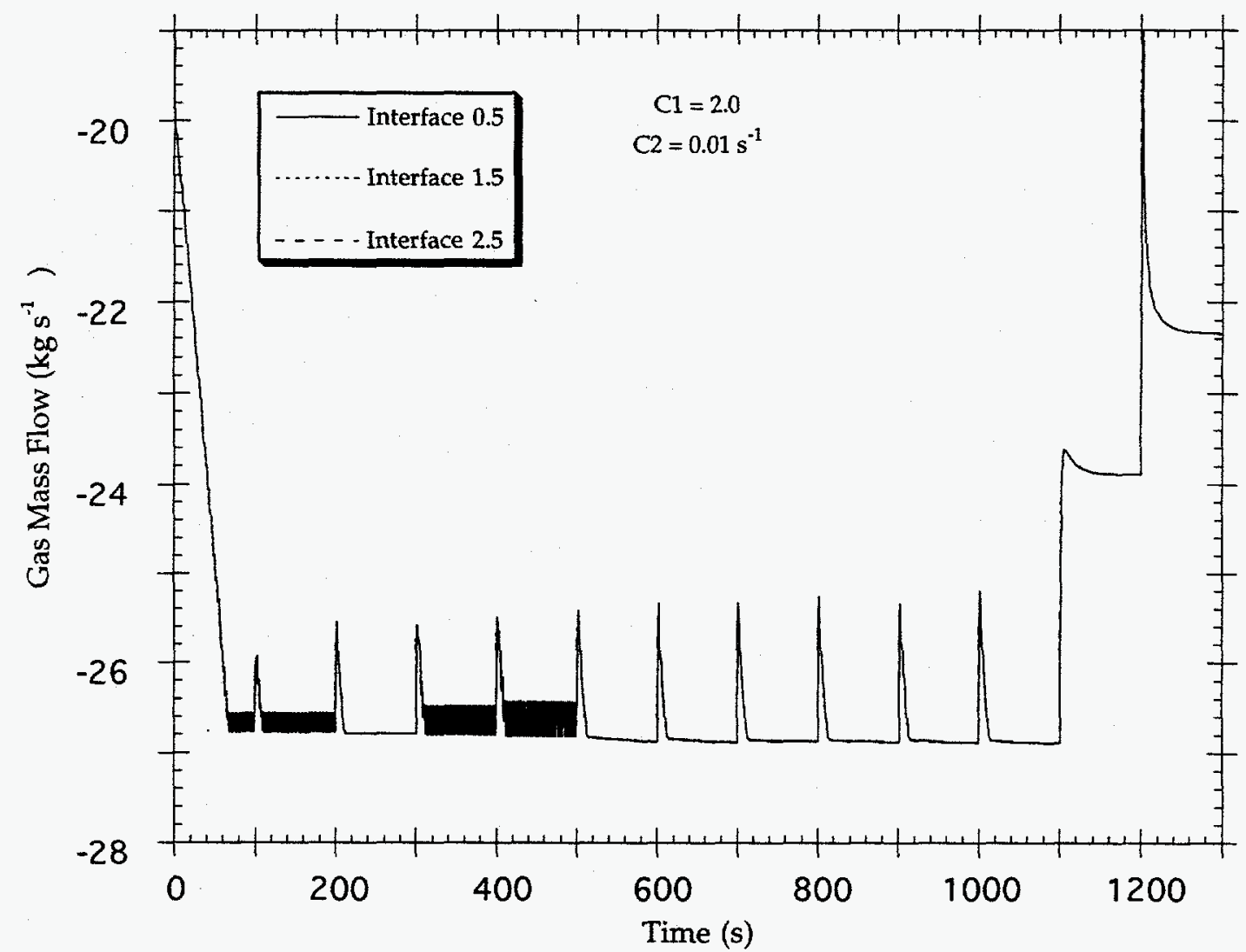

Fig. C.6. KAPL test problem gas mass flow vs time for $\mathrm{C} 1=2.0$ and $\mathrm{C} 2=0.01 \mathrm{~s}^{-1}$. 


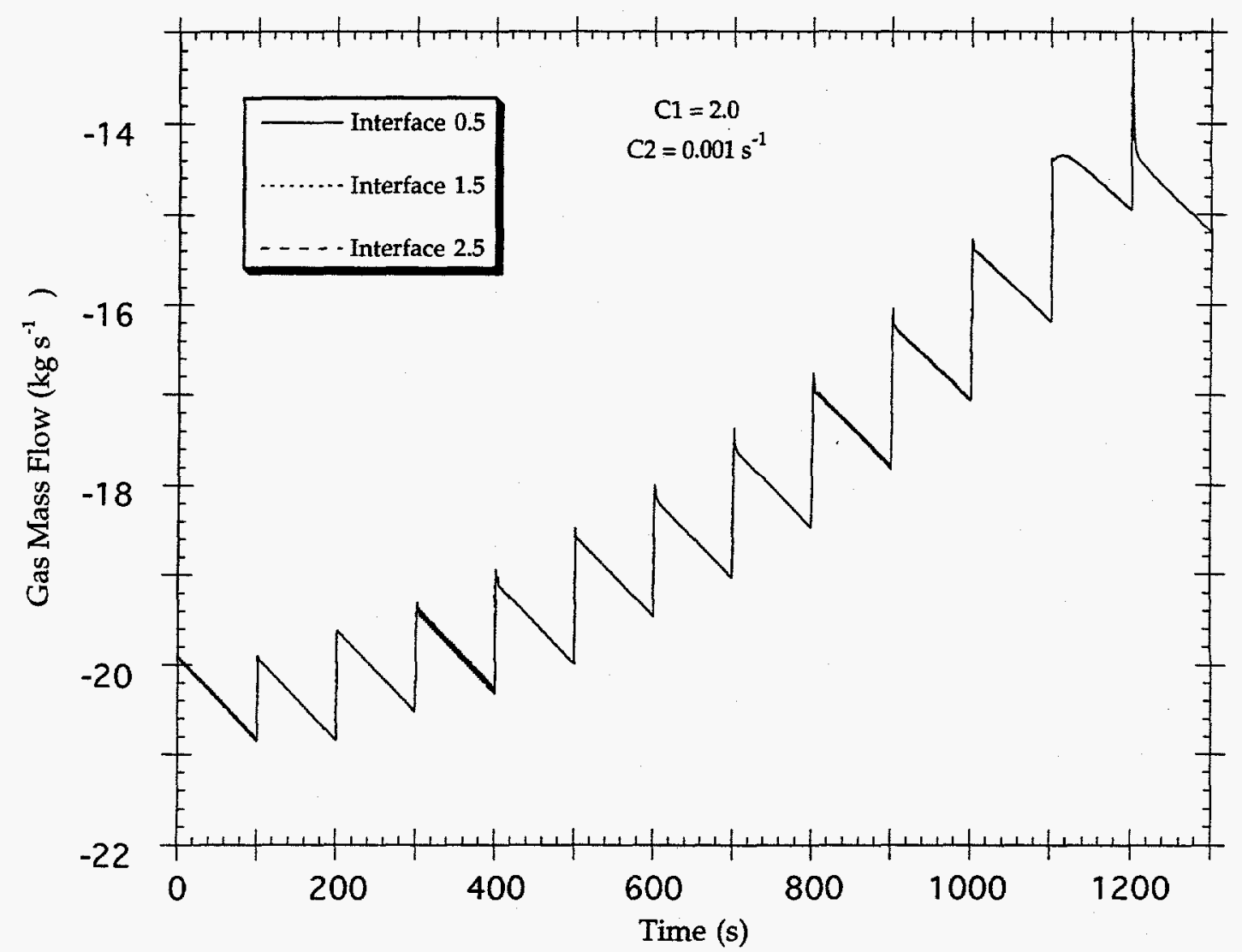

Fig. C.7. KAPL test problem gas mass flow vs time for $\mathrm{C} 1=2.0$ and $\mathrm{C} 2=0.001 \mathrm{~s}^{-1}$.

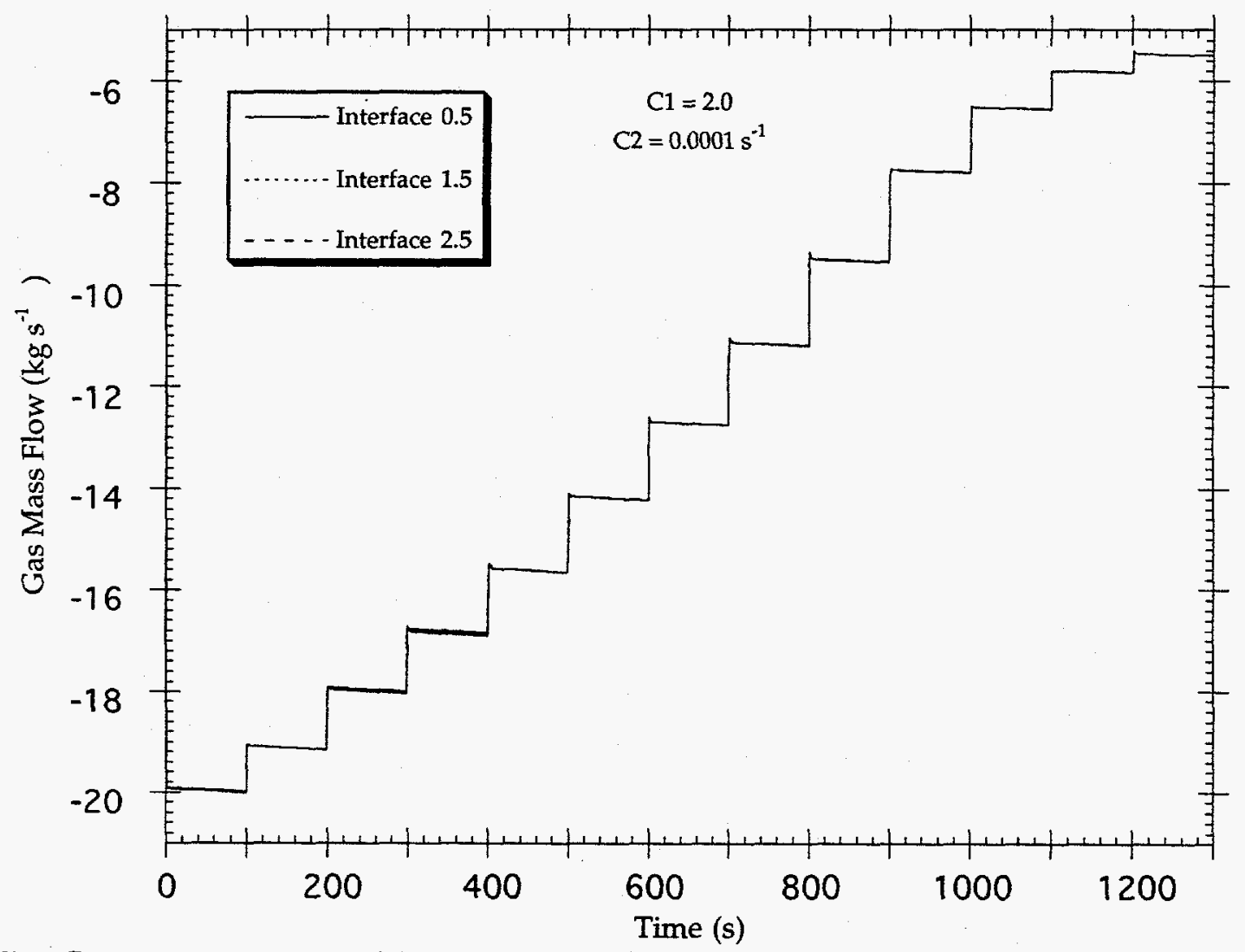

Fig. C.8. KAPL test problem gas mass flow vs time for $\mathrm{C} 1=2.0$ and $\mathrm{C} 2=0.0001 \mathrm{~s}^{-1}$. 


\section{APPENDIX D}

\section{EVALUATING THE MARVIKEN AND EDWARDS CRITICAL-FLOW BLOWDOWN TEST PROBLEMS}

\section{D.1. INTRODUCTION}

The Marviken and Edwards blowdown test problems model full-scale pressurevessel and horizontal-pipe critical-flow experiments, respectively. Measured pressures and temperatures provide fluid mass flow, pressure, and temperature data to compare with the predicted thermal-hydraulic solution of the calculative model. Tests 4, 13, 20, 22, and 24 from the Marviken blowdown experiment will be analyzed with Test 4 having the longest nozzle with a $1.5-\mathrm{m}$ straight section, $0.51-\mathrm{m}$ inside diameter, and L/D of 2.95 and Test 24 having the shortest nozzle with a $0.166-\mathrm{m}$ straight section, $0.51-\mathrm{m}$ inside diameter, and $\mathrm{L} / \mathrm{D}$ of 0.33 . The Edwards blowdown experiment consists of a 4.1-m-long straight pipe with a $0.073-\mathrm{m}$ inside diameter and $\mathrm{L} / \mathrm{D}$ of 56.1. Initially the vessel and pipe contain nonflowing subcooled water at high pressure. The blowdown transients were initiated by breaking a rupture disk at the lower end of the vertical nozzle and at one end of the horizontal pipe.

\section{D.2. ANALYSES AND RESULTS}

These tests have been analyzed with TRAC-P Version 5.4.28 and with TRAC-P Version 5.4.28 plus update FXCFM to determine the effect that the choked-flow model corrections of update FXCFM have on the TRAC-P thermal-hydraulic solution. The calculated fluid mass flow and pressure are plotted along with their measured data in Figs. D.1 through D.4 for Test 4, Figs. D.5 through D.8 for Test 13, Figs. D.9 through D.12 for Test 20, Figs. D.13 through D.16 for Test 22, and Figs. D.17 through D.20 for Test 24 of the Marviken-vessel experiment. The calculated pressures at the open and closed ends of the Edwards-pipe experiment are plotted along with their measured pressures in Figs. D.21 through D.24.

Earlier calculations with update FXCFM that were presented at the technical design review for update FXCFM showed some oscillation in the Marviken calculated results and an abort in the Marviken Test 24 calculation after 67 timesteps. This was 
traced to the need for the following additional changes in update FXCFM and in the timestep data of the Marviken tests.

1. The $d V / d P_{d}$ derivative of the choked velocity with respect to its donor-cell pressure needs its value reduced as the choked-velocity change from $V_{o}$ to $V$ increases to the point of being constrained by $\mathrm{V}_{0}{ }^{*} \mathrm{C} 1 \pm \mathrm{C} 2^{*} \Delta t$. For transient calculations where $\mathrm{V}_{\mathrm{o}}{ }^{*} \mathrm{C} 1-\mathrm{C} 2^{*} \Delta \mathrm{t} \leq \mathrm{V} \leq \mathrm{V}_{\mathrm{o}}{ }^{*} \mathrm{C} 11^{+C 2^{*} \Delta t}$ defines $\mathrm{V}_{\mathrm{n}}=\mathrm{V}$, update FXCFM now linearly varies $d V_{n} / d P_{d}$ from $d V_{n} / d P_{d}=d V / d P_{d}$ when $V=V_{o}$ to $\mathrm{dV}_{\mathrm{n}} / \mathrm{dP}_{\mathrm{d}}=0.1^{*} \mathrm{dV} / \mathrm{dP}_{\mathrm{d}}$ when $\mathrm{V}=\mathrm{V}_{\mathrm{o}}{ }^{*} \mathrm{C} 1^{ \pm C 2^{*} \Delta t}$.

2. The time-constants values of $\mathrm{C} 1=2.0$ and $\mathrm{C} 2=10.0 \mathrm{~s}^{-1}$, which were originally used, were not constraining the choked-velocity change for each timestep sufficiently to prevent oscillation in the thermal-hydraulic solution. With the derivative constraint of 1), C2 values of $0.1 \mathrm{~s}^{-1}$ and smaller eliminate oscillation in all the Marviken test-problem thermal-hydraulic solutions. However, a C2 value of $1.0 \mathrm{~s}^{-1}$ seemed to provide better agreement with the time delay evidenced in the Marviken and Edwards measured data over 10-s intervals while it only introduced some oscillation in the calculated mass flow of Marviken Test 4. Modeling the time delay of physical phenomena that affect choked flow is important. Thus, a C2 value of $1.0 \mathrm{~s}^{-1}$ has been selected as the recommended default value for future use.

3. Two sets of timestep data used in the Marviken test problems defined DTMIN $=0.001 \mathrm{~s}$ and TEND $=0.1 \mathrm{~s}$ in the first set, and DTMIN $=0.01 \mathrm{~s}$ and TEND $=80.0 \mathrm{~s}$ in the second set. At problem time $0.1 \mathrm{~s}$, the timestep size increases to $\sim 0.003 \mathrm{~s}$. Changing to the second timestep-data set resulted in a step change in the timestep size from $\sim 0.003 \mathrm{~s}$ to $0.01 \mathrm{~s}$. Combined with insufficient constraint on the choked-flow velocity each timestep because of a $\mathrm{C} 2$ value of $10.0 \mathrm{~s}^{-1}$, the Marviken test problems encountered numerical solution difficulties with the issuance of warning messages. It was severe enough in Marviken Test 24 to cause the calculation to abort. This inappropriately large step-change increase in the timestep size was avoided by deleting the second timestep-data set and changing TEND from 0.1 to $80.0 \mathrm{~s}$ and defining appropriate edit time intervals in the first timestep-data set. 
The Edwards test-problem, input-data model was changed as well even though there was no oscillation in its calculated results. The cell lengths where changed to position the pressure and temperature measurement locations exactly at cell centers where their comparison pressures and temperatuies are calculated. This improved agreement between the calculated and measured data.

When examining the plotted results with the above changes, we find very little difference in the results of these two critical-flow blowdown test problems because of the corrections of update FXCFM. There are a few situations of slightly better agreement and at least as many situations where agreement with the measured data is slightly less. The biggest change is in the pressures of the Edwards blowdown test problem. The Edwards-problem calculated pressures based on update FXCFM don't agree as well with the measured data. Be aware, however, that the uncertain initial subcooled liquid temperature magnitude and variation down the 4.91-m-long pipe was adjusted back in the early 1980s to improve agreement with the experimental data. The experiment was said to have an approximately uniform $515 \mathrm{~K}$ liquid temperature, ${ }^{1}$ but the input-data temperatures vary from $498.1 \mathrm{~K}$ at the broken end to $506.4 \mathrm{~K}$ near the closed end of the pipe. Increasing the liquid temperature would bring the update FXCFM calculated temperature in to better agreement with the experimental data. Changing the liquid-temperature variation could eliminate the calculated underprediction of pressure from 0.15 to $0.35 \mathrm{~s}$ in Figs. D.22 and D.24

Overall, the TRAC-P results are nearly the same. This should not be surprising because all of these blowdown test problems model the choked-flow interface adjacent downstream-cell pressure by a BREAK-component cell constant atmospheric pressure. The most significant second and third corrections of update FXCFM that primarily affect the choked-flow interface downstream-pressure solution should have little or no affect on these test problems.

The first correction of update FXCFM that replaces $10 \% / 90 \%$ weighting with a $V_{0}{ }^{*} \pm \Delta t$ constraint on the choked velocity provides less time delay on the choked velocity. During the technical design review of update FXCFM, Jay Spore said he felt that the $\mathrm{C} 2$ time constant probably has a value between 1.0 and $10.0 \mathrm{~s}^{-1}$. Increasing $\mathrm{C} 2$ from $1.0 \mathrm{~s}^{-1}$ would introduce even less time delay. In these blowdown test problems where fluid mass flow and pressure decrease over time, less time delay decreases them faster. This is the case in situations where the TRAC-P results with 
update FXCFM are less in agreement with the experimental data. More time delay with a smaller value of $\mathrm{C} 2$ would improve agreement with the experimental data in these situations, but making such a change is felt to be physically inappropriate. Better agreement with the experimental data probably requires making changes elsewhere in the choked-flow model. Such changes may need to be made in the modeling assumptions rather than in searching for further corrections.

\section{D.3. REFERENCE}

1. J. W. Spore, et al., "TRAC-PF1/MOD2 Theory Manual," Volume I, Los Alamos National Laboratory draft report LA-12031-M, NUREG/CR-5673, Sec. 7.2.6.2.2, pp. 7-57 to 7-59 (July 21, 1993). 


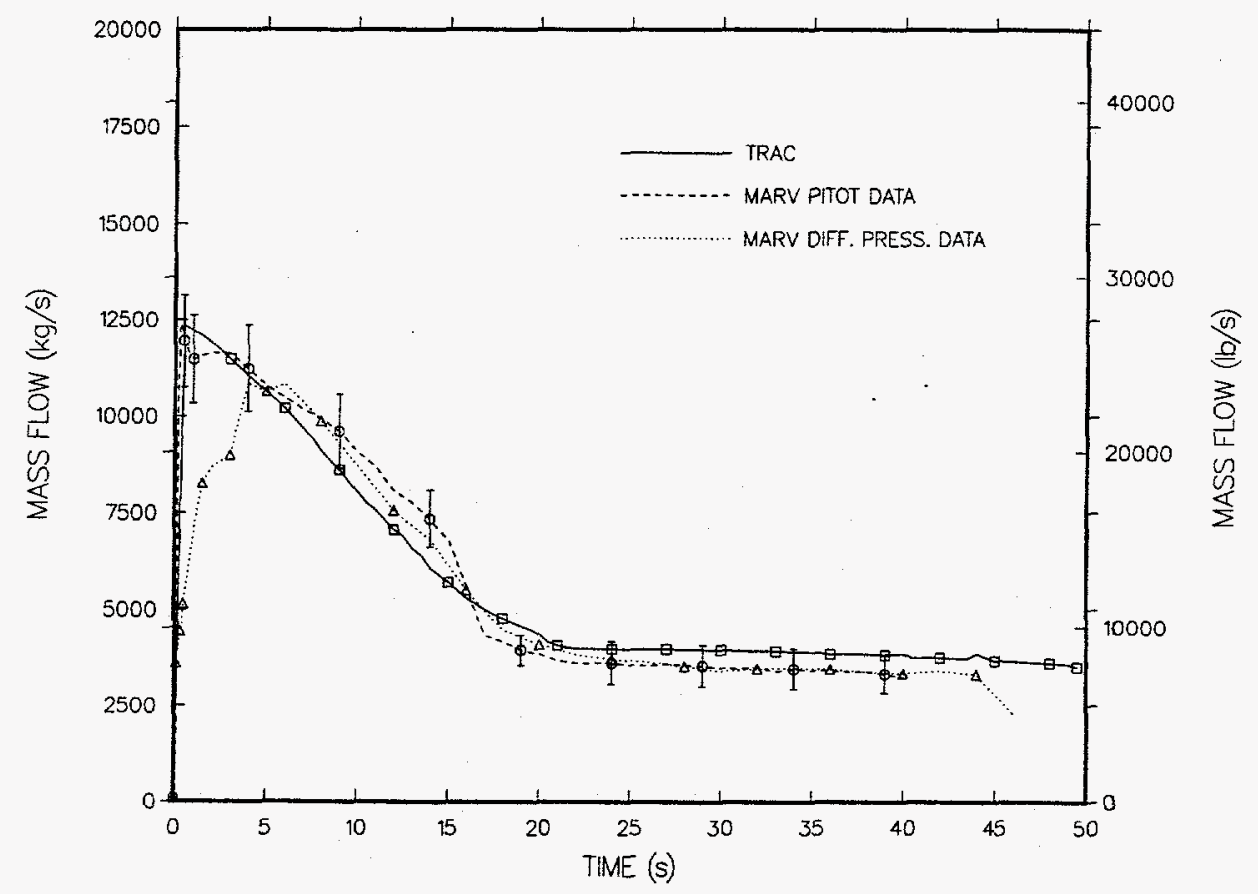

Figure D.1. Break mass flow, Marviken Test 4, TRAC-P Version 5.4.28.

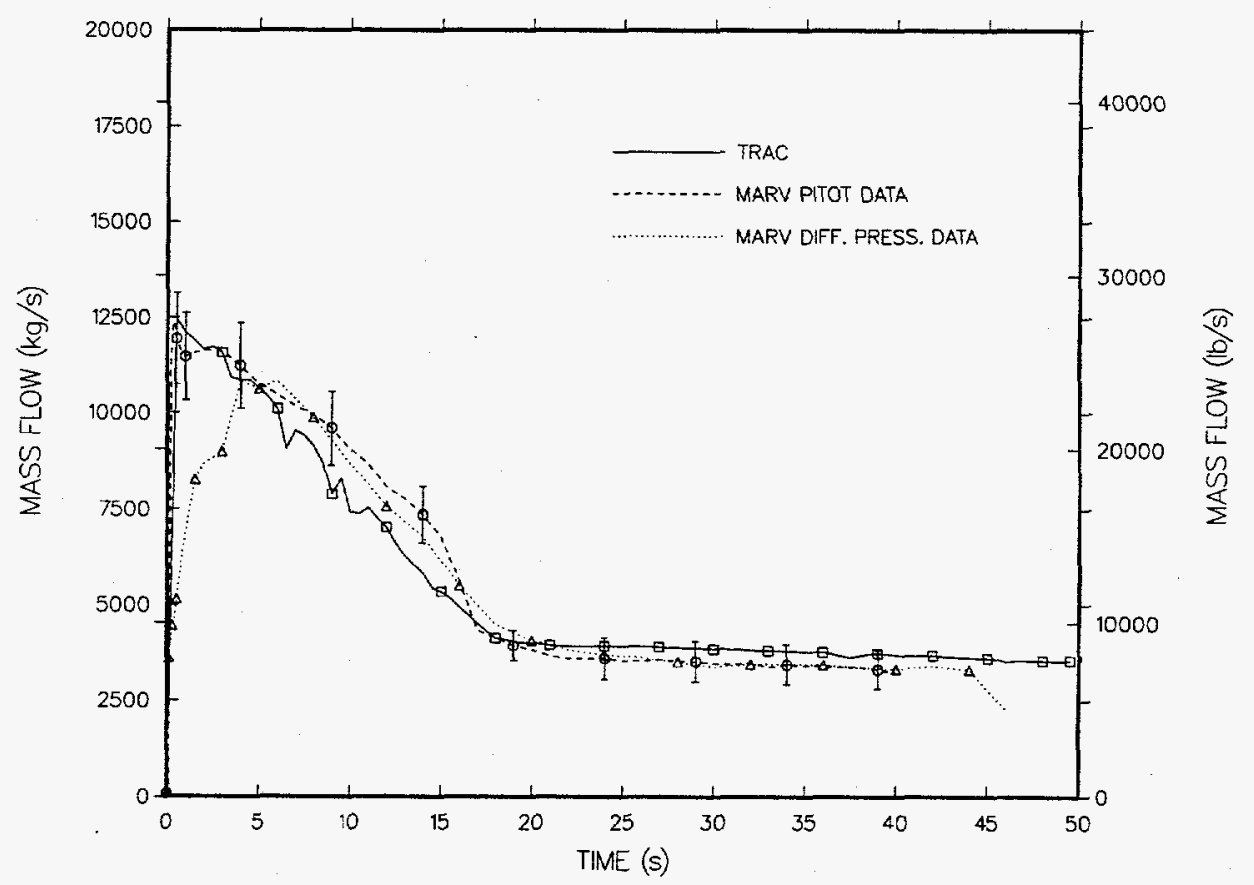

Figure D.2. Break mass flow, Marviken Test 4, TRAC-P with FXCFM. 


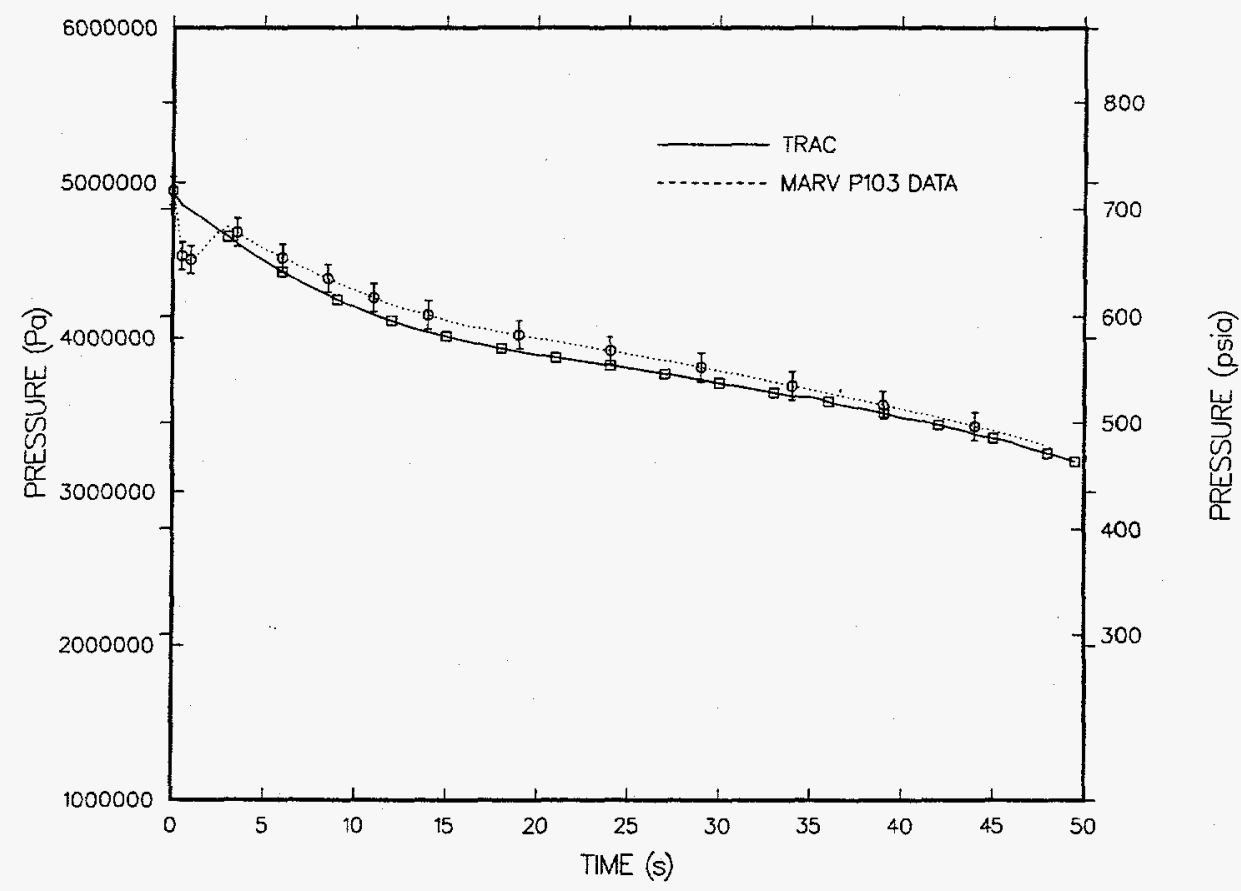

Figure D.3. Pressure, Marviken Test 4, TRAC-P Version 5.4.28.

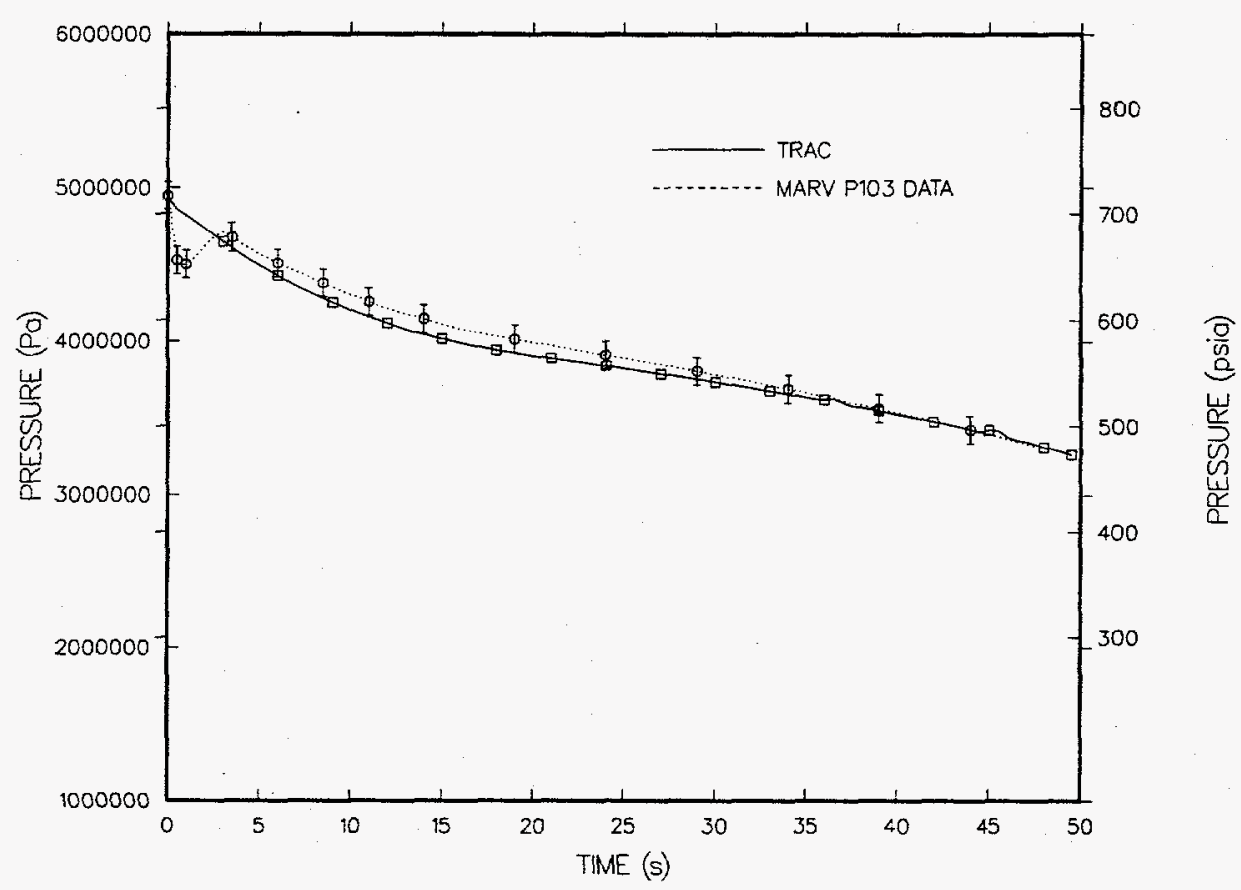

Figure D.4. Pressure, Marviken Test 4, TRAC-P with FXCFM. 


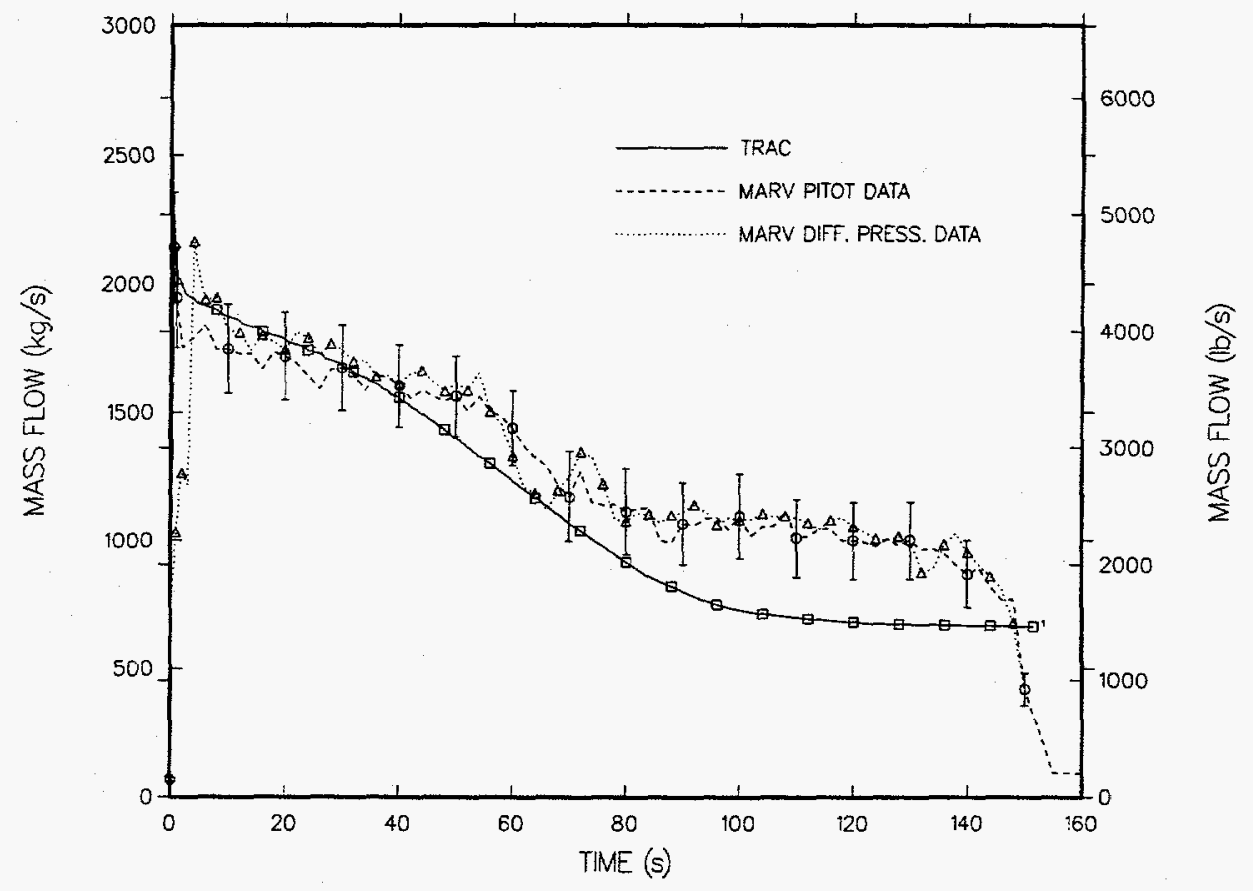

Figure D.5. Break mass flow, Marviken Test 13, TRAC-P Version 5.4.28.

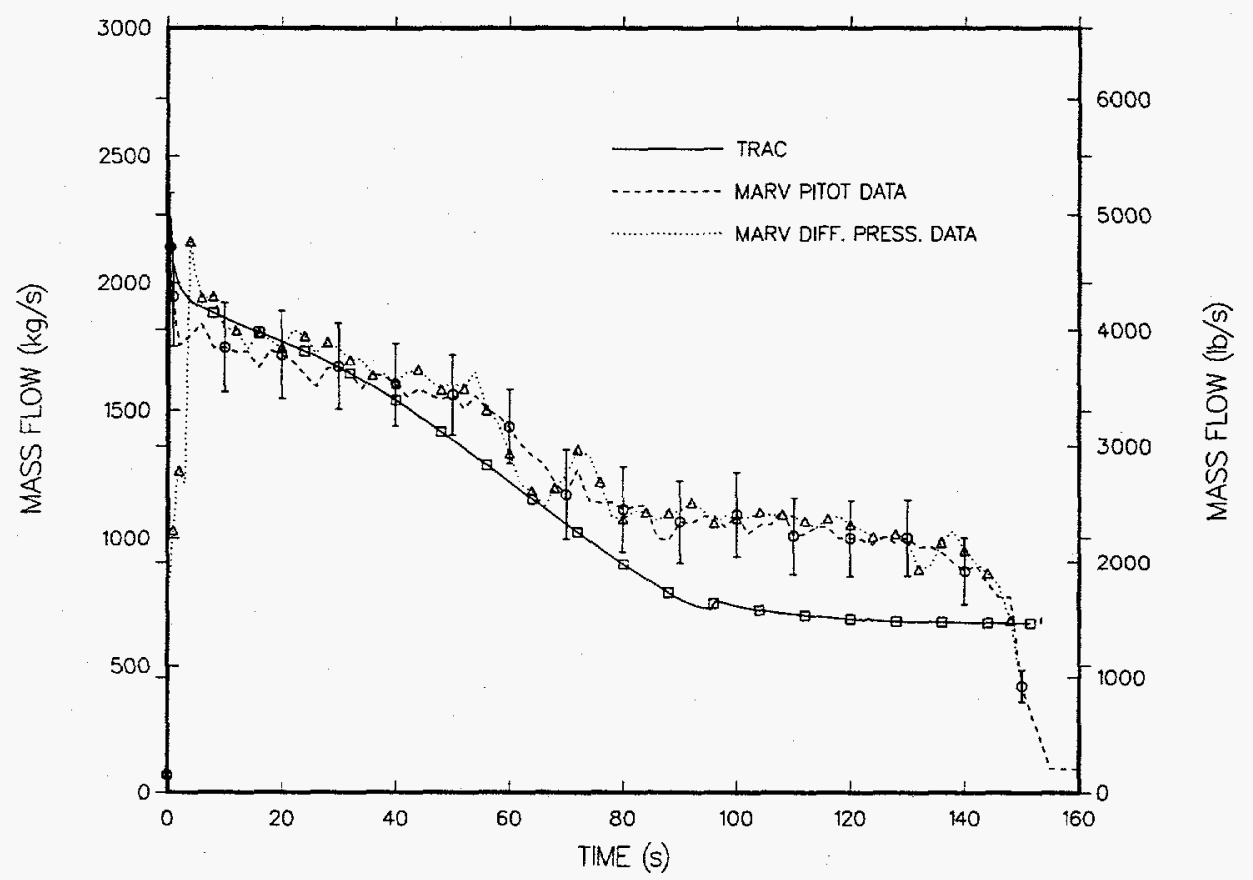

Figure D.6. Break mass flow, Marviken Test 13, TRAC-P with FXCFM. 


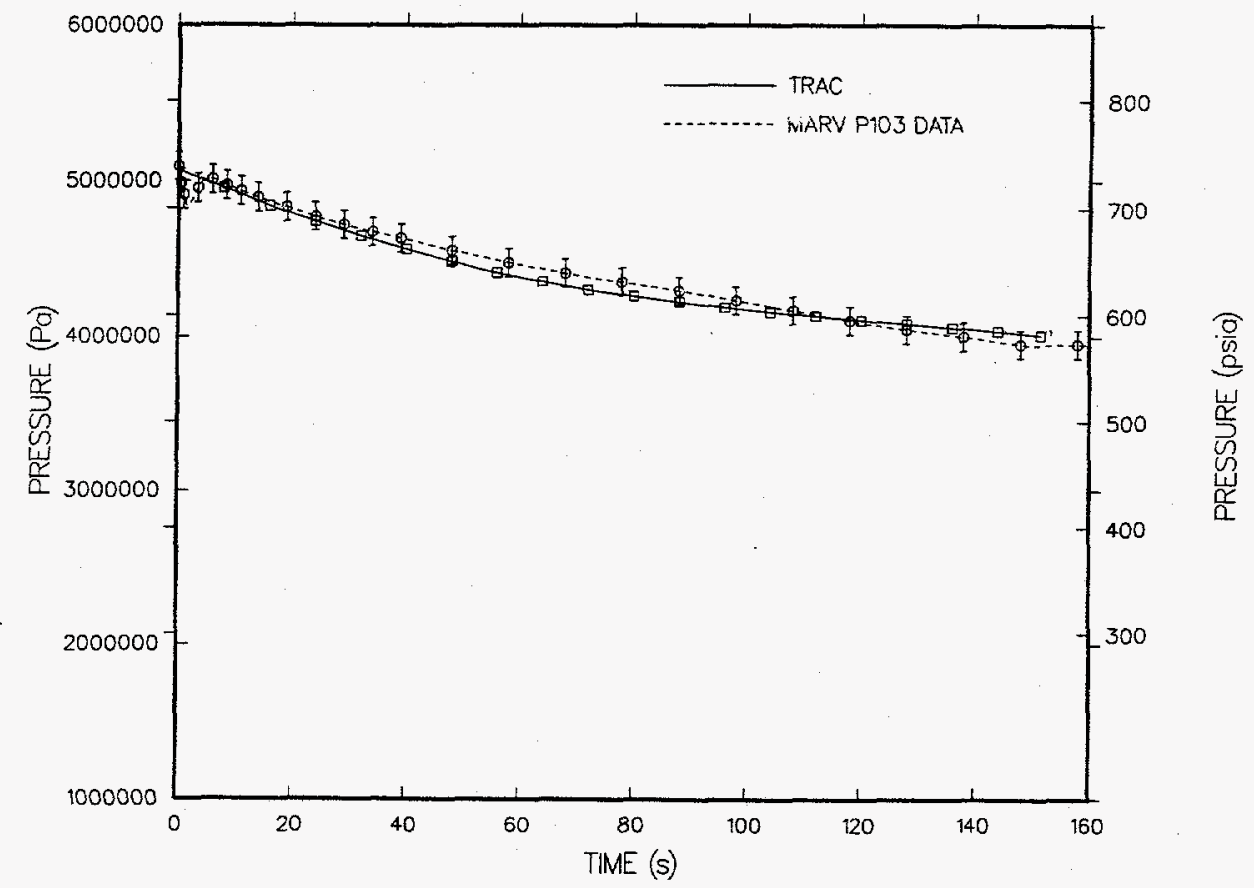

Figure D.7. Pressure, Marviken Test 13, TRAC-P Version 5.4.28.

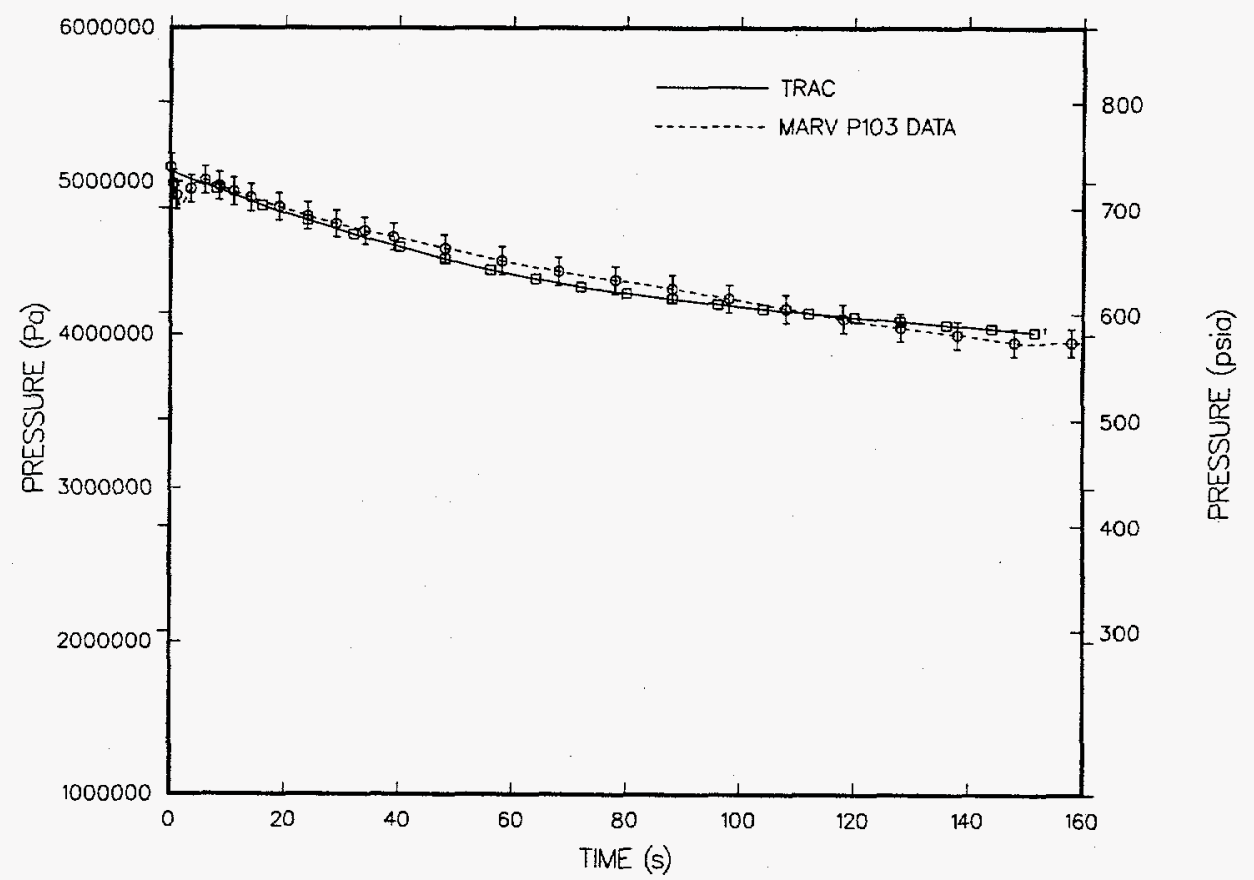

Figure D.8. Pressure, Marviken Test 13, TRAC-P with FXCFM. 


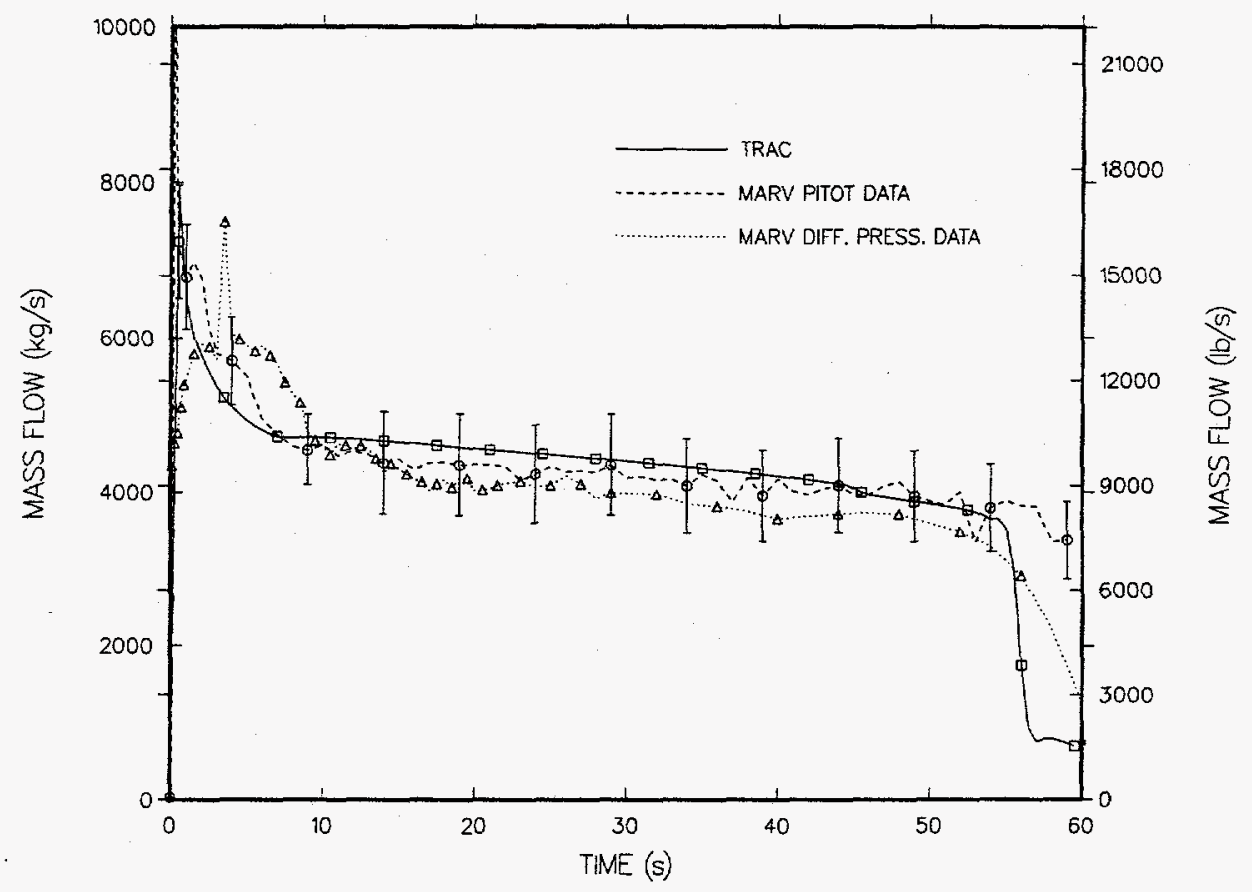

Figure D.9. Break mass flow, Marviken Test 20, TRAC-P Version 5.4.28.

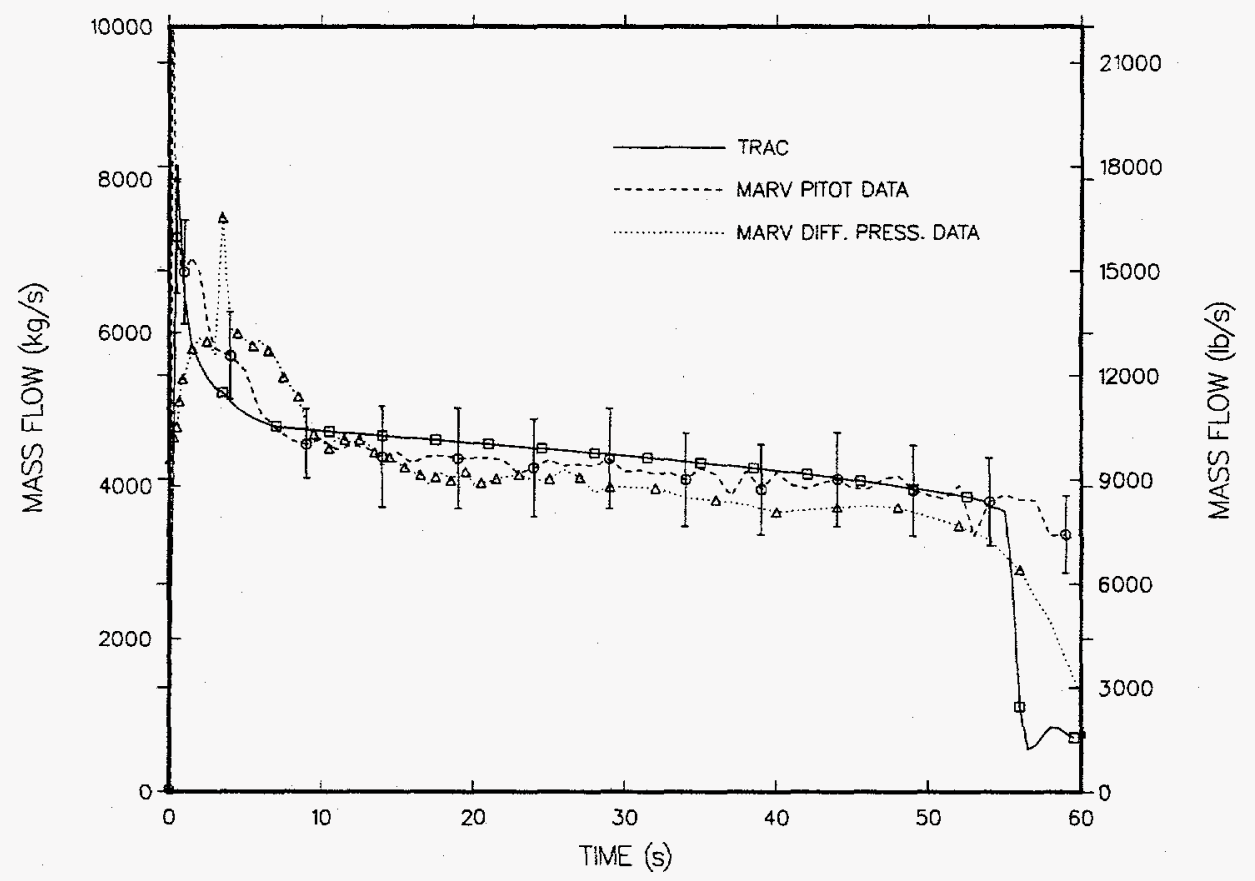

Figure D.10. Break mass flow, Marviken Test 20, TRAC-P with FXCFM. 


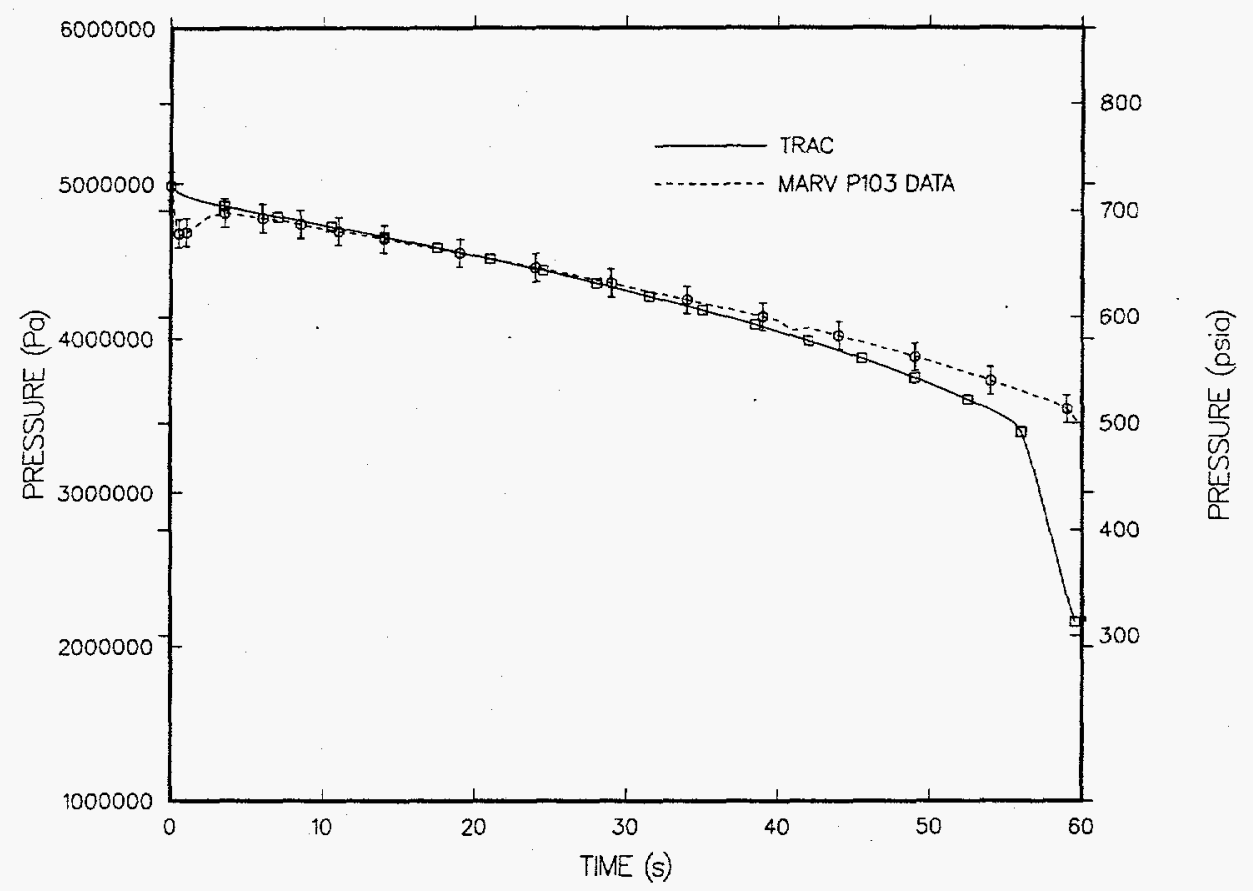

Figure D.11. Pressure, Marviken Test 20, TRAC-P Version 5.4.28.

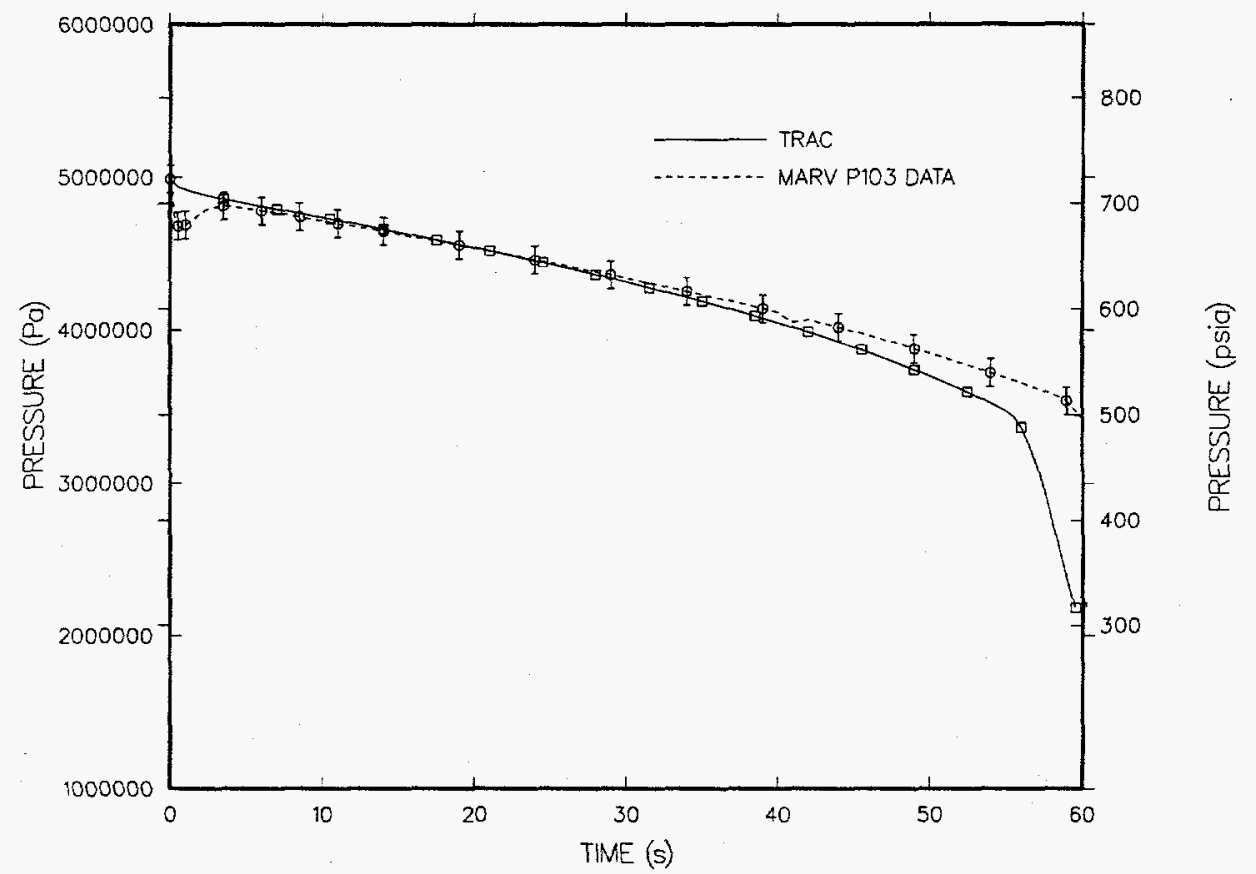

Figure D.12. Pressure, Marviken Test 20, TRAC-P with FXCFM. 


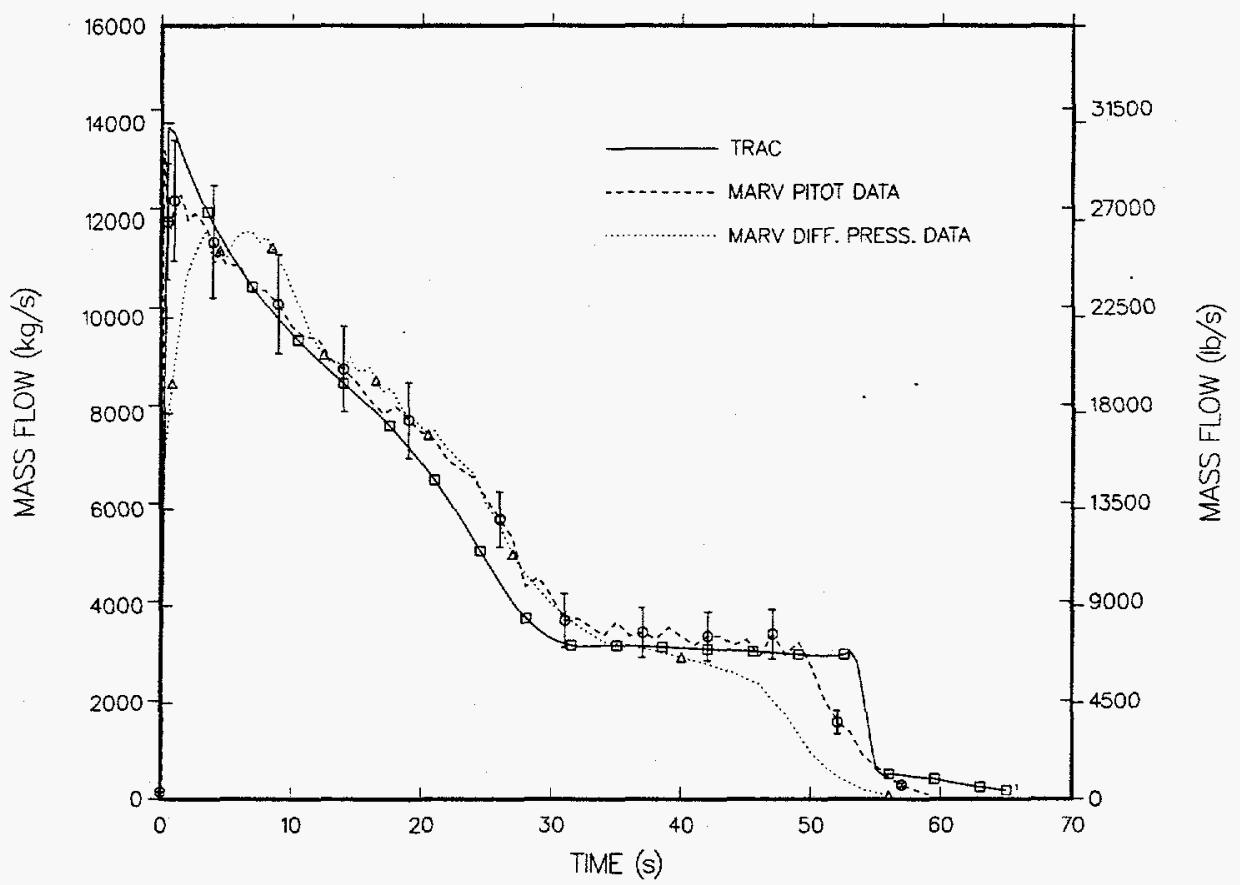

Figure D.13. Break mass flow, Marviken Test 22, TRAC-P Version 5.4.28.

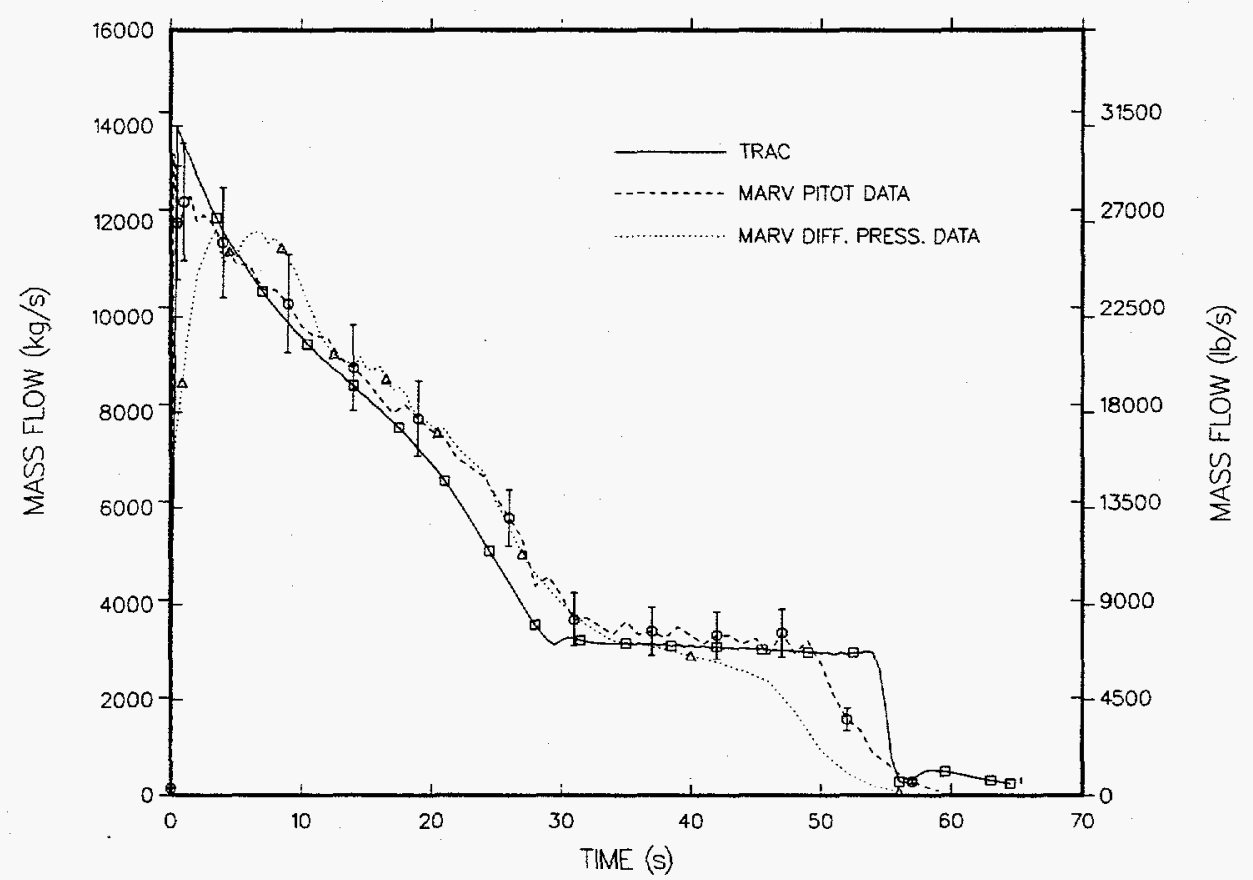

Figure D.14. Break mass flow, Marviken Test 22, TRAC-P with FXCFM. 


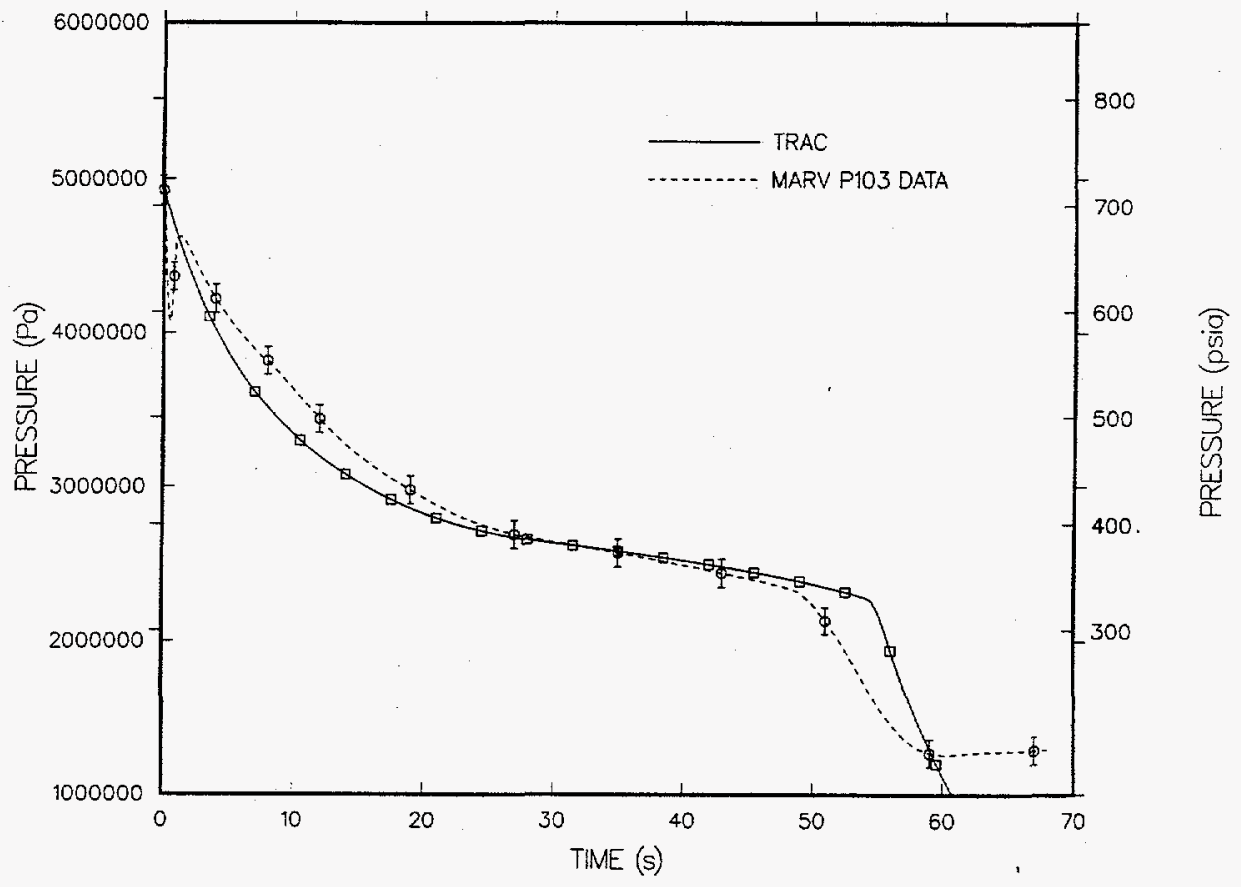

Figure D.15. Pressure, Marviken Test 22, TRAC-P Version 5.4.28.

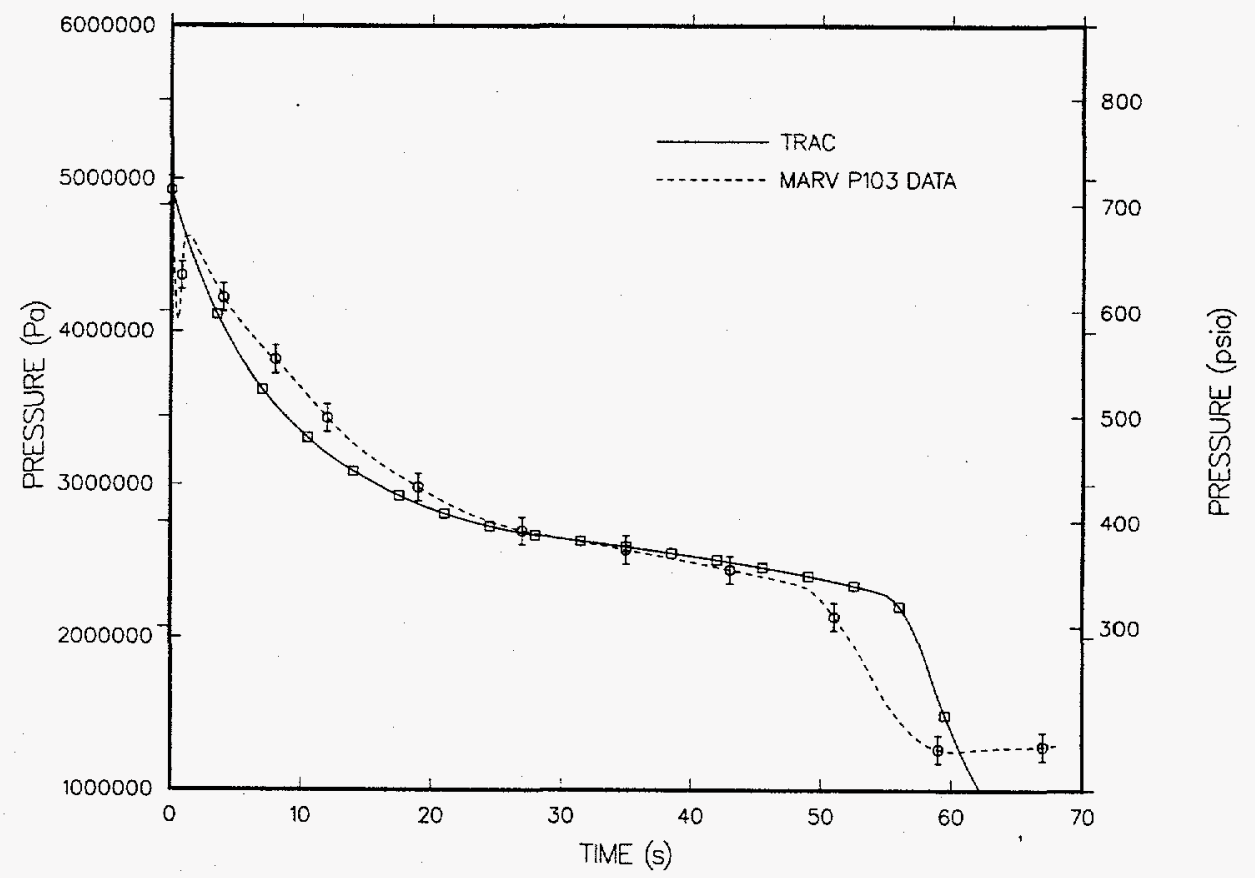

Figure D.16. Pressure, Marviken Test 22, TRAC-P with FXCFM. 


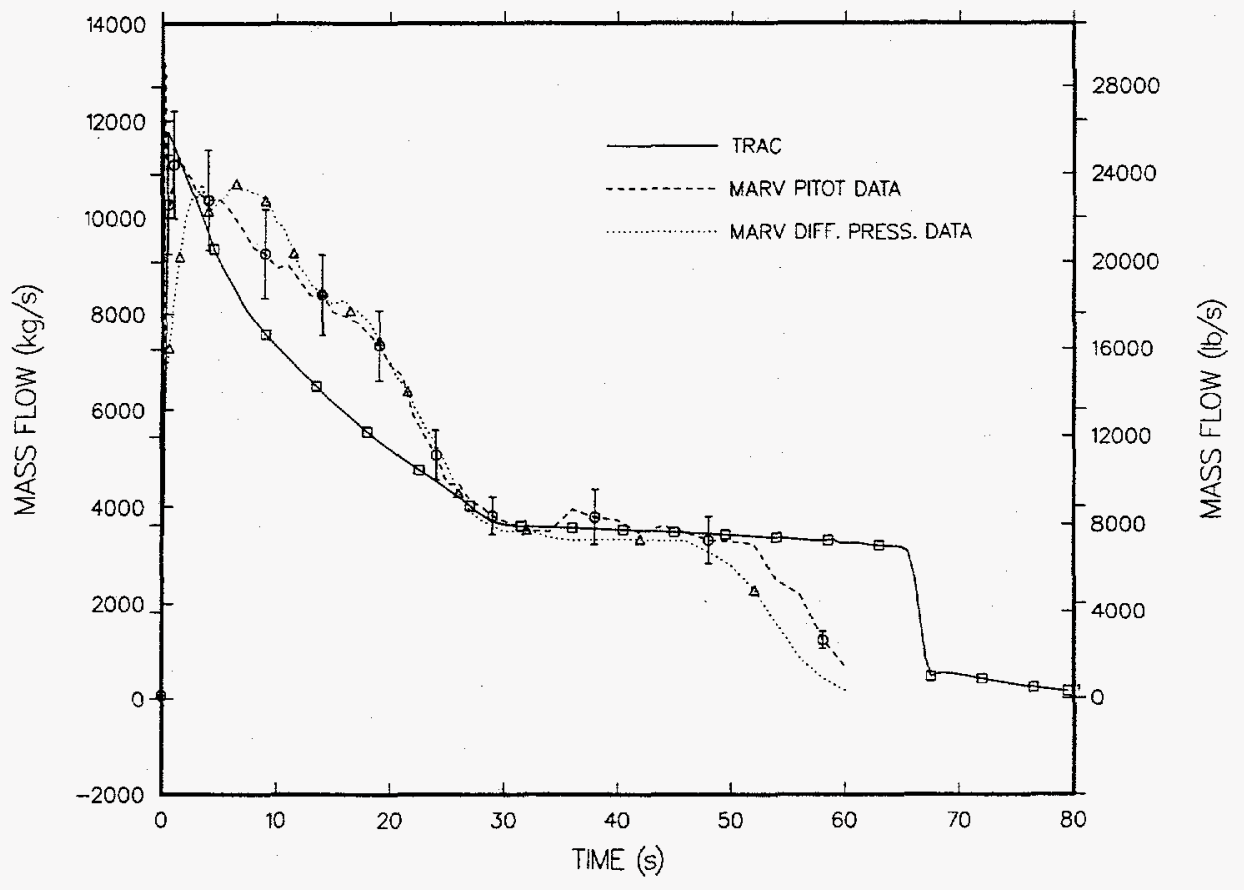

Figure D.17. Break mass flow, Marviken Test 24, TRAC-P Version 5.4.28.

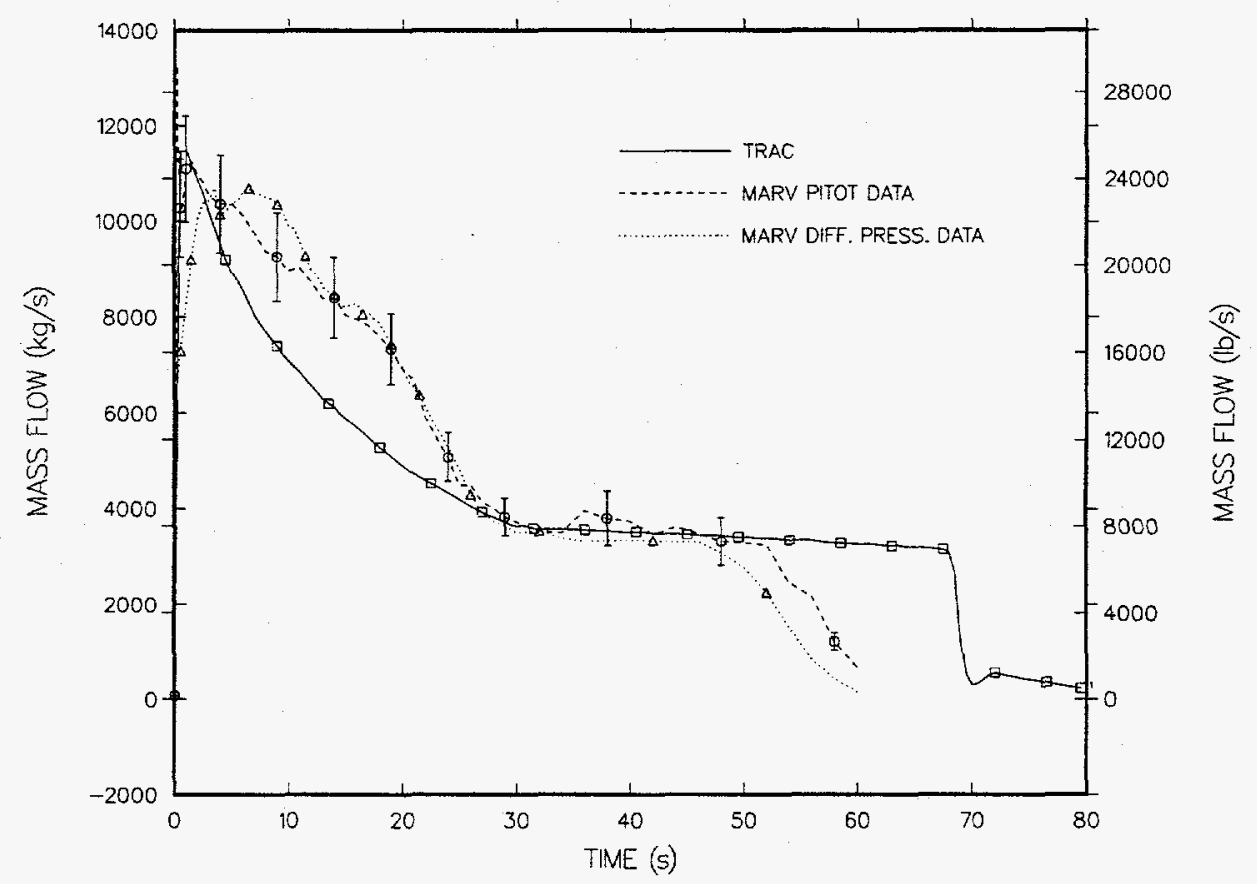

Figure D.18. Break mass flow, Marviken Test 24, TRAC-P with FXCFM. 


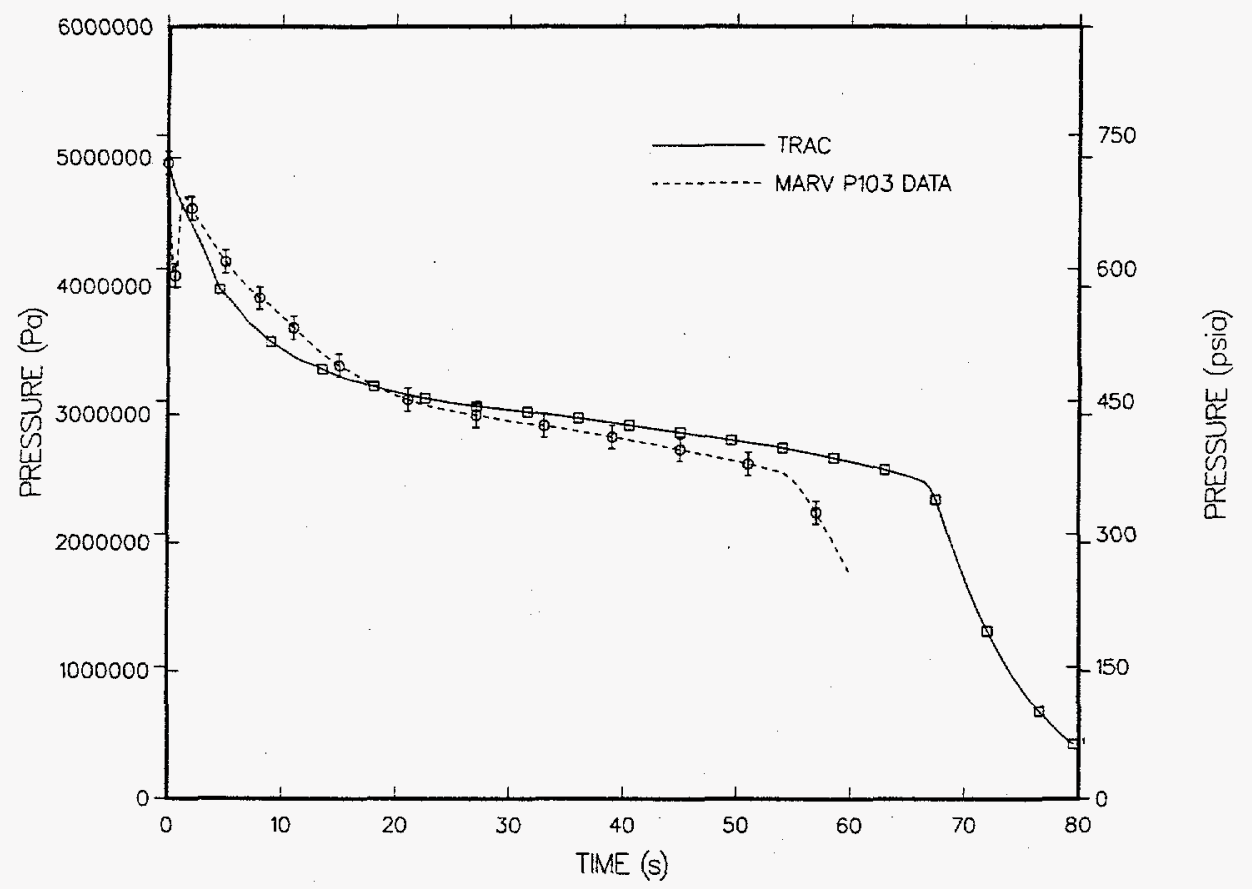

Figure D.19. Pressure, Marviken Test 24, TRAC-P Version 5.4.28.

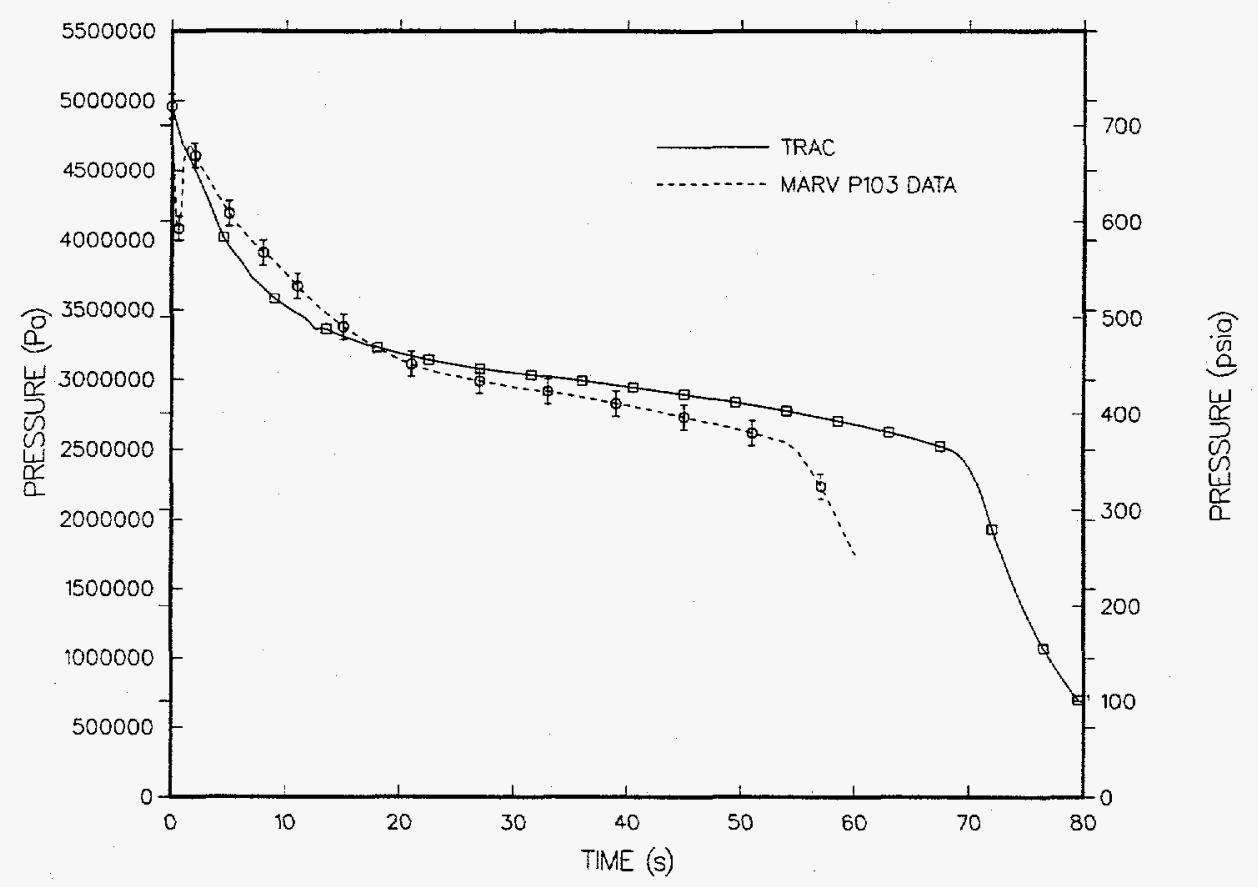

Figure D.20. Pressure, Marviken Test 24, TRAC-P with FXCFM. 


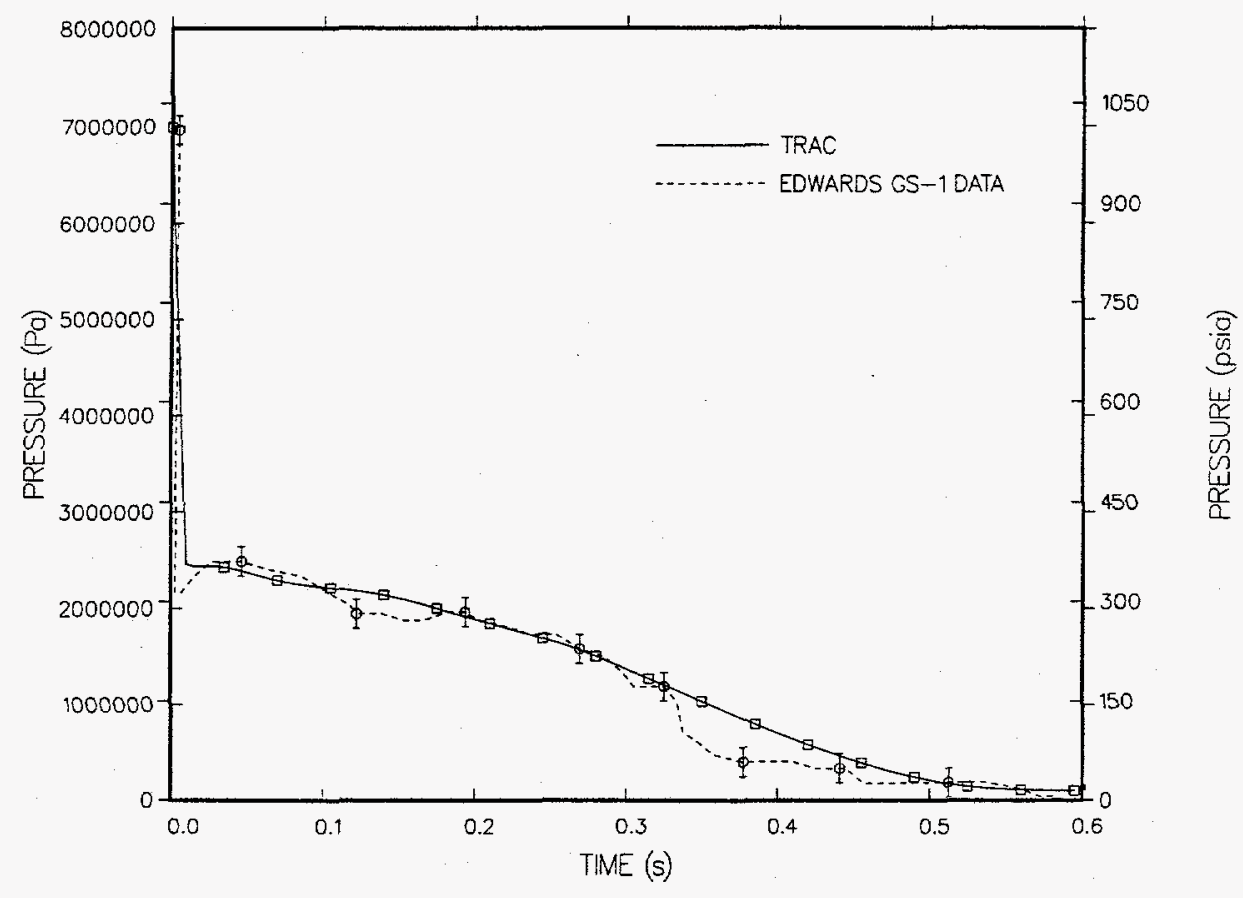

Figure D.21. Pressure at break end, Edwards blowdown, TRAC-P Version 5.4.28.

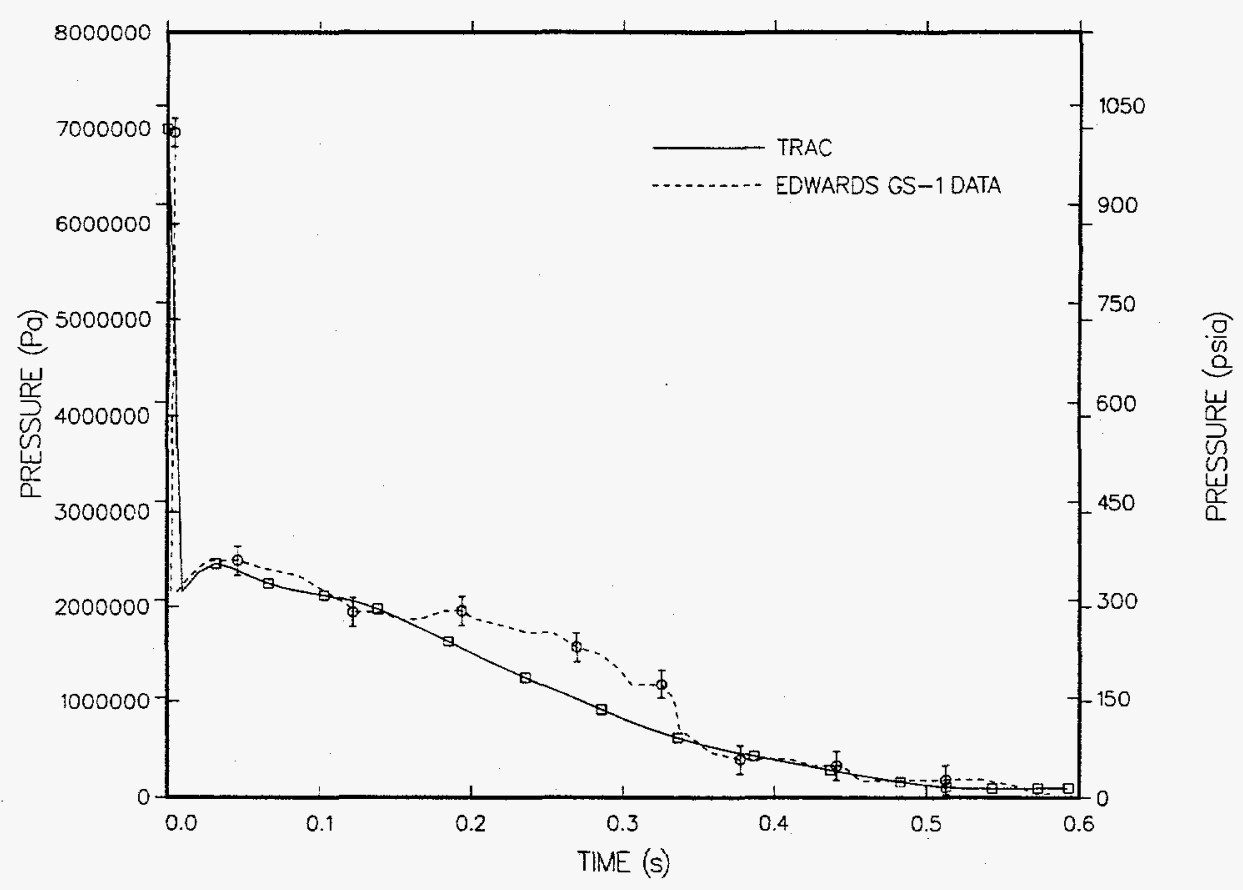

Figure D.22. Pressure at break end, Edwards blowdown, TRAC-P with FXCFM. 


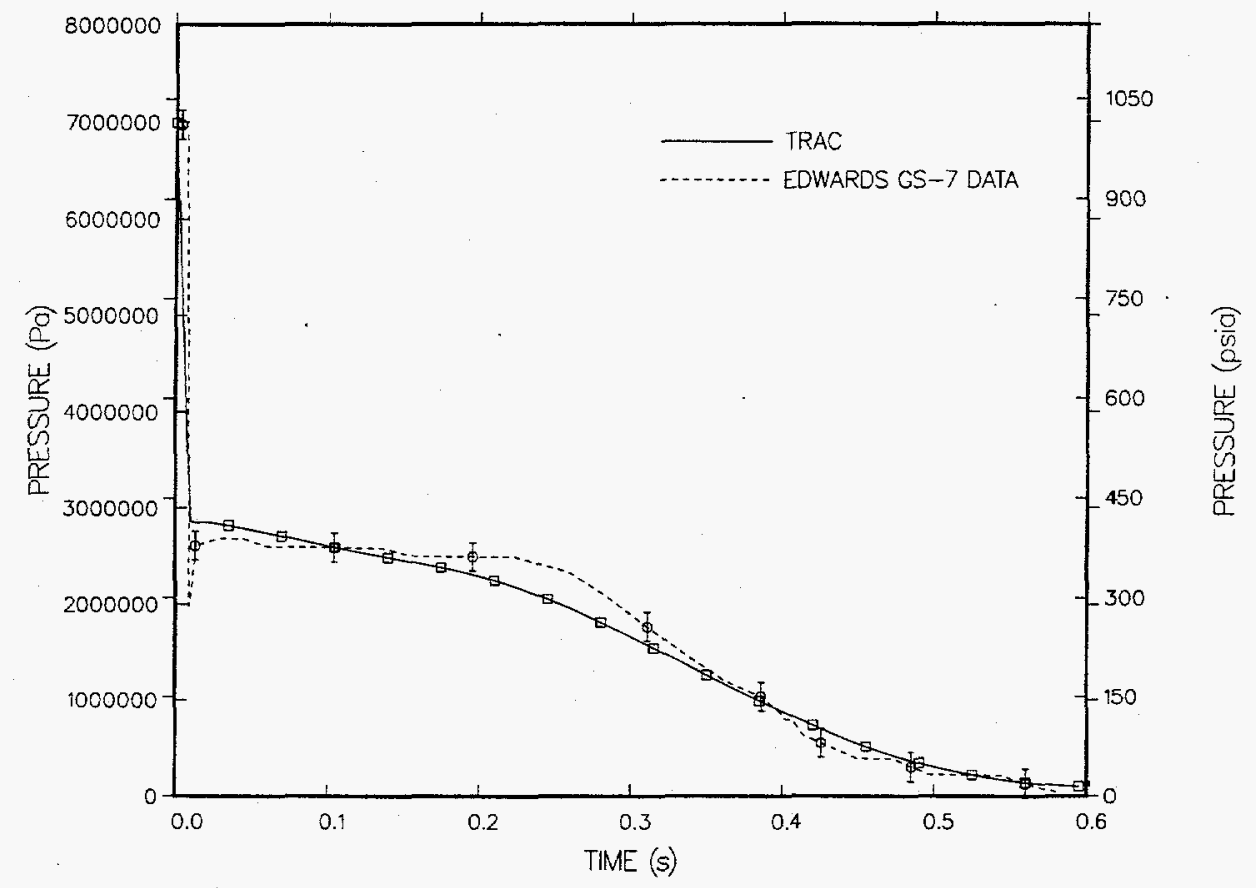

Figure D.23. Pressure at closed end, Edwards blowdown, TRAC-P Version 5.4.28.

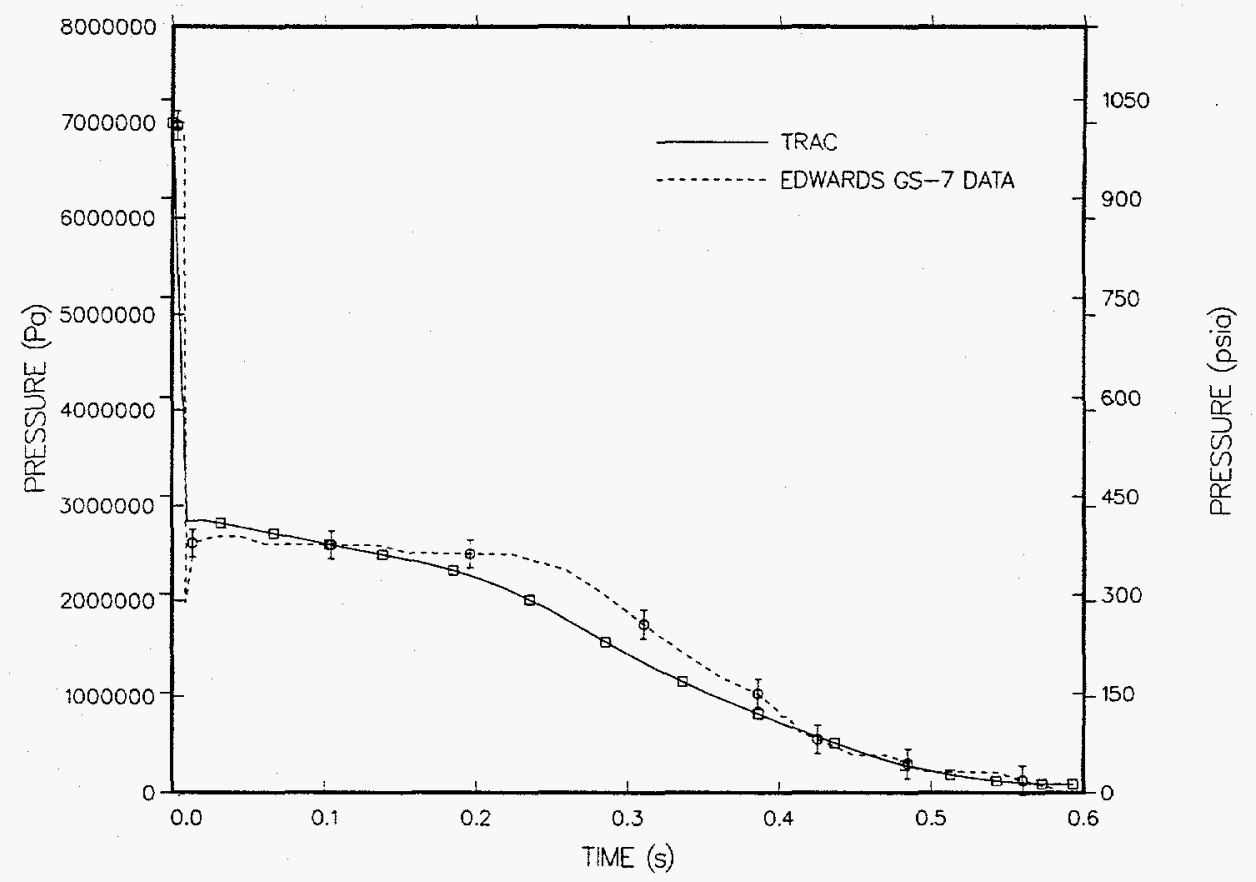

Figure D.24. Pressure at closed end, Edwards blowdown, TRAC-P with FXCFM. 


\section{APPENDIX E}

\section{EVALUATING THE SCIENTECH CHOKED-FLOW TEST PROBLEMS}

\section{E.1. INTRODUCTION}

Two test-problem input-data files for TRAC-P were received from Scientech for trouble report 235. They model a length of pipe with a small side break using a TEE and three BREAK components. The side break is modeled by a single side-channel cell of the TEE. The cell's flow area decreases by a factor of 3 from the TEE internal junction to the TEE external junction on the side-channel cell's opposite side. This change in flow area is based on a user guideline in Section 7.1.2.4 of the TRAC-P User's Guide. The choked-flow model is applied at the TEE side-channel external junction where the minimum flow area is modeled.

The two Scientech test problems model the pipe side-break conditions at $500 \mathrm{~s}$ and $1000 \mathrm{~s}$ from a small-break loss-of-coolant accident (SBLOCA) plant analysis. The test problem at $1000 \mathrm{~s}$ corresponds to the saturation choked-flow test results described in a 6-page documentation writeup received July 1997 for trouble report 235. The test problem input-data file for the subcooled choked-flow test results in that writeup, however, was not received. Those test results from RELAP-5 and TRAC-P are shown in Table E.1.

The test problem at $1000 \mathrm{~s}$ that gave the saturation choked-flow test results will be used to verify the same results by TRAC-P Version 5.4.28 and by TRAC-P Version 5.4.28 with all pending updates for KAPL. Then the choked-flow correction update FXCFM will be added to TRAC-P Version 5.4.28 with all pending KAPL updates to determine the change in the choked mass flow and number of timesteps made by the update FXCFM corrections. The test problem at $500 \mathrm{~s}$ will be evaluated for information as well (without RELAP-5 and TRAC-P Scientech results to compare

\section{TABLE E.1}

\section{Parameter}

Pressure (MPa)

Liquid Temperature (K)

Gas Volume Fraction (-)

Break Mass Flow $\left(\mathrm{kg} \mathrm{s}^{-1}\right)$

\section{Choked-Flow Test Results}

Subcooled

RELAP-5 TRAC-P

1.95

419.6

0.0

96.7
1.95

419.6

0.0

103.0
Saturation

RELAP-5 TRAC-P

$5.0642 \quad 5.0642$

537.2

0.0

537.2

0.0

47.3 
with). An input-data file for the subcooled choked-flow test results will be created from the test problem at $1000 \mathrm{~s}$ by changing the defined pressure and liquid temperature. It will be evaluated by TRAC-P Version 5.4.28 with all pending KAPL updates to determine if this created input-data file evaluates the same results as in Table E.1. It also will be evaluated by TRAC-P Version 5.4.28 with all pending KAPL updates and update FXCFM to determine the change in the choked mass flow and number of timesteps resulting from the choked-flow model corrections.

\section{E.2. ANALYSIS AND RESULTS}

In the results to be presented, TRAC-P Version 5.4.28 was evaluated on a subset of all the cases that TRAC-P Version 5.4.28 with pending KAPL updates was evaluated. These two versions of TRAC-P gave the same results for those cases. Those results are labeled TRAC28. Results from TRAC-P Version 5.4.28 with pending KAPL updates and update FXCFM are labeled TFXCFM.

Table E. 2 shows the results from the test problem at $1000 \mathrm{~s}$. Case 2.0 is based on the input-data file as received from Scientech. Note that TRAC28 evaluates the same break mass flow as evaluated by Scientech in Table E.1 (47.318 $\mathrm{kg} \mathrm{s}^{-1}$ vs $\left.47.3 \mathrm{~kg} \mathrm{~s}^{-1}\right)$. TFXCFM evaluates a slightly smaller break mass flow of $47.181 \mathrm{~kg} \mathrm{~s}^{-1}$ in $\sim 1 / 6$ the number of timesteps (497 vs 3039) for the $100 \mathrm{~s}$ transient (asymptotic steady-state) calculation. Case 2.1 evaluates the same input data for $200 \mathrm{~s}$ (the transient time evaluated by the test problem at $500 \mathrm{~s}$ ) to determine if the $100 \mathrm{~s}$ asymptotic steadystate solution of the transient calculation has converged. The small change in the break mass flow ( $+0.009 \mathrm{~kg} \mathrm{~s}^{-1}$ by TRAC28 and $+0.015 \mathrm{~kg} \mathrm{~s}^{-1}$ by TFXCFM) indicates that reasonable convergence was achieved in $100 \mathrm{~s}$. All subsequent results in this appendix are evaluated by transients calculations of $200 \mathrm{~s}$.

\section{TABLE E.2}

\begin{tabular}{cccccccc} 
Case\# & \multicolumn{2}{c}{ Break Mass Flow $\mathbf{( k g ~ s}^{-\mathbf{1}}$ ) } & \multicolumn{2}{c}{ Number of Timesteps } & \multicolumn{2}{c}{ Donor-Cell Gas Vol. Fr. } \\
& TRAC28 & TFXCFM & TRAC28 & TFXCFM & TRAC28 & TFXCFM \\
2.0 & 47.318 & 47.181 & 3039 & 497 & 0.0165 & 0.0179 \\
2.1 & 47.327 & 47.196 & 5983 & 831 & 0.0160 & 0.0175 \\
2.2 & 47.620 & 47.628 & 6193 & 831 & 0.0044 & 0.0048 \\
2.3 & 47.656 & 47.653 & 6187 & 831 & 0.0038 & 0.0041
\end{tabular}


Case 2.2 corrects what are believed to be the following two modeling errors in the case 2.0 and 2.1 input-data files.

1. The two BREAK components connected to the main channel of the TEE component define ISAT $=3$ rather than ISAT $=1$. When ISAT $=3$, the input liquid temperature of $537.2 \mathrm{~K}$ is replaced by the saturation temperature of $537.9 \mathrm{~K}$.

2 Cells 3 and 4 of the TEE-component main channel define DX $=1.29 \mathrm{~m}$ rather than $\mathrm{DX}=1.209 \mathrm{~m}$ (where VOL and FA are constant, and VOL/FA = $1.209 \mathrm{~m})$.

Defining the main-channel liquid to be $0.7 \mathrm{~K}$ subcooled as intended rather than at saturation increased the break mass flow by $0.293 \mathrm{~kg} \mathrm{~s}^{-1}$ from TRAC28 and by 0.432 $\mathrm{kg} \mathrm{s}^{-1}$ from TFXCFM.

Case 2.3 is case 2.2 with the input TEE-component wall temperature changed from 559.1 to the $537.2 \mathrm{~K}$ temperature of the liquid. A hotter wall temperature in case 2.2 caused subcooled boiling and a gas volume fraction of $\sim 0.002$ in the main-channel cells of the TEE component. Case 2.3 has a gas volume fraction of 0.0 in the mainchannel cells without subcooled boiling. Cases 2.2 and 2.3 show that a small gas volume fraction upstream due to subcooled boiling has little effect on the break mass flow.

For case 2.2 input data, the two-phase choked-flow multiplier is varied from 1.0 to 5.0 in 0.5 increments to see if the nonlinear dependence of the break mass flow on the two-phase choked-flow multiplier, evaluated by Scientech with TRAC Version $5.4 .28 \mathrm{c}$, is evaluated by TRAC28. Scientech evaluated a break mass flow of 47,52 , and $65 \mathrm{~kg} \mathrm{~s}^{-1}$ for two-phase multiplier values of $1.0,2.0$, and 3.0, respectively, followed by a step rise in the break mass flow from $77 \mathrm{~kg} \mathrm{~s}^{-1}$ to $144 \mathrm{~kg} \mathrm{~s}^{-1}$ for a two-phase multiplier value of $\sim 3.5$. A similar evaluation by TFXCFM was done to determine if the update FXCFM corrections made to the choked-flow model provide a more linear dependence that is expected. Table E.3 shows the results from those calculations. The TRAC28 results are essentially the same as the TFXCFM results and only similar to the Scientech results where there is a step change in the break mass flow 


\section{TABLE E.3}

\begin{tabular}{|c|c|c|c|c|c|c|c|}
\hline \multirow[t]{2}{*}{ Case\# } & \multirow[t]{2}{*}{ CHM2 } & \multicolumn{2}{|c|}{ Break Mass Flow $\left(\mathrm{kg} \mathrm{s}^{-1}\right)$} & \multicolumn{2}{|c|}{ Number of Timesteps } & \multicolumn{2}{|c|}{ Donor Gas Vol. Fr. } \\
\hline & & TRAC28 & TFXCFM & TRAC28 & TFXCFM & TRAC28 & TFXCFM \\
\hline 2.2 & 1.0 & 47.620 & 47.628 & 6193 & 831 & 0.0044 & 0.0048 \\
\hline 2.4 & 1.5 & 47.621 & 47.615 & 6179 & 831 & 0.0044 & 0.0046 \\
\hline 2.5 & 2.0 & 47.621 & 47.628 & 6160 & 831 & 0.0044 & 0.0047 \\
\hline 2.6 & 2.5 & 47.621 & 47.627 & 6127 & 831 & 0.0044 & 0.0048 \\
\hline 2.7 & 3.0 & 47.621 & 47.622 & 6074 & 831 & 0.0044 & 0.0048 \\
\hline 2.8 & 3.5 & 47.621 & 47.643 & 5911 & 831 & 0.0044 & 0.0050 \\
\hline 2.9 & 4.0 & 171.638 & 171.612 & 2850 & 831 & 0.1069 & 0.1068 \\
\hline 2.10 & 4.5 & 184.268 & 184.194 & 2614 & 831 & 0.1241 & 0.1242 \\
\hline 2.11 & 5.0 & 196.048 & 195.978 & 2414 & 831 & 0.1390 & 0.1391 \\
\hline
\end{tabular}

between the CHM2 multiplier values of 3.5 and 4.0. Note that the gas volume fraction in the side-channel cell of the TEE component has a step change as well between the CHM2 values of 3.5 and 4.0. Before the step change, the donor-cell gas volume fraction is 0.0044 and $0.0048 \pm 0.0002$ in Table E.3 for the choked-flow interface at the TEE external junction to the atmospheric-pressure BREAK. Choked flow is evaluated for subcooled liquid when the donor-cell gas volume fraction is $\leq 0.01$. In this situation, changing the value of the two-phase multiplier CHM2 has no effect on the break mass flow, as we see in Table E.3. When the donor-cell gas volume fraction is $\geq 0.1$, choked flow is evaluated for two-phase liquid. The effect of multiplying CHM2 to the two-phase sonic velocity to determine the break mass flows for CHM2 $=4.0,4.5$, and 5.0 is seen in Table E.3. There is a donor-cell gas volume fraction transition range between 0.01 and 0.1 where a linearly weighted average of the subcooled sonic velocity times CHM1 and the two-phase sonic velocity times CHM2 is determined. Had the donor-cell gas volume fraction increased gradually through this transition range, we would have seen a gradual effect on the break mass flow of multiplying CHM2 to the two-phase sonic velocity.

Even though the RELAP5 and TRAC-P subcooled choked mass flows in Table E.1 are in close agreement with the subcooled multiplier $\mathrm{CHM1}=1.0$, at saturation one may need to vary the values of both CHM1 and the two-phase multiplier CHM2 so that the subcooled sonic velocity is adjusted as well for $\alpha<0.1$. Those results are shown in Table E.4. Both TRAC28 and TFXCFM evaluate similar break mass flows that vary in approximate proportion to the change in CHM1 and CHM2. Note that the donor-cell gas volume fraction in the TEE side-channel cell increases progressively when both CHM1 and CHM2 are increased rather than the step-change increase between CHM2 $=3.5$ and 4.0 when only CHM2 is increased. At saturation, changing both CHM1 and CHM2 together gives results that are expected. The corrections of 
update FXCFM decrease the number of timestep evaluated (increase the average timestep size) by a factor of 7.5 to 2.9 for CHM1- and CHM2-multiplier values from 1.0 to 5.0 .

\section{TABLE E.4}

\begin{tabular}{lccccccc} 
Case\# & \multicolumn{2}{c}{ CHM1 } & Break Mass Flow (kg s & -1 & \multicolumn{2}{c}{ Number of Timesteps } & \multicolumn{2}{c}{ Donor Gas Vol. Fr. } \\
& CHM2 & TRAC28 & TFXCFM & TRAC28 & TFXCFM & TRAC28 & TFXCFM \\
2.2 & 1.0 & 47.620 & 47.628 & 6193 & 831 & 0.0044 & 0.0048 \\
2.12 & 1.5 & 71.385 & 71.298 & 5218 & 831 & 0.0232 & 0.0236 \\
2.13 & 2.0 & 101.755 & 101.475 & 4447 & 831 & 0.0430 & 0.0432 \\
2.14 & 2.5 & 137.814 & 137.709 & 3575 & 831 & 0.0704 & 0.0704 \\
2.15 & 3.0 & 153.207 & 153.128 & 3237 & 831 & 0.0855 & 0.0857 \\
2.16 & 3.5 & 162.016 & 161.883 & 3051 & 831 & 0.0955 & 0.0956 \\
2.17 & 4.0 & 171.637 & 171.612 & 2850 & 831 & 0.1069 & 0.1068 \\
2.18 & 4.5 & 184.268 & 184.194 & 2614 & 831 & 0.1241 & 0.1242 \\
2.19 & 5.0 & 196.048 & 195.978 & 2414 & 831 & 0.1390 & 0.1391
\end{tabular}

Table E. 5 shows results from the test problem at $500 \mathrm{~s}$. Case 1.0 is based on the inputdata file as received from Scientech. TRAC28 and TFXCFM evaluate similar break mass flows with TFXCFM requiring $\sim 1 / 8$ the number of timesteps (826 vs 7038). Case 1.1 makes the same two corrections to the input-data file as were made to the Case 2.2 input-data file with little change in the results. From 500 to $1000 \mathrm{~s}$ in the SBLOCA analysis, the break mass flow has decreased from 61.2 to $47.6 \mathrm{~kg} \mathrm{~s}^{-1}$ because of the main-channel pressure decreasing from 6.9580 to $5.0642 \mathrm{MPa}$ and the liquid subcooling decreasing from 21.4 to $0.9 \mathrm{~K}$.

The next analysis involves creating input-data files for the subcooled choked-flow test results shown in Table E.1 from trouble report 235. From cases 2.1 and 2.2, the main-channel liquid pressure and temperature were changed from $5.0642 \mathrm{MPa}$ and $537.2 \mathrm{~K}$ to $1.95 \mathrm{MPa}$ and $419.6 \mathrm{~K}$, respectively, to create cases 0.1 and 0.2 whose results are shown in Table E.6. From case 0.1 to case 0.2 , changing ISAT $=3$ to ISAT $=1$ changed the liquid temperature from saturation $(483.7 \mathrm{~K})$ to $64.1 \mathrm{~K}$ of subcooling, which caused a significant increase in the break mass flow. The TRAC28 break mass flow of $105.874 \mathrm{~kg} \mathrm{~s}^{-1}$ is slightly greater than the Scientech-evaluated break mass flow of $103.0 \mathrm{~kg} \mathrm{~s}^{-1}$ in Table E.1. Cases 0.3 and 0.4 are cases 0.1 and 0.2 , respectively, with the input TEE-component wall temperature changed from 559.1 to the $537.2 \mathrm{~K}$ temperature of the liquid. This eliminates subcooled boiling that occurs in case 0.1 and heat transfer from the wall to the fluid that reduces the subcooling of the fluid. 


\section{TABLE E.5}

\begin{tabular}{|c|c|c|c|c|c|c|}
\hline \multirow[t]{2}{*}{ Case\# } & \multicolumn{2}{|c|}{ Break Mass Flow $\left(\mathrm{kg} \mathrm{s}^{-1}\right)$} & \multicolumn{2}{|c|}{ Number of Timesteps } & \multicolumn{2}{|c|}{ Donor-Cell Gas Vol. Fr. } \\
\hline & TRAC28 & TFXCFM & TRAC28 & TFXCFM & TRAC28 & TFXCFM \\
\hline 1.0 & 60.422 & 60.291 & 7038 & 826 & 0.0136 & 0.0149 \\
\hline \multirow[t]{2}{*}{1.1} & 61.247 & 61.245 & 7171 & 826 & 0.0015 & 0.0016 \\
\hline & \multicolumn{6}{|c|}{ TABLE E.6 } \\
\hline Case\# & Break Mas & Flow $\left(\mathrm{kg} \mathrm{s}^{-1}\right)$ & Number o & Timesteps & Donor-Cel & Gas Vol. Fr. \\
\hline 0.1 & 22.722 & 22.723 & 3925 & 843 & 0.0129 & 0.0142 \\
\hline 0.2 & 105.874 & 105.880 & 1006 & 900 & 0.0 & 0.0 \\
\hline 0.3 & 27.198 & 27.080 & 826 & 826 & 0.0 & 0.0 \\
\hline 0.4 & 106.423 & 106.423 & 826 & 826 & 0.0 & 0.0 \\
\hline
\end{tabular}

The final analysis involves considering an alternative to the small-break modeling guideline in Section 7.1.2.4 of the TRAC User's Guide. Rather than decrease the low area by a factor of 3 in going from the TEE internal junction to the TEE side-channel external junction, we instead increase it by a factor of 3 by reversing the side-channel cell-interface flow areas. This moves the minimum flow area and the choked-flow interface from the TEE side-channel external junction to the TEE internal junction. It changes the choked-flow-interface donor cell from the side-channel cell to the main-channel JCELL. This increases the choked-flow-interface donor-cell pressure and the subcooling of its liquid.

The resulting increase in break mass flow of the saturation choked-flow test problem at $1000 \mathrm{~s}$ is significant. This is shown in Table E.7 in going from case 2.2 to case 2.20. Scientech determined a break mass flow of $107.9 \mathrm{~kg} \mathrm{~s}^{-1}$ from RELAP-5 for this situation, as shown in Table E.1. Now the RELAP-5 and TRAC-P small-break modeling is more consistent because the choked-flow-interface donor cell in RELAP-5 is the equivalent of JCELL in TRAC-P. The choked-flow-interface donorcell gas volume fraction decreased from 0.0044 and 0.0048 in case 2.2, to 0.0021 and 0.0023 in case 2.20 .

Case 2.21 changes the TEE wall temperature from 559.1 to $537.2 \mathrm{~K}$ to turn off subcooled boiling, so that the JCELL gas volume fraction reduces to 0.0 . This has little effect on the break mass flow, as shown in Table E.7. 
Case 2.22 doubles the volume of the TEE side-channel cell and increases its externaljunction interface flow area by a factor of 4 from case 2.21. Because these changes only affect the choked-flow interface downstream hydraulic condition, there should be no change in the break mass flow. Both TRAC28 and TFXCFM evaluate a slight increase in the break mass flow. This may le due to the case 2.22 transient calculation being evaluated with larger timestep sizes because it requires $27 \%$ fewer timesteps (1211 vs 1657 and 1205 vs 1643).

\section{TABLE E.7}

$\begin{array}{lcccccc}\text { Case\# } & \begin{array}{c}\text { Break Mass Flow } \mathbf{( k g ~ s}^{-1} \text { ) } \\ \text { TRAC28 }\end{array} & \begin{array}{c}\text { Number of Timesteps } \\ \text { TFXM }\end{array} & \begin{array}{c}\text { Donor-Cell Gas Vol. Fr. } \\ \text { TRAC28 }\end{array} & \begin{array}{c}\text { TFXCFM } \\ \text { TRAC28 }\end{array} & \text { TFXCFM } \\ 2.2 & 47.620 & 47.628 & 6193 & 831 & 0.0044 & 0.0048 \\ 2.20 & 71.263 & 71.596 & 1647 & 1625 & 0.0021 & 0.0023 \\ 2.21 & 71.410 & 71.737 & 1657 & 1643 & 0.0 & 0.0 \\ 2.22 & 71.430 & 71.783 & 1211 & 1205 & 0.0 & 0.0\end{array}$

The difference in modeling the geometry of the break path caused a large difference in the saturation choked mass flows from TRAC-P. An appropriate geometry model requires comparing such TRAC-P predicted break mass flows with measured break mass flows from experiments with prototypic pipe side-wall breaks. 